No. 20-2

\title{
The Inflation Target and the Equilibrium Real Rate
}

\section{Christopher D. Cotton}

\begin{abstract}
:
Many economists have proposed raising the inflation target to reduce the probability of hitting the zero lower bound (ZLB). It is both a common assumption and a feature of standard models that raising the inflation target does not impact the equilibrium real rate. I demonstrate that in the New Keynesian model, once heterogeneity is introduced, raising the inflation target causes the equilibrium real rate to fall. This implies that raising the inflation target will increase the nominal interest rate by less than expected and thus will be less effective in reducing the probability of hitting the ZLB. The channel involves a rise in the inflation target lowering the average markup by price rigidities and a fall in the average markup lowering the equilibrium real rate by household heterogeneity, which could come from overlapping generations or idiosyncratic labor shocks. I find that raising the inflation target from 2 percent to 4 percent lowers the equilibrium real rate between 3 and 28 basis points. Since raising inflation lowers the equilibrium real rate, it might seem optimal to raise inflation by more in response to the ZLB. However, this channel also implies that the marginal benefit of raising inflation is lower because a given increase in inflation raises the nominal interest rate by less and thus is less effective at preventing the ZLB. In a welfare simulation, these two effects approximately cancel out each other. Therefore, even though this channel implies that raising the inflation target is less effective in preventing the ZLB, the inflation target should still be raised by a similar amount in response to the problem of the ZLB.
\end{abstract}

\section{JEL Classifications: E31, E52, E58}

Keywords: inflation target, steady state real interest rate, equilibrium real rate, heterogeneity, zero lower bound

Christopher D. Cotton is an economist in the research department of the Federal Reserve Bank of Boston; his email is Christopher.Cotton@bos.frb.org.

The author is indebted to Jón Steinsson and Michael Woodford for their guidance and support in writing this paper and throughout his PhD. He thanks Hassan Afrouzi, Etienne Gagnon, Matthieu Gomez, Cameron LaPoint, Jennifer La'O, Benjamin Johannsen, Martin Uribe, Scott Weiner, and Fabian Winkler for highly valuable discussions and guidance. Part of this paper was written while the author was a dissertation fellow at the Federal Reserve Board.

This paper presents preliminary analysis and results intended to stimulate discussion and critical comment. The views expressed herein are those of the author and do not indicate concurrence by the Federal Reserve Bank of Boston, the principals of the Board of Governors, or the Federal Reserve System. This paper, which may be revised, is available on the website of the Federal Reserve Bank of Boston at https://www.bostonfed.org/publications/researchdepartment-working-paper.aspx. 


\section{Introduction}

Many economists have proposed raising the inflation target to reduce the probability of hitting the zero lower bound (ZLB). Nearly all developed countries were constrained by the ZLB during the financial crisis. Moreover, it is widely believed that average real interest rates have fallen. ${ }^{1}$ This implies that average nominal interest rates will be lower going forward. Consequently, there has been a re-evaluation of the risk that central banks will hit the ZLB. Hitting the bound is bad for economic outcomes because it leaves central banks with less room to lower nominal interest rates and stimulate the economy during bad times. Therefore, many economists (including Blanchard, Dell'Ariccia, and Mauro 2010; Ball 2014; and Krugman 2014) have proposed raising the inflation target from the standard objective of 2 percent to 4 percent, claiming this will raise average nominal interest rates and thus reduce the probability of hitting the ZLB.

It is widely assumed that raising the inflation target will not affect the equilibrium real rate. The equilibrium real (nominal) rate is the real (nominal) interest rate on short-term safe assets when there are no shocks. Standard macroeconomic models commonly assume flexible prices, a representative agent, or both. With any of these assumptions, the equilibrium real rate is unaffected by changing average inflation. This is also a historic concept introduced by Fisher (1907) and is often taken for granted in policy discussions. For example, Ball (2014) states that the long-run level of the real interest rate is "independent of monetary policy." Thus, it is widely believed that raising the inflation target by 2 percentage points will have no impact on the equilibrium real rate and will therefore raise the equilibrium nominal rate by a corresponding 2 percentage points.

My primary contribution is to demonstrate a new channel by which raising the inflation target will lower the equilibrium real rate. Once I account for household heterogeneity (through either overlapping generations or idiosyncratic risk) in the standard New Keynesian model, I find that raising the inflation target lowers the equilibrium real rate. Since nominal interest rates will rise by less than expected, raising the inflation target will reduce the probability of avoiding the ZLB by less than is commonly believed. The channel has two stages. First, price rigidities imply that a rise in the inflation target lowers the markup. Second, household heterogeneity implies that a fall in the markup lowers the equilibrium real rate. Therefore, I hereafter refer to the channel as the IMR (inflation markup real rate) channel.

The first part of the IMR channel is a standard, albeit often overlooked feature of New Keynesian models. A firm's markup is the ratio of its price to its nominal marginal cost. When firms set their prices infrequently, a higher average inflation level has two opposing impacts on average markups. First, higher inflation means that when a firm does not reset its price, its markup falls by relatively more, since nominal marginal costs rise relatively quicker with higher inflation. Second, firms observe that their markups fall more quickly and therefore set their markup higher when they reset their prices. It can be shown that with no discounting, these two effects cancel out each other, and thus average markups are unchanged by raising average inflation. However, with discounting, the first effect dominates, since firms care more about making profits in the current period and so do not want to set their current markup very high when they reset their price. Therefore, a rise in average inflation lowers the average markup. This holds under price rigidities based on both infrequent adjustment (Calvo pricing) and costs of adjustment (menu costs).

In the second part of the channel, a fall in the markup lowers the equilibrium real rate once household

\footnotetext{
${ }^{1}$ Holston, Laubach, and Williams (2017) estimate that it has fallen by an average of 2.3 percentage points since 1990 (across the United States, Canada, the euro area and the United Kingdom). Recent estimates of the US equilibrium real rate by Del Negro et al. (2017), Holston, Laubach, and Williams (2017), Johannsen and Mertens (2016), Kiley (2015), Laubach and Williams (2016), and Lubik and Matthes (2015) lie between 0.1 percent and 1.8 percent .
} 
heterogeneity is allowed for. Taking the example of heterogeneity through overlapping generations (OLG), a fall in the markup lowers firm profits and thus reduces the value of shares and of overall savings. A fall in the amount of savings, all else being equal, lowers the consumption of old people relative to young people. This means the old have higher marginal utility from consuming compared with the young. Thus, there is greater competition among young people to save for when they are old, and so the price of savings rises. As the price of savings rises, the return on savings (the equilibrium real rate) falls. To my knowledge, the literature does not cover this part of the channel.

This contrasts with a representative agent New Keynesian model in which a fall in the markup has no impact on the equilibrium real rate. In the long run, the aggregate consumption path follows some balanced growth path that is independent of the level of savings. With a representative agent, the representative agent's consumption path equals the aggregate consumption path. The Euler equation implies that the real interest rate is an increasing function of the agent's consumption in the future relative to now. Therefore, since the representative agent's consumption path is constant regardless of the level of savings, the real interest rate is constant and, even though a fall in the markup lowers profits and thus the supply of savings, it does not affect the equilibrium real rate. The key impact of household heterogeneity, therefore, is that it introduces a wedge between the agent's consumption path and the aggregate consumption path of the economy.

I estimate the impact of the IMR channel through a calibrated model. I incorporate household heterogeneity through a life-cycle framework modeling each quarter of adult life. I model other parts of the economy following a standard New Keynesian setup in the baseline model with monopolistic firms that face Calvo pricing. In the baseline model, I find that raising the inflation target from 2 percent to 4 percent lowers the equilibrium real rate 3 basis points. I consider various extensions. Allowing for a lower intertemporal elasticity of substitution (IES) of 0.1 rather than 0.5 boosts the effect to 8 basis points, since with a low IES, agents are keener to ensure they consume at the same level when they are old as when they are young. One concern may be that this result comes from the fact that raising inflation does not affect the degree to which firms change their prices under Calvo pricing. However, with menu costs instead of Calvo pricing, the results are slightly stronger ( 3 to 5 basis points depending on how the menu costs are treated), although at higher inflation levels, raising inflation does have a stronger impact on the equilibrium real rate under Calvo pricing. Introducing factors that boost the negative relationship between trend inflation and the markup-such as a high firm discounting, intermediate goods, and heterogeneous sectors-strengthens the relationship. With high firm discounting, raising inflation from 2 percent to 4 percent lowers the equilibrium real rate 11 basis points; with both high firm discounting and low IES, the effect is 28 basis points.

The IMR channel also holds within a Heterogeneous Agent New Keynesian (HANK) model. In recent years, there has been significant work involving models in which household heterogeneity is embedded into the New Keynesian model through idiosyncratic labor shocks and a borrowing constraint (for example Nakamura and Steinsson 2008; Kaplan, Moll, and Violante 2018). These are commonly referred to as HANK models. This form of heterogeneity also leads to the IMR channel. A fall in the markup lowers firm profits and thus the supply of assets. With fewer assets in which to save, agents are, all else being equal, more likely to hit the borrowing constraint. Thus, when agents are not constrained by the borrowing constraint, they are prepared to pay a higher price for savings to avoid the borrowing constraint, which is equivalent to a fall in the return on savings or the equilibrium real rate. I embed this HANK style of heterogeneity into my life-cycle New Keynesian model. This strengthens the effect of the rise in the inflation target on the 
equlibrium real rate 1 to 2 basis points in the baseline case. This also allows me to qualitatively match the hump-shaped path of agents' lifetime consumption.

Next, I investigate how much the IMR channel affects optimal inflation when the equilibrium real rate falls. A common argument for raising the inflation target is that the equilibrium real rate has fallen for reasons exogenous to the IMR channel, such as demographics, global savings glut, secular stagnation, etc. Recent work by Andrade et al. (2019) shows how such exogenous falls affect optimal inflation. I investigate how the IMR channel affects optimal inflation by computing how it changes in response to exogenous falls in the equilibrium real rate both with and without the IMR channel. I find that the IMR channel has little effect on how much optimal inflation rises following falls in the exogenous real rate. This is true even in an extended model where the IMR channel is strong, that is, where raising inflation substantially lowers the equilibrium real rate.

To investigate this surprising result, I decompose how the IMR channel affects the response of optimal inflation to an exogenous fall in the equilibrium real rate. I find two key effects. First, if the equilibrium real rate falls for exogenous reasons, optimal inflation rises, which implies that the equilibrium real rate falls further, meaning the economy is more constrained by the ZLB. This implies that raising the nominal interest rate higher would be more beneficial. Second, since raising inflation lowers the equilibrium real rate, it implies that the effectiveness of raising the inflation target is reduced. Thus, even though it would be more beneficial to raise the nominal interest rate, raising the inflation target is less effective at doing this under the IMR channel. Therefore, with the IMR channel, it is optimal to raise inflation to about the same degree in response to an exogenous fall in the equilibrium real rate, even though the IMR channel implies that nominal interest rates will rise by less and the ZLB will be more constraining.

It is difficult to assess how long-run changes in trend inflation affect the equilibrium real rate, but some empirical evidence supports the IMR channel. Across developed countries in recent years, both inflation and the real interest rate have fallen. This would contradict the IMR channel, by which inflation and equilibrium real rates should move in opposite directions if the fall in inflation is the only channel affecting the equilibrium real rate. However, various studies propose many other reasons for the lower real interest rates across developed countries.. They include demographic changes (Carvalho, Ferrero, and Nechio 2016; Gagnon, Johannsen, and Lopez-Salido 2016), global savings glut (Caballero and Farhi 2017), secular stagnation (Eggertsson, Mehrotra, and Robbins 2019), low productivity growth (Yi and Zhang 2017), and high inequality (Lancastre 2018). Indeed, it is puzzling that real interest rates have not fallen by more. Gagnon (2009) argues that demographic factors alone can explain the fall in the equilibrium real rate, while Eggertsson, Mehrotra, and Robbins (2019) argue that real rates should be much lower. An ideal assessment of the IMR channel's empirical validity would involve random variation in inflation targets, not just shortrun inflation, but it does not seem possible to directly identify such random variation. However, some authors have attempted to identify the long-run relationship between inflation and the equilibrium real rate through structural methods. In a structural VAR model using US data, King and Watson (1997) show that an increase in long-run inflation leads to a decrease in the long-run real interest rate under a variety of different restrictions. Rapach (2003) extends the analysis to 14 countries with a richer structural model and finds similar qualitative results.

The Mundell-Tobin effect offers an alternative reason for why a rise in inflation can affect the equilibrium real rate. Mundell (1963) and Tobin (1965) argue that when inflation rises, it becomes costlier to hold money, so agents save more in capital, leading to a rise in the price of holding capital and thus a fall in the equilibrium real rate. There is a deep historical literature that uses this effect of rebalancing away from 
money. For instance, Stockman (1981) proposes a reverse-Mundell-Tobin effect in which raising inflation raises the equilibrium real rate due to a cash-in-advance constraint on investment; that is, you need to take money out of the bank a period before investing. The common thread across these papers is that there is a pool of non-interest-paying money, which is less attractive to hold when inflation falls. This is very different from the IMR channel, in which money holdings play no role. Indeed, it is possible that this channel is less applicable in modern central banking, where central banks pay an interest rate on reserves that, at least in theory, should imply no portfolio shift away from money when inflation rises. However, the IMR channel holds regardless of whether the Mundell-Tobin effect remains relevant, because the IMR channel is based on how a rise in inflation affects the markup rather than how it affectsmoney holdings.

My model relates to several interesting literatures on heterogeneous agent models: (1) the allocation of profits, (2) redistributional effects of monetary policy, and (3) optimal monetary policy with heterogeneous agents. Unlike many heterogeneous agent models, mine allows for the endogenous allocation of profits. Most heterogeneous agent models exogenously allocate profits; that is, certain agents are assigned to receive profits. For instance, Werning (2015) considers how these exogenous profit allocations impact the marginal propensity to consume and related implications. I instead consider the case where agents receive profits only by owning shares in firms that are traded each period. Thus, it is an endogenous feature of my model that old people naturally consume less as a result of the fall in the markup.

This paper is part of a literature analyzing the effectiveness of raising the inflation target. In concurrent work, L'Huillier and Schoenle (2019) present an alternative channel by which raising the inflation target may be less effective than expected. They argue that higher inflation induces firms to change their prices more frequently, which makes monetary policy less effective, mitigating the benefits of the rise in the inflation target. Kiley and Roberts (2017) show that to maintain average inflation of 2 percent, taking into account periods of below-target inflation at the zero lower bound, an inflation target of 3 percent is needed. De Michelis and Iacoviello (2016) study how effective the introduction of an inflation target in Japan has been in raising inflation.

Raising the inflation target in a heterogeneous agent model can generate interesting long-run distributional effects. Raising the inflation target can have short-term redistributional effects that hurt savers and benefit borrowers by lowering the value of nominal assets. Doepke, Schneider, and Selezneva (2015) consider these short-term redistributional effects in detail. My paper implies that there can be long-run redistributional effects as well. A rise in the inflation target reduces profits and thus reduces the value of shares and total savings. This implies that old people, who rely on savings, consume relatively less, and young people consume relatively more indefinitely as a result of a rise in the inflation target.

I contribute to the literature on optimal monetary policy in heterogeneous agent models by investigating optimal monetary policy in a New Keynesian model with OLG features. Lepetit (2018) shows that within a New Keynesian model with perpetual youth, it can be optimal to set a positive inflation target, because heterogeneity can imply that private discounting is higher than social discounting. In this case, central banks raise the inflation target to lower average markups. Lepetit does not consider the impact of the ZLB. In my paper, the primary reason for a positive inflation target is to avoid the ZLB.

In section 2, I outline a simple model that captures the key features found in the rest of the paper. I then outline the full model (section 3). I discuss the model solution and calibration in section 4. I use the full model to analyze the size of the IMR channel and the factors that determine it in section 5. I then consider how the IMR channel affects how much the optimal inflation target should respond to exogenous falls in the equilibrium real rate in section 6 . Section 7 concludes. 


\section{Intuition through a Simplified Model}

I break the explanation for the intuition for the IMR channel into two parts. First, I demonstrate that a rise in inflation lowers the average markup through firms' pricing decisions. Next, I show that a fall in the markup lowers the equilibrium real rate through multiple forms of household heterogeneity.

\subsection{Relationship between the Inflation Level and the Markup}

A firm's markup, denoted $m_{t}$, is its current price, $P_{t}^{\star}$, divided by its nominal marginal cost, $\mathcal{M C}_{t}$ :

$$
m_{t}=\frac{P_{t}^{\star}}{\mathcal{M C}_{t}} .
$$

A firm's profits depend on its markups. If a firm sets its markup too high, it will not make enough sales. If a firm sets its markup too low, the firm will make a lot of sales but with too little profit on each sale. When a firm has fully flexible prices, it can set its price so that its markup yields the maximum profits each period. In the common case where firms face constant elasticity of demand, the optimal markup is just $\frac{\sigma}{\sigma-1}$, where $\sigma$ is the CES parameter.

Setting markups is more complex when price adjustment is infrequent. When a firm can change its prices only infrequently, it is no longer able to set the optimal flexible price markups each period. Positive trend inflation has two effects on markups. First, if a firm cannot change its price in a period, its markup will fall. This is because the firm's nominal marginal costs $\left(\mathcal{M C}_{t}\right)$ rise (due to the rise in the price level) while its prices $\left(P_{t}^{\star}\right)$ remains constant. Second, since a firm anticipates this, when it does get to change its price, it sets a markup that is higher than the optimal flexible price markup.

The impact of trend inflation on the markup depends on the degree of discounting. In the case of no discounting, a firm will weight its profits equally in current and future periods. This leads to a special case where the markup is unaffected by changing the level of inflation, since the two effects on the markup cancel out each other. However, when a firm discounts the future, it will weight its current period markup more in its decision-making. This implies that a firm sets a lower markup when it can change its price and thus that the average markup is lower with positive inflation. As the level of inflation rises, the markup falls by more.

This effect can be informally observed in the classic Phillips Curve, which is shown in equation 1 and is a standard building block of the New Keynesian model (Woodford 2003; Galí 2008). The real marginal cost term is, when firms set the same price, equivalent to the inverse of the markup; that is, $\frac{\mathcal{M C} \mathcal{C}_{t}}{P_{t}}=\frac{1}{m_{t}}$. It can then be observed that when firms do not discount $(\beta=1)$, the markup is fixed $(\bar{m}=0)$, and if firms do discount $(\beta<1)$, a rise in inflation $(\bar{\pi} \uparrow)$ leads to a fall in the markup $(\bar{m} \downarrow)$. Note that the derivation of this Phillips Curve involves log-linearizing around zero inflation, which does not make much sense when non-zero inflation is considered - it is used here to provide simple intuition.

$$
\pi_{t}=\kappa \frac{\mathcal{M C} \mathcal{C}_{t}}{P_{t}}+\beta \mathbb{E}_{t}\left[\pi_{t+1}\right]
$$

More formally, this result can be shown to always hold under Calvo pricing, which assumes that a firm can change its price each period with some exogenous period. Appendix A.1 demonstrates that with Calvo pricing, if a firm does not discount, the markup is constant regardless of the level of inflation. When a firm does discount, the markup falls monotonically as inflation rises. 
One concern might be that this relationship holds only under the strong assumption in Calvo pricing that a firm does not change its frequency of price adjustment as inflation rises. If a firm does set prices more frequently when there is higher inflation, a firm would set its markup for shorter periods of time, on average, which means that the markup would fall by less before being changed for higher levels of inflation. However, this paper focuses on the frequency of price adjustment under low levels of inflation, and empirical evidence suggests that under low inflation there is little change in the frequency of price adjustment. For example, Gagnon (2009) demonstrates that the frequency with which firms change their price does not appear to vary below annual rates of inflation of 10 percent. This makes sense, because a firm is likely to change its prices for reasons other than just inflation (such as idiosyncratic demand or costs), so the frequency of price changes does not need to change with low inflation.

Moreover, even when alternative price adjustment methods that allow for the frequency of price adjustment to rise as inflation rises are considered, the negative inflation-markup relationship still holds. For example, under menu costs, when there is some fixed cost of changing prices, firms will pay this adjustment cost more frequently when trend inflation rises. With low inflation, after adjusting their price, some firms will receive idiosyncratic shocks that lower their costs, implying that their markup rises above the markup to which they reset when they pay the menu cost. Since they face fixed costs of price adjustment, they may choose to wait rather than adjust. This implies that raising inflation under low inflation has a large impact on the markups, since these high markups do not last as long. In section 5, I show that the relationship between inflation and the markup can actually be stronger under low inflation for menu costs than for Calvo pricing as a result of this effect.

The features needed to generate the negative inflation-markup relationship appear to generally hold in the data. To achieve a negative relationship between inflation and the markup, firms need to set their prices infrequently and discount the future. Nakamura and Steinsson (2008) demonstrate that firms change prices infrequently. Jagannathan et al. (2016) show that firms discount the future significantly. It is also worth stressing that this relationship is present in the representative agent New Keynesian model — nothing here depends on household heterogeneity.

\subsection{Relationship between the Markup and the Equilibrium Real Rate}

Simple Model In section 2.1, the markup is shown to be determined purely by the level of inflation. Here the markup is taken as a given and instead the focus is on how changes in the markup affect the real side of a simple model; that is, the pricing side of the model is set aside.

Firms produce using a linear production function. ${ }^{2}$ Therefore, output $Y_{t}$ equals labor $L_{t}$ :

$$
Y_{t}=L_{t}
$$

The real marginal cost of firms $M C_{t}$ is therefore the real wage $W_{t}$ :

$$
M C_{t}=W_{t}
$$

The markup $m_{t}$ is the price divided by the nominal marginal cost, which, by definition, equals the inverse of the real marginal $\operatorname{cost}\left(\frac{1}{M C_{t}}\right)$, so the relation between marginal cost and wage (equation 3 ) can be

\footnotetext{
${ }^{2}$ Here we have effectively assumed that firms do not face price dispersion. This would be true, for example, under Rotemberg Pricing. The case with price dispersion generates exactly the same equations but is a little bit more complicated to derive. The results are shown in appendix A.2.
} 
rewritten as:

$$
\frac{1}{m_{t}}=W_{t}
$$

The total real profits $\Omega_{t}$ of firms are their real sales, which is their output minus their costs of labor:

$$
\Omega_{t}=Y_{t}-W_{t} L_{t}
$$

$Y_{t}$ can be replaced with $L_{t}$ using equation 2 . The right-hand side can be multiplied and divided by $W_{t}$ to give:

$$
\Omega_{t}=\left(\frac{1}{W_{t}}-1\right) W_{t} L_{t}
$$

The markup-wage relationship (equation 4) can be applied to yield:

$$
\Omega_{t}=\left(m_{t}-1\right) \frac{W_{t}}{P_{t}} L_{t}
$$

Asset Supply The solution is broken down into the supply and demand for assets. Asset supply is the quantity of assets available for households to hold. Asset demand is the quantity of assets that agents want to hold.

The only assets in which agents can save are shares in firms. The total real value of firms is denoted by $Z_{t}$. Therefore, asset supply, denoted $A_{t}^{s}$, is given by:

$$
A_{t}^{s}=Z_{t}
$$

By standard asset pricing, the price of buying $b$ shares, $b Z_{t}$, must equal the next period return on those shares discounted at $r_{t+1}$. The next period return of those shares is the dividends received from profits $\left(b \Omega_{t+1}\right)$ plus the price the shares are sold for at $t+1\left(b Z_{t+1}\right)$. Therefore:

$$
Z_{t}=\frac{\Omega_{t+1}+Z_{t+1}}{1+r_{t+1}}
$$

In the steady state, equation 7 can be rewritten as:

$$
\bar{Z}=\frac{\bar{\Omega}}{\bar{r}}
$$

The value of shares with profits (equation 8) can be substituted into the asset supply equation (equation 6) to yield:

$$
\bar{A}^{s}=\frac{\bar{\Omega}}{\bar{r}} .
$$

Profits can then be substituted out using equation 5:

$$
\bar{A}^{s}=\frac{\bar{m}-1}{\bar{r}} \bar{W} \bar{L} .
$$

To make the problem simpler, relative assets $a$ are defined as assets relative to labor income:

$$
a=\frac{A}{W L} .
$$


Figure 1: Relative Asset Supply under a Fall in the Markup

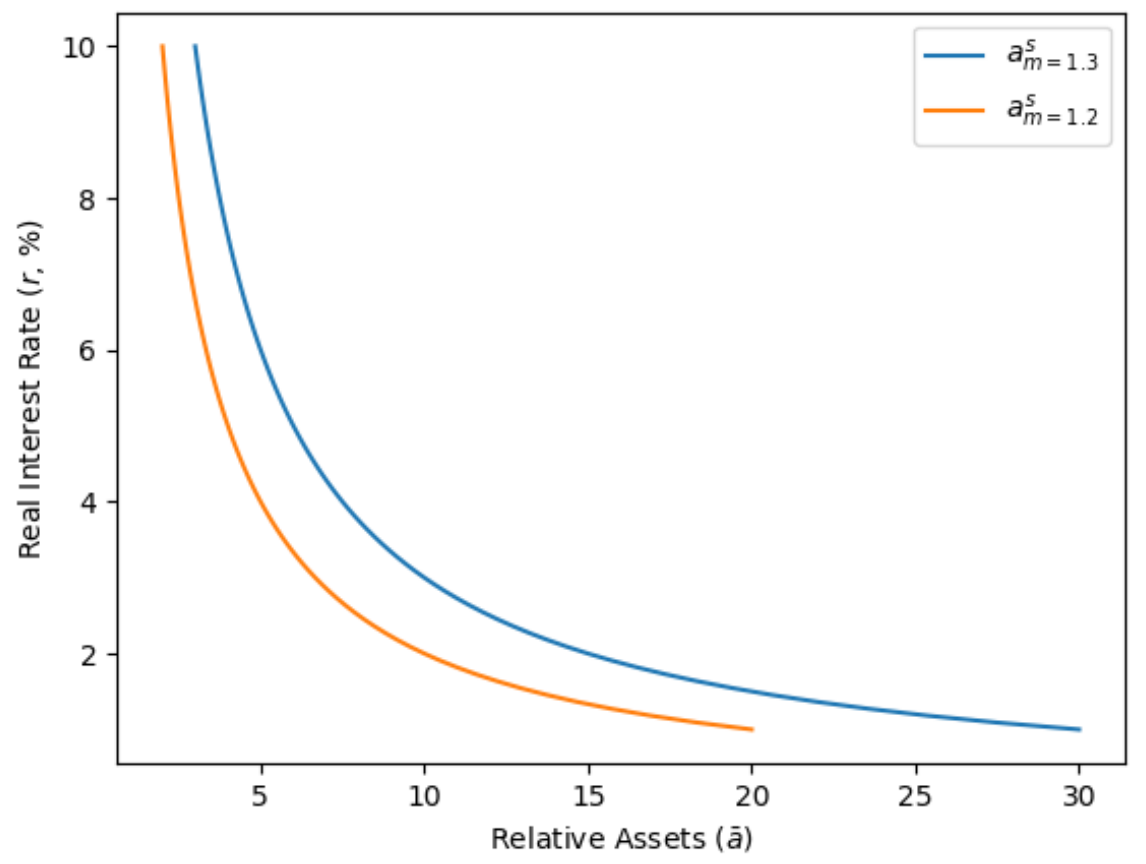

The supply of assets (equation 10) can be rewritten in relative terms to get:

$$
\bar{a}^{s}=\frac{\bar{m}-1}{\bar{r}}
$$

Two features can be observed. First, in equation 12 a rise in $\bar{r}$ lowers $\bar{a}^{s}$. This makes sense, because higher discounting implies the discounted sum of profits is lower so the value of firms falls. Equation 12 is plotted in figure 1. The blue curve represents $\bar{a}^{s}$ with $\bar{m}=1.3$, and the orange curve represents $\bar{a}^{s}$ with $\bar{m}=1.2$. Since raising $\bar{r}$ lowers $\bar{a}^{s}$, the curve has a downward slope. It may seem strange that the supply curve is downward sloping, but this is because the vertical axis is the return on assets. The return on assets is like the inverse of the price of assets (since the return that agents make on assets falls as the price of those assets rises). If the curve was drawn with the price of assets on the vertical axis, it would have the usual upward-sloping supply curve.

Second, note that in equation 12 a fall in the markup $\bar{m}$ lowers the relative asset supply $\bar{a}^{s}$ for any real interest rate $\bar{r}$. This makes sense, because when the markup falls, the value of firms falls and thus the value of owning shares in firms falls. This can also be seen in figure 1. Observe that the fall in the markup shifts the relative asset supply curve left, from the blue curve with markup 1.3 to the orange curve with markup 1.2 .

Asset Demand: 1. Representative Agent Next, the shape of the asset demand is considered under three different household structures: (1) representative agent, (2) heterogeneity through overlapping generations, and (3) heterogeneity through idiosyncratic labor.

In all standard representative agent problems, an Euler condition of a form similar to the following is 
Figure 2: Equilibrium under a Fall in the Markup: 1. Representative Agent

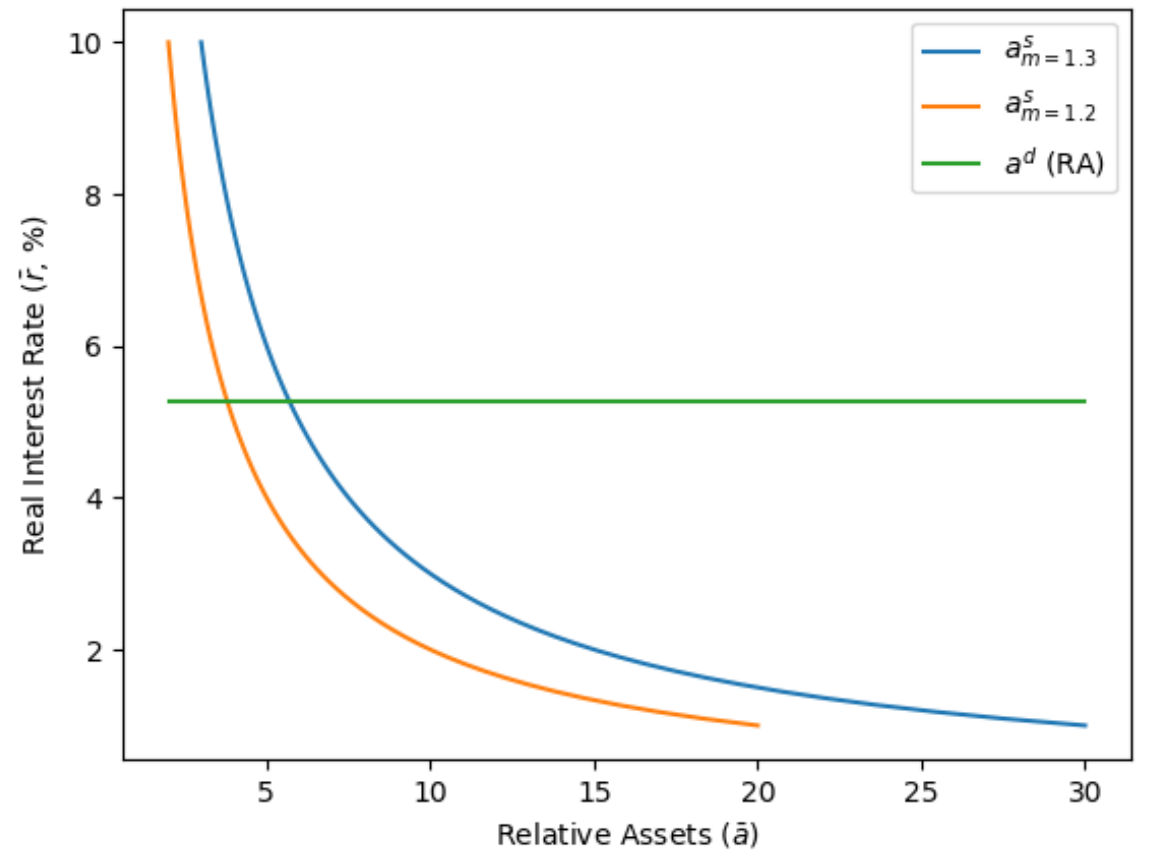

derived:

$$
C_{t+1}^{\gamma}=\beta\left(1+r_{t+1}\right) C_{t}^{\gamma} .
$$

A steady state equilibrium requires that a representative agent consumes the same amount over time. If $1+r_{t+1}$ is more (less) than $\beta$, consumption must be growing (falling). Therefore, the only way a steady state is possible is if:

$$
\beta(1+\bar{r})=1
$$

This can be rewritten as:

$$
\bar{r}=\frac{1}{\beta}-1 .
$$

Equation 14 is plotted in figure 2. As in figure 1, the impact of a fall in the markup is considered. Observe that the asset demand is just a horizontal line since $\bar{r}$ is always pinned down. Thus, a shift left in the supply of assets reduces the quantity of assets held by the household but has no impact on $\bar{r}$.

The assumption of a representative agent pins down the real interest rate regardless of changes in the supply of assets. The agent's Euler condition dictates that the real interest rate is an increasing function of savers' consumption in the future relative to now. The intuition is that the only way agents will consume more in the future than they do now is if they get a high real interest rate on their savings. Otherwise they would save less and consume more now. With a representative agent, however, consumption of the agent equals aggregate consumption. And in a steady state with no growth, aggregate consumption will be constant. Therefore, since aggregate consumption is constant, the representative agent's consumption will be constant, and this means that the real interest rate must stay the same. Therefore, even if average inflation rises, which from the firm side leads to a fall in the quantity of assets in which agents can save, 
this has no impact on the real interest rate in the long run.

Asset Demand: 2. Overlapping Generations Now, household heterogeneity is introduced. The reason household heterogeneity makes a difference is that it implies that the agent's consumption and aggregate consumption can be different. This implies that even though the economy may remain on the same balanced growth path in the steady state, a change in the supply of assets can affect the agent's consumption in the future relative to now, which by the Euler condition feeds back to adjust the real interest rate.

A simple overlapping generations model based on Diamond (1965) is first considered. In every period, a new generation is born. Each generation lives for two periods and then dies. The utility of a young agent is given by:

$$
\log \left(C_{1, t}\right)+\beta \log \left(C_{2, t+1}\right) .
$$

Log utility is used for simplicity. Young agents work $L$ units and devote their income to either consumption $C_{1, t}$ or asset purchases $A_{t+1}$ :

$$
C_{1, t}+A_{t+1}=W_{t}
$$

Old agents merely consume $C_{2, t+1}$ from their available assets. Their available assets are the assets from when they were young on which they have earned a return of $r_{t+1}$ :

$$
C_{2, t+1}=\left(1+r_{t+1}\right) A_{t+1}
$$

The amount the young save can be solved for by inputting equations 16 and 17 into equation 15 and then taking first-order conditions. This yields:

$$
A_{t+1}=\frac{\beta}{1+\beta} W_{t} L
$$

which shows that the young save some constant fraction of their income each period. It is simpler to rewrite the agent's demand for assets in relative terms; thus equation 18 is divided by labor income and also written in steady state terms to yield:

$$
\bar{a}^{d}=\frac{\beta}{1+\beta} .
$$

In this case, the demand for savings is perfectly inelastic to changes in $\bar{r}$. This is a special case (due to $\log$ utility and the inclusion of only two periods). In the full model, demand for relative assets is not perfectly inelastic. However, the generation structure in the full model is still such that the elasticity of demand is not perfectly elastic and thus the real interest rate changes in response to a shift left in the demand for assets.

Equation 19 is plotted in figure 3, in which the impact of a fall in the markup is considered (as in figure 1). Observe that the asset demand is just a vertical line since $\bar{a}^{d}$ is fixed. Thus, a shift left in the supply of assets lowers $\bar{r}$ but has no impact on the quantity of assets demanded by the agent. The relative asset supply on this graph looks a bit different from previous asset demand/supply graphs because each period represents a generation and lasts 25 to 30 years, making it necessary to rescale the curves to get back to an annual basis. The non-annualized case is shown in appendix A.3.

This is very different from the representative agent case in which a fall in the supply of assets does not impact the real interest rate but reduces equilibrium assets. The reason is that when the supply of assets falls, it reduces the consumption of the old relative to the young. Thus, young people want to save more to pass more consumption on to when they are old. Consequently, they are prepared to pay more to save, 
Figure 3: Equilibrium under a Fall in the Markup: 2. OLG

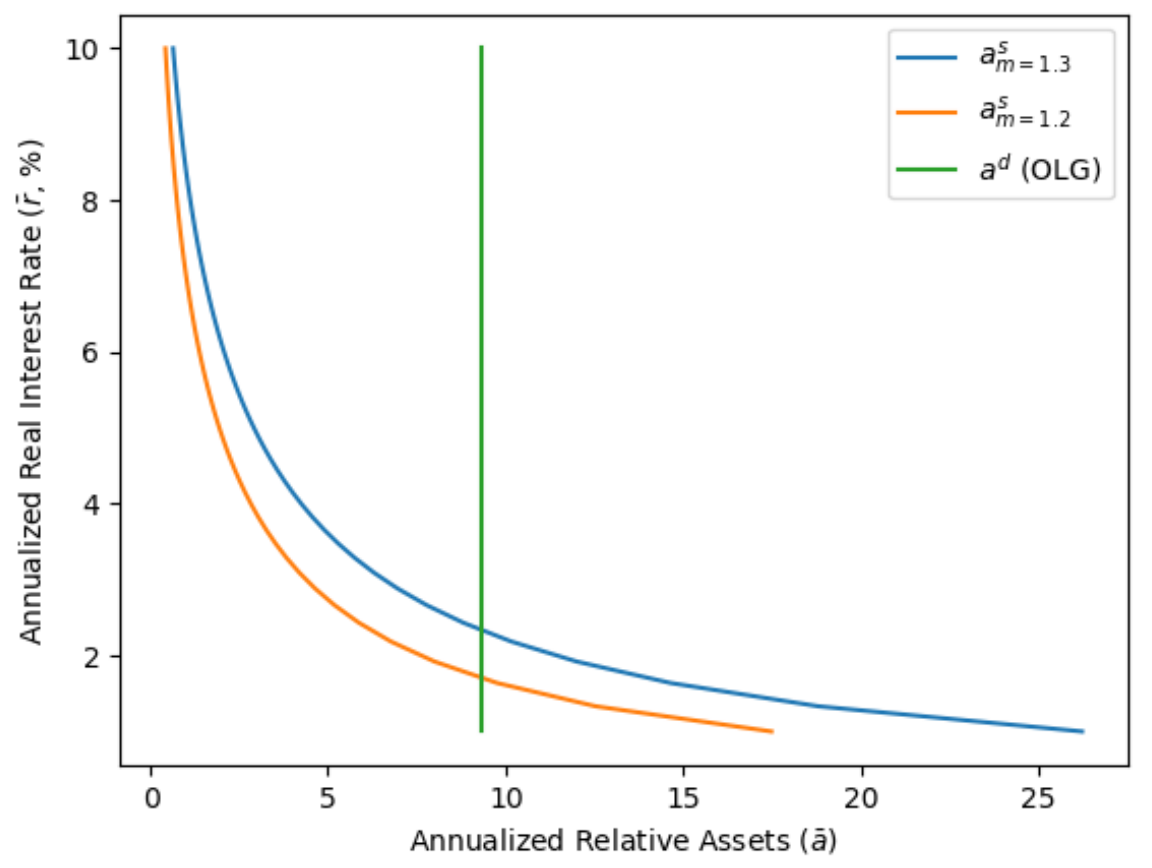

which is equivalent to accepting a lower return on their savings and thus lower real interest rates.

Asset Demand: 3. Idiosyncratic Labor In this paper, household heterogeneity is primarily introduced through overlapping generations. However, an extension with idiosyncratic labor is considered, and it is worthwhile to demonstrate that a similar intuition explains why the channel holds in this case. This form of heterogeneity has been studied extensively in recent years (McKay, Nakamura, and Steinsson 2016; Kaplan, Moll, and Violante 2018) using what are frequently referred to as HANK models.

There are many agents, each denoted with subscript $i$. Agents live forever and maximize their lifetime utility:

$$
\max \sum_{t=0}^{\infty} \mathbb{E}_{0}\left[\beta^{t} u\left(C_{i, t}\right)\right]
$$

Agents receive a wage $W$ from the amount they work $L_{i, t}$, which varies over time and across agents, and some real return $r$ on assets $A_{i, t}$. Agents spend their money on consumption $C_{i, t}$ and assets for the next period. Note that there are no aggregate shocks, which is why $W$ and $r$ have no time subscripts. Their budget constraint is:

$$
C_{i, t}+A_{i, t+1}=(1+r) A_{i, t}+W L_{i, t} .
$$

A key additional feature is that agents face some borrowing constraint, which is set to be 0 , and this limits the amount they may borrow each period:

$$
A_{i, t+1} \geq 0
$$


Figure 4: Equilibrium under a Fall in the Markup: 3. Idiosyncratic Labor



This problem can be solved by value function iteration. Again, to easily separate out the supply and the demand for assets, the problem needs to be rewritten in terms of relative assets (equation 11):

$$
\max \mathbb{E}_{0}\left[\sum_{t=0}^{\infty} \beta^{t} u\left(c_{i, t}\right)\right],
$$

s.t.

$$
\begin{gathered}
a_{i, t+1}=(1+r) a_{t}+\frac{L_{i, t}}{L}-c_{i, t}, \\
a_{i, t+1} \geq 0 .
\end{gathered}
$$

The asset demand $\bar{a}^{d}$ can then be computed for any equilibrium real rate $\bar{r}$.

$\bar{a}^{d}$ is plotted in figure 4 where a fall in the markup is considered (as in figure 1). A shift left in the asset supply due to a fall in the markup leads to a fall in relative assets and a fall in the equilibrium real rate. As the level of assets increases, the fall in the markup reduces relative assets more and lowers the equilibrium real rate less.

Again, introducing this form of heterogeneity yields results that are very different from those of the representative case. This is because a fall in assets implies that there are fewer assets in which agents can save to avoid hitting their borrowing constraint in subsequent periods. Therefore, agents are keener to save. They thus pay a higher price for savings, which is equivalent to receiving a lower return on their savings and a lower real interest rate.

The degree to which a shift left in assets lowers the equilibrium real rate depends on how many agents are close to the borrowing constraints. When the level of assets is high (low), a fall in assets implies it is a 
little (lot) more difficult to save for the future, so it raises the price of savings a little (lot) and thus lowers the equilibrium real rate a little (lot). This can be seen in figure 4 , which shows that the relative asset demand is steeper when relative assets are low.

\section{Model}

I now introduce the main model, which is used to assess the degree to which a change in trend inflation affects the real interest rate and to conduct welfare analysis.

\subsection{Households}

I start by describing the general overlapping generations framework. Each agent lives for $M$ periods. Agents born in different periods overlap. An agent is denoted by their age in periods, so an agent born $i$ periods ago is denoted as $i$. Therefore, the $M$ cohorts in any given period are denoted as $0, \ldots, M-1$. Each period, new agents are born (cohort 0 ), the oldest agents from the previous period (cohort $M-1$ at time $t-1$ ) have died, and all other generations mature from cohort $i$ to $i+1$.

The population of the cohort born at time $t$ is defined as $N_{t}$. The total population is defined as $\mathbb{N}_{t}$, and thus $\mathbb{N}_{t}=\sum_{i=0}^{M-1} N_{t-i}$. It is assumed that the population grows at a constant rate of $n$ so that $N_{t+1}=$ $(1+n) N_{t}$, and thus $\mathbb{N}_{t+1}=(1+n) \mathbb{N}_{t}$.

An agent of cohort $i$ at time $t$ has a budget constraint given by equation 20. The consumption and labor of agent $i$ at time $t$ are denoted by $C_{i, t}$ and $L_{i, t}$, respectively. An agent of cohort $i$ works for $L_{i, t}$. $W_{t}$ is the real wage paid at time $t$ for each unit of work. An agent can invest in bonds, capital, or shares in firms. $B_{i, t}, K_{i, t}$ are, respectively, the bonds and capital held by agents of cohort $i$ at the start of period $t$ (so they were chosen at $t-1$ when that agent was of cohort $i-1)$. Bonds are in nominal terms, and a bond issued at $t-1$ that pays out at $t\left(B_{i, t}\right)$ pays interest rate $i_{t-1}$ at time $t$. Capital is in real terms, and agents get a real return of $r_{t}$ from selling their capital to the firm at time $t . \tilde{\omega}_{i, t}$ is the number of shares of the composite firm that agent $i$ owns at the start of time $t$. The total number of shares issued is 1 , so $\tilde{\omega}_{i, t}$ also represents the proportion of the composite firm owned by an agent of cohort $i$ at time $t$. The price of a share is $\tilde{Z}_{t}$, and it pays out a proportional amount of the firm's total profits $\tilde{\Omega}_{t}$ each period. It is assumed that the agent starts with zero assets, so $K_{i, 0}=B_{i, 0}=\tilde{\omega_{i, 0}}=0$. For ease of notation, the gross return of capital and the gross nominal interest rate are also defined as $R_{t}=1+r_{t}$ and $I_{t}=1+i_{t}$, respectively.

$$
C_{i, t}+\frac{B_{i+1, t+1}}{P_{t}}+K_{i+1, t+1}+\tilde{Z}_{t} \tilde{\omega}_{i+1, t+1} \leq W_{t} L_{i, t}+I_{t-1} \frac{B_{i, t}}{P_{t}}+R_{t} K_{i, t}+\left(\tilde{\Omega}_{t}+\tilde{Z}_{t}\right) \tilde{\omega}_{i, t} .
$$

The agent's lifetime utility function when they are in cohort $k$ is given by equation 21. CRRA utility is used (equation 22). Both endogenous and exogenous labor are allowed for. In the exogenous labor case, the labor supply is fixed by each cohort so that $L_{i, t}=L_{i} \forall t$ and the disutility of labor term $v\left(L_{i, t}\right)$ does not appear in the utility function. In the endogenous labor case, the disutility of labor is given by equation 23 , where $\eta$ is the elasticity of labor supply. Also, bonds are allowed to offer higher utility relative to other assets with a similar return. The theoretical reason for this is that bonds might offer safety or liquidity benefits. The practical reason is that it provides a simple method for modeling a fall in the real interest rate on bonds. I model the additional utility on bonds by a very specific utility function (equation 24) 
that introduces a wedge between the real interest rate on bonds and the real interest rate on other assets. ${ }^{3}$ The wedge is captured by $\xi$. When $\xi=0-$ when there is no additional utility afforded by bonds - the standard case applies where the real interest on bonds and other assets is the same. When $\xi>0$, bonds afford additional utility, so the real interest rate on bonds falls relative to other assets. Otherwise, this additional utility on bonds plays no role.

$$
\begin{aligned}
\mathbb{E}_{t}\left[\sum _ { i = k } ^ { M - 1 } \beta ^ { i - k } \left[u\left(C_{i, t}\right)\right.\right. & \left.\left.+u_{b}\left(\frac{B_{i, t}}{P_{t}}\right)-v_{i}\left(L_{i, t}\right)\right]\right], \\
u(C) & =\frac{C^{1-\gamma}}{1-\gamma} \\
v_{i}\left(L_{i, t}\right) & =\frac{1}{1+\eta} x_{i} L_{i, t}^{1+\eta} \\
u_{b}\left(\frac{B_{i, t}}{P_{t}}\right) & =\xi I_{t-1} \frac{B_{i, t}}{P_{t}} u^{\prime}\left(\bar{C}_{i, t}\right) .
\end{aligned}
$$

Therefore, an agent of age $k$ faces the following problem:

$$
\max _{\left\{C_{i, t+i}, B_{i+1, t+i+1}, K_{i+1, t+i+i}, \tilde{\omega}_{i+1, t+i+1}\right\}_{i=k}^{M-1}} \mathbb{E}_{t}\left[\sum_{i=k}^{M-1} \beta^{i-k}\left[u\left(C_{i, t}\right)+u_{b}\left(\frac{B_{i, t}}{P_{t}}\right)-v\left(L_{i, t}\right)\right]\right],
$$

s.t. $\forall i \in k, \ldots, M-1$ :

$$
\begin{gathered}
C_{i, t+i}+\frac{B_{i+1, t+i+1}}{P_{t+i}}+K_{i+1, t+i+1}+\tilde{Z}_{t+i} \tilde{\omega}_{i+1, t+i+1} \\
\leq W_{t+i} L_{i, t+i}+I_{t-1} \frac{B_{i, t+i}}{P_{t+i}}+R_{t+i} K_{i, t+i}+\left(\tilde{\Omega}_{t+i}+\zeta \tilde{Z}_{t+i}\right) \tilde{\omega}_{i, t+i}, \\
B_{M, t+M-k}, K_{M, t+M-k}, \omega_{M, t+M-k} \geq 0 .
\end{gathered}
$$

First-order conditions are applied. This yields arbitrage conditions on bonds (equation 25), capital (equation 26), and shares (equation 27). Note that inflation is defined in the usual way $\left(1+\pi_{t}=\Pi_{t+1}=\right.$ $\frac{P_{t+1}}{P_{t}}$ ). Also, observe that the only impact of the utility on bonds (equation 24) is to add the constant wedge ( $\xi$ ) to equation 25. $\forall i \in 0, \ldots, M-2$ :

$$
\begin{gathered}
u^{\prime}\left(C_{i, t}\right)=\beta \mathbb{E}_{t}\left[u^{\prime}\left(C_{i+1, t+1}\right) \frac{I_{t}}{\Pi_{t+1}}(1+\xi)\right], \\
u^{\prime}\left(C_{i, t}\right)=\beta \mathbb{E}_{t}\left[R_{t+1} u^{\prime}\left(C_{i+1, t+1}\right)\right], \\
\tilde{Z}_{t} u^{\prime}\left(C_{i, t}\right)=\beta \mathbb{E}_{t}\left[u^{\prime}\left(C_{i+1, t+1}\right)\left(\tilde{\Omega}_{t+1}+\tilde{Z}_{t+1}\right)\right] .
\end{gathered}
$$

With endogenous labor, there is also a labor-leisure condition $\forall i \in 0, \ldots, M-1$ given by equation 28 .

$$
W_{t} u^{\prime}\left(C_{i, t}\right)=v^{\prime}\left(L_{i, t}\right)
$$

To make the model tractable, aggregate variables are written in per capita terms. Define $\omega_{i, t}=\mathbb{N}_{t} \tilde{\omega}_{i, t}$,

\footnotetext{
${ }^{3} \bar{C}_{i, t}$ denotes the fact that agents take as a given their consumption when computing their additional utility from bond holdings. This is needed to yield the simple wedge between returns on bonds and other assets.
} 
so that $\omega_{i, t}$ represents the proportional per capita holdings of an agent of cohort $i$ at time $t$ of firm shares rather than the aggregate holdings of cohort $i$ at $t$. Then define $Z_{t}$ as the price of a per capita share in firms, that is $Z_{t}=\frac{\tilde{Z}_{t}}{\mathbb{N}_{t}}$, and $\Omega_{t}$ to be the profits paid by a per capita share in firms, that is $\Omega_{t}=\frac{\tilde{\Omega}_{t}}{\mathbb{N}_{t}}$. Equations 20 and 27 become, respectively,

$$
\begin{gathered}
Z_{t} u^{\prime}\left(C_{i, t}\right)=\beta \mathbb{E}_{t}\left[u^{\prime}\left(C_{i+1, t+1}\right)(1+n)\left(\Omega_{t+1}+Z_{t+1}\right)\right] \\
C_{i, t}+\frac{B_{i+1, t+1}}{P_{t}}+K_{i+1, t+1}+\frac{Z_{t} \omega_{i+1, t+1}}{1+n} \leq W_{t} L_{i, t}+I_{t-1} \frac{B_{i, t}}{P_{t}}+R_{t} K_{i, t}+\left(\Omega_{t}+Z_{t}\right) \omega_{i, t} .
\end{gathered}
$$

Next, the budget constraint is rewritten more simply. To do this, first define the amount that agents of cohort $i$ have available at the start of $t$ from savings they made in $t-1$ as $T_{i, t}$ (equation 32) and the amount that agents of cohort $i$ save at $t$ for $t+1$ as $S_{i+1, t+1}$ (equation 31). This implies that equation 30 can be rewritten as equation 33 .

$$
\begin{gathered}
S_{i+1, t+1}=\frac{B_{i+1, t+1}}{P_{t}}+K_{i+1, t+1}+\frac{Z_{t} \omega_{i+1, t+1}}{1+n}, \\
T_{i, t}=I_{t-1} \frac{B_{i, t}}{P_{t}}+R_{t} K_{i, t}+\left(\Omega_{t}+Z_{t}\right) \omega_{i, t}, \\
C_{i, t}+S_{i+1, t+1} \leq W_{t} L_{i, t}+T_{i, t} .
\end{gathered}
$$

Aggregated per capital variables are defined for savings held at $t\left(T_{t}\right)$, savings made at $t\left(S_{t+1}\right)$, capital $\left(K_{t}\right)$, labor $\left(L_{t}\right)$, and bonds $\left(B_{t}\right)$. The aggregations for labor $\left(L_{t}\right)$ and savings made at $t\left(S_{t+1}\right)$ are given in equations 34 and 35, respectively. Equations 31 and 32 can then be aggregated to yield equations 36 and 37. Details on these aggregation steps are given in appendix B.1.

$$
\begin{gathered}
L_{t}=\frac{\sum_{i=0}^{M-1}\left(\frac{1}{1+n}\right)^{i} L_{i, t}}{\sum_{i=0}^{M-1}\left(\frac{1}{1+n}\right)^{i}}, \\
S_{t+1}=\frac{\sum_{i=0}^{M-1} \frac{1}{(1+n)^{i}} S_{i+1, t+1}}{\sum_{i=0}^{M-1} \frac{1}{(1+n)^{i}}}, \\
T_{t}=I_{t-1} \frac{B_{t}}{P_{t}}+R_{t} K_{t}+\Omega_{t}+Z_{t}, \\
S_{t+1}=(1+n) \frac{B_{t+1}}{P_{t}}+(1+n) K_{t+1}+Z_{t} .
\end{gathered}
$$

The share of savings made by an agent of cohort $i$ at $t$ is defined as $s_{i+1, t+1}=\frac{S_{i+1, t+1}}{S_{t+1}}$. Equation 35 can be rewritten as equation 38, which demonstrates that the shares of savings must sum to 1 across cohorts. To a first-order approximation, agents of different cohorts care only about their total savings each period but are indifferent regarding whether these savings are held in capital, shares, or bonds. Here it is specified that $T_{i, t}=s_{i, t-1}^{p} T_{t}$. This implies that a cohort's share of savings held at the start of period $t$ equals their share of the savings made at the end of period $t-1$, suggesting that equation 33 can be rewritten as equation 39 .

$$
\begin{gathered}
1=\frac{\sum_{i=0}^{M-1}\left(\frac{1}{1+n}\right)^{i} L_{i, t}}{\sum_{i=0}^{M-1}\left(\frac{1}{1+n}\right)^{i}}, \\
C_{i, t}+s_{i+1, t+1} S_{t+1}=W_{t} L_{i, t}+s_{i, t} T_{t} .
\end{gathered}
$$




\subsection{Firms}

The model has a standard firm setup with a competitive goods firm, aggregating monopolistic intermediate firms with Calvo pricing.

Final Goods Firm There is a single competitive final goods firm that aggregates intermediate goods in different industries to produce a final good through constant elasticity of substitution (CES) production (equation 40).

$$
Y_{t}=\left(\int_{0}^{1} Y_{i, t}^{\frac{\sigma-1}{\sigma}}\right)^{\frac{\sigma}{\sigma-1}} .
$$

The final goods firm has the usual CES demand for intermediate goods given by equation 41. Combining equations 40 and 41 allows the computation of the CES price aggregator (equation 42).

$$
\begin{aligned}
& Y_{i, t}=Y_{t}\left(\frac{P_{i, t}}{P_{t}}\right)^{-\sigma}, \\
& P_{t}=\left(\int_{0}^{1} P_{i, t}^{1-\sigma}\right)^{\frac{1}{1-\sigma}} .
\end{aligned}
$$

Intermediate Goods Firms Cost Minimization Firms minimize their costs (equation 43) subject to their production function (equation 44). $A_{t}$ represents productivity, $K_{i, t}$ represents firm $i$ 's capital, and $L_{i, t}$ represents firm $i$ 's labor.

$$
\begin{gathered}
\left(R_{t}-1+\delta\right) K_{i, t}+W_{t} L_{i, t}, \\
Y_{i, t}=A_{t} K_{i, t}^{\alpha} L_{i, t}^{1-\alpha} .
\end{gathered}
$$

The marginal cost of producing one additional unit of output is defined as $M C_{t}$. Cost minimization (and noting that $\frac{K_{i, t}}{L_{i, t}}$ is identical across firms) implies equations 45 and 46.

$$
\begin{gathered}
M C_{t}=\frac{r_{t}+\delta}{\alpha A_{t} K_{t}^{\alpha-1} L_{t}^{1-\alpha}}, \\
M C_{t}=\frac{W_{t}}{(1-\alpha) A_{t} K_{t}^{\alpha} L_{t}^{-\alpha}} .
\end{gathered}
$$

Noting that $\frac{K_{i, t}}{L_{i, t}}=\frac{K_{t}}{L_{t}}$, inputting equation 41 into equation 44 yields an equation for aggregate profits (equation 47) that includes a term for price dispersion (equation 48).

$$
\begin{gathered}
\nu_{t} Y_{t}=A_{t} K_{t}^{\alpha} L_{t}^{1-\alpha}, \\
\nu_{t}=\int_{0}^{1}\left(\frac{P_{i, t}}{P_{t}}\right)^{-\sigma} d i .
\end{gathered}
$$

We can rewrite equations 45 and 46 using equation 47 to get equations 49 and 50.

$$
\begin{gathered}
\alpha M C_{t} \nu_{t}=\frac{\left(r_{t}+\delta\right) K_{t}}{Y_{t}}, \\
(1-\alpha) M C_{t} \nu_{t}=\frac{W_{t} L_{t}}{Y_{t}} .
\end{gathered}
$$


Being able to vary the profitability of firms is useful for calibrating the model. A tax (subsidy) on firm production is introduced to enable such variation. $M C_{t}$ represents the marginal cost of producing one good before tax. Firms actually pay $(1+\tau) M C_{t}$, where $\tau$ is the rate of tax. To see how this affects profitability, note that by the properties of CES demand, intermediate firms always set approximately the same markup over their after-tax marginal costs $\left(\approx \frac{\sigma}{\sigma-1}\right)$. Thus, even if they pay higher taxes, their after-tax marginal costs remain the same, implying a fall in their marginal costs and thus higher profits. To avoid potential issues with how the receipts (costs) of the tax (subsidy) are distributed, it is assumed that the receipts (costs) are paid back to (taken from) the firm as a lump sum. Profits of an individual firm are then denoted by equation 51 . Equation 51 can be aggregated to yield equation 52 . Since the taxes are paid back to the firm, they play no part in the aggregated profit equation.

$$
\begin{gathered}
\Omega_{i, t}=\frac{P_{i, t}}{P_{t}} Y_{i, t}-M C_{t} Y_{i, t}(1+\tau)+\tau Y_{t} \nu_{t}, \\
\Omega_{t}=Y_{t}\left(1-M C_{t} \nu_{t}\right) .
\end{gathered}
$$

Intermediate Goods Firm Profit Maximization Each intermediate goods firm is monopolistic. A firm can change its price only with probability $\lambda$. It faces CES demand from the final goods firm. A firm discounts a period $t+i$ periods in the future by $\bar{R}^{-i}$. Their profits are thus given by equation 53 (where terms that are not functions of the firm's chosen price are ignored).

$$
\mathbb{E}_{t}\left[\sum_{j=0}^{\infty} \bar{R}^{-j}(1-\lambda)^{j}\left[\frac{P_{t}^{\star} Y_{i, t+j}}{P_{t+j}}-(1+\tau) M C_{t+j} Y_{i, t+j}\right]\right] .
$$

Equation 53 is maximized subject to equation 41 in the usual manner to yield equation 54

$$
\mathbb{E}_{t}\left[\sum_{j=0}^{\infty}(1-\lambda)^{j} \bar{R}^{-j} Y_{t+j}\left(\frac{P_{t+j}}{P_{t}}\right)^{\sigma}\left[\frac{P_{t}^{\star}}{P_{t}} \frac{P_{t}}{P_{t+j}}-\frac{\sigma}{\sigma-1}(1+\tau) M C_{t+j}\right]\right] .
$$

Equation 54 is rewritten as equation 55, where two additional recursive variables $\left(U_{t}, V_{t}\right)$ are defined through equations 56 and 57.

$$
\begin{gathered}
U_{t} \frac{P_{t}^{\star}}{P_{t}}=V_{t}, \\
U_{t}=Y_{t}+\mathbb{E}_{t}\left[\Pi_{t+1}^{\sigma-1}(1-\lambda) \frac{1}{\bar{R}} U_{t+1}\right], \\
V_{t}=Y_{t} \frac{\sigma}{\sigma-1}(1+\tau) M C_{t}+\mathbb{E}_{t}\left[\Pi_{t+1}^{\sigma}(1-\lambda) \frac{1}{\bar{R}} V_{t+1}\right] .
\end{gathered}
$$

Equations 42 and 48 are recursively rewritten as equations 58 and 59, respectively.

$$
\begin{gathered}
1=\lambda\left(\frac{P_{t}^{\star}}{P_{t}}\right)^{1-\sigma}+(1-\lambda) \Pi_{t}^{\sigma-1}, \\
\nu_{t}=(1-\lambda) \nu_{t-1} \Pi_{t}^{\sigma}+\lambda\left(\frac{P_{t}^{\star}}{P_{t}}\right)^{-\sigma} .
\end{gathered}
$$




\subsection{Monetary and Fiscal Policy}

In the steady state, the only component of monetary policy that matters is the inflation target $\pi^{\star}$. Once shocks are introduced, as they are in section 6 , it becomes necessary to specify a monetary policy rule. I consider a simple case in which central banks react to inflation only with coefficient $\phi_{\pi}$. Following Coibion, Gorodnichenko, and Wieland (2012) and Andrade et al. (2019), I incorporate inertia. Thus, $\rho_{i}$ of the interest rate set in the current period follows what was set in the preceding period, while $1-\rho_{i}$ is a response to inflation in the current period. The ideal policy rule is given in log-linear terms by equation 60 . However, the central bank is sometimes constrained by the zero lower bound (equation 61).

$$
\begin{gathered}
I_{t}^{\star}=I_{t-1}^{\star} \rho_{i}\left(\bar{\Pi}\left(\frac{\Pi_{t}}{\bar{\Pi}}\right)^{\phi_{\pi}}\right)^{1-\rho_{i}}, \\
I_{t}=\max \left\{I_{t}^{\star}, 1\right\} .
\end{gathered}
$$

The government is assumed to have no debt/savings, so $B_{t}=0$.

\section{Model Solution and Calibration}

In this section, I discuss how the conditions derived in section 3 can be modeled.

\subsection{Full Conditions}

In this subsection, the conditions derived in section 3 are summarized.

The household's problem is summarized by $2 M+5$ conditions: $M-1$ Euler condition(s) (equation 26), two arbitrage conditions (equations 25 and 29), the sum of labor (equation 34), the quantities of savings and assets (equations 36 and 37), the sum of savings shares (equation 38), and $M$ simplified budget constraints (equation 39). The firm's cost minimization problem is summarized by four conditions: the two cost minimization conditions (equations 49 and 50), the definition of output (equation 47), and the definition of profits (equation 52). The firm's profit maximization problem is summarized by five conditions: equations 55 to 59 . There are two monetary policy conditions (equations 60 and 61). In total, there are $2 M+16$ conditions. These correspond to the following variables:

$$
\left\{C_{i, t}\right\}_{i=0}^{M-1},\left\{s_{i, t}\right\}_{i=1}^{M-1}, I_{t}, \Pi_{t}, R_{t}, W_{t}, M C_{t}, K_{t}, L_{t}, Y_{t}, Z_{t}, \Omega_{t}, S_{t}, T_{t}, \nu_{t}, \frac{P_{t}^{\star}}{P_{t}}, U_{t}, V_{t}, I_{t}^{\star}
$$

\subsection{Steady State}

The steady state is computed here in a manner similar to how it is computed in section 2 . The demand and the supply of relative assets are computed as a function of the real interest rate. Relative assets are defined in equation 62. Equilibrium is the point where the demand and the supply of relative assets intersect.

$$
a_{t}=\frac{S_{t+1}}{W_{t} L_{t}}
$$

The supply of relative assets comes from the firm side because assets are made up of shares and capital, and the firm side determines the value of the shares and the amount of capital that needs to be supplied. 
Note that although demand for capital is commonly given as coming from firms, in this context the firm is actually supplying the opportunity for the household to own capital as an asset. As the real interest rate rises, the value of firms falls and firms rent less capital from households, so the supply of assets falls. The derivation of the supply of relative assets can be broken into two parts. First, the steady state marginal cost can be computed from firms' profit maximization conditions - the derivation is given in appendix C.1. Second, the supply of assets can be computed given the steady state marginal cost from firms' cost minimization conditions - the derivation is given in appendix C.2.

The demand for relative assets comes from the household side, since households wish to hold assets to save for the future. As the real interest rate rises, whether the demand for assets increases depends on whether a substitution effect or income effect dominates. The substitution effect is that agents gain more from saving and therefore want to save more when the real interest rate rises. The income effect is that when the real interest rate rises, the old become richer and thus the young want to save less. The derivation of the demand for relative assets is given in appendix C.3.

\subsection{Shocks and Log-linearized Conditions}

In this subsection, shocks are incorporated into the log-linearized versions of the full set of model conditions found in section 4.1 .

Shocks similar to those in Coibion, Gorodnichenko, and Wieland (2012) are used. The shocks are to technology, the risk premium, and the Phillips Curve, and they are denoted as $\epsilon_{a, t}, \epsilon_{q, t}$, and $\epsilon_{m, t}$, respectively, with standard deviations of the shocks given as $\sigma_{a}, \sigma_{q}$, and $\sigma_{m}$, respectively. These follow $\mathrm{AR}(1)$ processes:

$$
\begin{gathered}
\hat{A}_{t}=\rho_{a} \hat{A}_{t-1}+\epsilon_{a, t}, \\
\hat{q}_{t}=\rho_{q} \hat{q}_{t-1}+\epsilon_{q, t}, \\
\hat{m}_{t}=\rho_{m} \hat{m}_{t-1}+\epsilon_{m, t} .
\end{gathered}
$$

Denote the log-linearization of $X$ around the steady state as $\hat{X}$ :

$$
\hat{X}_{t}=\log \left(X_{t}\right)-\log (\bar{X})
$$

Household conditions (equations 25, 26, 29, 34, and 36 to 39) are log-linearized to yield:

$$
\begin{aligned}
& \mathbb{E}_{t}\left[\hat{C}_{i+1, t+1}\right]=\frac{1}{\gamma}\left(\mathbb{E}_{t}\left[\hat{R}_{t+1}\right]+\hat{q}_{t}\right)+\hat{C}_{i, t}, \\
& \mathbb{E}_{t}\left[\hat{R}_{t+1}\right]=\hat{I}_{t}-\mathbb{E}_{t}\left[\hat{\Pi}_{t+1}\right], \\
& \hat{Z}_{t}+\mathbb{E}_{t}\left[\hat{R}_{t+1}\right]=\frac{\bar{\Omega}}{\bar{\Omega}+\bar{Z}} \mathbb{E}_{t}\left[\hat{\Omega}_{t+1}\right]+\frac{\bar{Z}}{\bar{\Omega}+\bar{Z}} \mathbb{E}_{t}\left[\hat{Z}_{t+1}\right], \\
& \hat{L}_{t}=\frac{\sum_{i=0}^{M-1}\left(\frac{1}{1+n}\right)^{i} \hat{L}_{i, t}}{\sum_{i=0}^{M-1}\left(\frac{1}{1+n}\right)^{i}}, \\
& \left.\bar{T} \hat{T}_{t}=\bar{R} \overline{\bar{P}} \widehat{\bar{P}} \widehat{\frac{B_{t}}{P_{t-1}}}\right)+\bar{R} \bar{K}\left(\hat{R}_{t}+\hat{K}_{t}\right)+\bar{\Omega} \hat{\Omega}_{t}+\bar{Z} \hat{Z}_{t}
\end{aligned}
$$




$$
\begin{gathered}
\bar{S} \hat{S}_{t+1}=\frac{\bar{B}}{\bar{P}}\left(\widehat{\frac{B_{t+1}}{P_{t}}}\right)+\bar{K} \hat{K}_{t+1}+\bar{Z} \hat{Z}_{t}, \\
0=\frac{\sum_{i=0}^{M-1} \frac{1}{(1+n)^{i}} \bar{s}_{i} \hat{s}_{i, t}}{\sum_{i=0}^{M-1} \frac{1}{(1+n)^{i}}}, \\
\bar{C}_{i} \hat{C}_{i, t}+\bar{s}_{i+1} \bar{S}\left[\hat{s}_{i+1, t+1}+\hat{S}_{t+1}\right]=\bar{W} \bar{L}_{i} \hat{W}_{t}+\bar{s}_{i} \bar{T}\left[\hat{s}_{i, t}+\hat{T}_{t}\right] .
\end{gathered}
$$

Firm cost minimization conditions (equations 47, 49, 50, and 52) are log-linearized to yield:

$$
\begin{gathered}
\hat{\nu}_{t}+\hat{M} C_{t}=\frac{\bar{R}}{\bar{R}-1+\delta} \hat{R}_{t}+\hat{K}_{t}-\hat{Y}_{t}, \\
\hat{\nu}_{t}+\hat{M} C_{t}=\hat{W}_{t}+\hat{L}_{t}-\hat{Y}_{t}, \\
\hat{Y}_{t}+\hat{\nu}_{t}=\hat{A}_{t}+\alpha \hat{K}_{t}+(1-\alpha) \hat{L}_{t}, \\
\hat{\Omega}_{t}=\hat{Y}_{t}-\frac{\bar{M} C \bar{\nu}}{1-\bar{M} C \bar{\nu}}\left(\hat{M} C_{t}+\hat{\nu}_{t}\right) .
\end{gathered}
$$

Firm profit maximization conditions (equations 55 to 59) are log-linearized to yield:

$$
\begin{gathered}
\hat{U}_{t}+\frac{\widehat{P_{t}^{\star}}}{P_{t}}=\hat{V}_{t}, \\
\bar{U} \hat{U}_{t}=\bar{Y} \hat{Y}_{t}+\bar{\Pi}^{\sigma-1}(1-\lambda) \frac{1}{\bar{R}} \bar{U} \mathbb{E}_{t}\left[(\sigma-1) \hat{\Pi}_{t+1}+\hat{U}_{t+1}\right], \\
\bar{V} \hat{V}_{t}=\bar{Y} \frac{\sigma}{\sigma-1}(1+\tau) \overline{M C}\left(\hat{Y}_{t}+\widehat{M C} \hat{C}_{t}+\hat{m}_{t}\right)+\bar{\Pi}^{\sigma}(1-\lambda) \frac{1}{\bar{R}} \bar{V} \mathbb{E}_{t}\left[\sigma \hat{\Pi}_{t+1}+\hat{V}_{t+1}\right], \\
\lambda \overline{\left(\frac{P^{\star}}{P}\right)} 1-\sigma \widehat{P_{t}^{\star}} \frac{\widehat{P}_{t}}{P}=(1-\lambda) \bar{\Pi}^{\sigma-1} \hat{\Pi}_{t}, \\
\left.\bar{\nu} \hat{\nu}_{t}=(1-\lambda) \bar{\nu} \bar{\Pi}^{\sigma}\left(\hat{\nu}_{t-1}+\sigma \hat{\Pi}_{t}\right)-\sigma \lambda \frac{P^{\star}}{P}\right)
\end{gathered}
$$

The monetary rule (equation 60) is log-linearized to yield:

$$
\begin{gathered}
\hat{I}_{t}^{\star}=\rho_{i} \hat{I}_{t-1}^{\star}+\left(1-\rho_{i}\right) \phi_{\pi} \hat{\Pi}_{t}, \\
\hat{I}_{t}=\max \left\{\hat{I}_{t}^{\star},-\log (\bar{I})\right\} .
\end{gathered}
$$

\subsection{Simulation Method}

This subsection explains how to simulate the model taking into account the zero lower bound (ZLB).

First, note that a standard dynamic stochastic general equilibrium (DSGE) model has been derived. Therefore, a first-order linear perturbation of the conditions given in section 4.3 can be applied. However, any first-order perturbation will ignore the ZLB in section 4.3.

To capture the impact of the ZLB, a method similar to that of Guerrieri and Iacoviello (2015) is used. The basic idea is that agents' choices at time $t$ are solved for by finding what they would do without shocks in the future if there were no ZLB. If the central bank would set a nominal interest rate below zero in this 
case, then the estimation is rerun with the central bank constrained in certain periods to be at the ZLB. This process continues until a situation in which the central bank is not setting a nominal interest rate below zero is found. The exact algorithm used is as follows:

1. Set $t$ to be the first period of the simulation.

2. Assume that at $t+20$, without any further shocks, the ZLB will no longer bind.

3. Guess the following regime: The ZLB does not bind in any period from $t$ through $t+19$.

4. Solve backwards from $t+19$ through $t$ to get the policy function for each period under the guessed regime. ${ }^{4}$

5. Using the policy functions computed in step 4, solve out for the path of the economy from $t$ to $t+19$ in the case where there are no shocks from $t+1$ to $t+19$.

6. If the current regime is such that the ZLB does not bind in every period from $t$ through $t+19$, follow these steps:

(a) If the current regime is such that the economy was never at the ZLB, set the new regime so that the ZLB binds at $t$ but not in future periods. If the current regime is such that the economy was at the ZLB until period $t+s$, set the new regime so that the economy is at the ZLB until $t+s+1$.

(b) Go back to step 3.

7. Take agents' choices at $t$ to be the simulation values for $t$. Now set $t$ as the next period of the simulation and go back to step 2 .

The difference between my method and that of Guerrieri and Iacoviello (2015) is in step 6. In my method, step 6 implies that if a central bank knows that it would hit the ZLB in the future without additional shocks, it will lower its nominal interest rate to zero in all preceding periods. ${ }^{5}$ Guerrieri and Iacoviello's algorithm implies that the ZLB should bind only in periods when the nominal interest rate would have been below zero according to the monetary rule. This means the ZLB can bind in nonconsecutive periods and in the future even if it doesn't bind today.

Guerrieri and Iacoviello mention that their method is a general first-pass method, and I find there are advantages to using the method outlined here in this specific case. First, the Guerrieri and Iacoviello method often does not converge to a single solution here. Second, my method works more quickly. Third, I think it is more realistic to assume that if a central bank knows that the economy is likely to hit the ZLB in the future, it will lower nominal interest rates to zero immediately rather than waiting.

\subsection{Calibration}

The model is calibrated to match certain moments from the period 1987 through 2006. This timespan was chosen because it captures a period of relative stability (the Great Moderation) before the Great Recession, and because it allows me to study how optimal inflation changed before and after the recent apparent fall

\footnotetext{
${ }^{4}$ The computations used to solve backwards from $t+19$ to $t$ is the same as in Guerrieri and Iacoviello (2015).

${ }^{5} \mathrm{My}$ algorithm could also be considered a simpler version of the one of Andrade et al. (2019), who also adapt the algorithm of Guerrieri and Iacoviello (2015). They allow for the ZLB to start binding at some period $t_{1} \geq t$ and then stop binding at some later period $t_{2}>t_{1}$. I effectively set that $t_{1}=t$ always.
} 
in the real interest rate. The reason these specific years were chosen is because they correspond to Alan Greenspan's tenure as chairman of the Federal Reserve.

Each period is set to represent a quarter. $M=220$ is calibrated to capture each quarter of life of an adult between the ages of 24 and 78. The simulation begins at age 24 to avoid having to worry about how to capture college. Agents' last year of life is 78 because life expectancy in the United States is currently just under 79 years.

Panel A of table 1 presents the values of parameters that determine the steady state and were selected from data or standard values. For households, the discount factor $\left(\beta=0.976=\frac{1}{1.0246}\right)$ is set to correspond to the value the discount factor would need to take in a representative agent model to yield the average fed funds rate after inflation for the period 1987 through $2006(\bar{r}=2.456)$. With exogenous labor supply, $\bar{L}_{i}$ (hours worked by each age) is set to match the average number of hours worked of a person of that age in the American Time Use Survey for the years 2003 through 2016 (data are available only from 2003 onward, and it is useful to use many years to get smooth estimates). With endogenous labor supply, $x_{i}$ in the disutility of labor function (equation 23) is set so that when $\beta \bar{R}=1, \bar{L}_{i}$ matches the hours worked in the exogenous case. This is explained in appendix D.1. The elasticity of substitution $\left(\frac{1}{\gamma}=0.5\right)$ and the Frisch elasticity of labor supply $(\eta=3)$ are set to be standard values. Population growth and the relative preference for bonds over other assets $(n=0, \xi=0)$ are not included in the baseline calibration.

For firms, the frequency of price change $(\lambda=0.24)$ is set to correspond to a monthly frequency of price change of 8.7 percent based on Nakamura and Steinsson (2008). The elasticity of substitution between goods $(\sigma=8)$ is set between the lower and upper bounds of 6 and 10, respectively, used in Carvalho, Ferrero, and Nechio (2016). The rate of depreciation $(\delta=0.025)$ is set to a standard value.

Panel B of table 1 presents the steady state parameters that are calibrated. The coefficient of capital in the Cobb-Douglas production function $(\alpha=0.34$ ) is calibrated so that the labor share equals 0.62 , which was the average US labor share in the period 1987 through 2006. Note the labor share and capital share do not sum to 1 due to the presence of the profit share, which averaged 6.06 percent during this period. The tax on marginal production is calibrated to fix the real interest rate under 2 percent inflation to equal 2.456 percent in the steady state. $\tau$ is varied across each model (including extensions) to obtain the same real interest rate under 2 percent inflation. Taxing (subsidizing) marginal production implies that firms' after-tax marginal cost is higher (lower), but firms always set the same markup on after-tax marginal costs, so a tax (subsidy) on marginal production implies lower (higher) before-tax marginal costs and thus higher (lower) profits. Higher (lower) profits imply a higher (lower) supply of assets and thus a higher (lower) real interest rate. In the baseline case, $\tau=-0.108$, implying marginal production is actually subsidized.

Panel C of table 1 presents the parameters affecting only the simulation (but not the steady state) that are chosen. The response of interest rates to deviations from the inflation target $\left(\phi_{\pi}=2.5\right)$ is set to be the same as it is in Coibion, Gorodnichenko, and Wieland (2012). The inertia in the monetary policy rule $\left(\rho_{i}=0.66\right)$ is set to be the same as it is in Andrade et al. (2019).

Panel D of table 1 presents the parameter values for parameters that affect only the simulation and are estimated through Bayesian methods. The size and type of the shocks in the simulation affect how much it makes sense to raise the inflation target in response to the ZLB. Moreover, on the household side, this model is quite different from standard New Keynesian models. Thus, for each shock, the size and persistence of the shock are estimated through Bayesian methods. They are estimated over the 1987-2006 period using US HP-filtered output and inflation. The estimation uses the standard Bayesian DSGE technique in which the policy functions under given parameters are used to construct log likelihoods through the Kalman filter. 
Table 1: Calibration Summary

Panel A: Steady State Parameters: Chosen

\begin{tabular}{lccc}
\hline Description & Parameter & Value & Source \\
\hline Discount factor & $\beta$ & 0.976 & rep. agent $\bar{r}=2.456$ \\
Relative labor supply & $L_{i} / x_{i}$ & - & ATUS \\
Elasticity of income substitution & $1 / \gamma$ & 0.5 & \\
Frisch elasticity labor supply & $\eta$ & 3 & \\
Frequency price change & $\lambda$ & 0.24 & Nakamura and Steinsson (2008) \\
Elasticity subs. between goods & $\sigma$ & 8 & Carvalho, Ferrero, and Nechio (2016) \\
Depreciation & $\delta$ & 0.025 & \\
\hline
\end{tabular}

Panel B: Steady State Parameters: Calibrated

\begin{tabular}{lccc}
\hline Description & Parameter & Value & Target \\
\hline Cobb-Douglas capital coeff. & $\alpha$ & 0.34 & Labor share \\
Tax on marginal production & $\tau$ & -0.108 & $\bar{r}=2.46$ \\
\hline
\end{tabular}

Panel C: Simulation Parameters: Chosen

\begin{tabular}{lccc}
\hline Description & Parameter & Value & Source \\
\hline Policy rule response inflation & $\phi_{\pi}$ & 2.5 & Coibion, Gorodnichenko, and Wieland (2012) \\
Policy rule persistence & $\rho_{i}$ & 0.66 & Andrade et al. (2019) \\
\hline
\end{tabular}

Panel D: Simulation Parameters: Bayesian Estimation

\begin{tabular}{lcccccc}
\hline Description & Parameter & Distribution & Prior mean & Prior s.d. & Post. mean & Post. s.d. \\
\hline Prod. shock s.d. & $\sigma_{a}$ & Inv. Gamma & 0.009 & 0.01 & 0.0067 & 0.0023 \\
Risk prem. shock s.d. & $\sigma_{q}$ & Inv. Gamma & 0.0024 & 0.005 & 0.0034 & 0.0023 \\
Phillips shock s.d. & $\sigma_{m}$ & Inv. Gamma & 0.0014 & 0.005 & 0.0279 & 0.0026 \\
Prod. shock pers. & $\rho_{a}$ & Beta & 0.9 & 0.02 & 0.8791 & 0.0268 \\
Risk prem. shock pers. & $\rho_{q}$ & Beta & 0.947 & 0.02 & 0.9136 & 0.0289 \\
Phillips shock pers. & $\rho_{m}$ & Beta & 0.9 & 0.02 & 0.9258 & 0.0129 \\
\hline
\end{tabular}

The estimation is conducted through a 10,000-period simulation from which the first 1,000 periods are discarded. The priors for the shock standard deviations are, where possible, set to be the values of the shocks in Coibion, Gorodnichenko, and Wieland (2012). The results of the Bayesian estimation show that the risk premium and Phillips Curve shocks are of greater magnitude than the priors while the productivity shock is weaker. The persistence of each shock is not very different from its priors.

\section{Measuring the IMR Channel}

This section measures the size of the IMR channel in the long run and the factors that determine it. Since I consider the long-run effect, this section considers only the steady state. Table 2 reports the steady state real interest rate under different trend inflation levels. Table 3 reports how raising trend inflation from 2 percent to 4 percent affects a variety of different economic variables. The reason for the focus on raising inflation from 2 percent to 4 percent is that this is what many prominent economists have proposed (Blanchard, Dell'Ariccia, and Mauro 2010; Ball 2014; Krugman 2014).

Model A reports results for the baseline model. In table 2, it can be observed that where inflation rises from 2 percent to 4 percent, the real interest rate in the steady state falls by 3 basis points. Figure 5 plots 
Table 2: Real Interest Rate ( $r$ p.p.) under Different Trend Inflation Levels

\begin{tabular}{lcccccc}
\hline Trend Inflation & $0 \%$ & $2 \%$ & $4 \%$ & $6 \%$ & $8 \%$ & $10 \%$ \\
\hline A. Baseline & 2.475 & 2.456 & 2.424 & 2.364 & 2.242 & 1.959 \\
B. Endog. Labor & 2.470 & 2.456 & 2.432 & 2.386 & 2.292 & 2.068 \\
C. Low IES & 2.503 & 2.456 & 2.378 & 2.240 & 1.990 & 1.533 \\
D. Menu Costs & 2.517 & 2.456 & 2.409 & 2.361 & 2.313 & 2.265 \\
E. Menu Costs (Internal) & 2.497 & 2.456 & 2.422 & 2.387 & 2.355 & 2.322 \\
F. High Firm Discount & 2.521 & 2.456 & 2.341 & 2.113 & - & - \\
G. Adjusted Profit Share & 2.479 & 2.456 & 2.417 & 2.346 & 2.202 & 1.870 \\
H. Inter. Goods & 2.501 & 2.456 & 2.379 & 2.236 & 1.957 & - \\
I. Multiple Sectors & 2.500 & 2.456 & 2.320 & - & - & - \\
J. Low IES + High Discount & 2.620 & 2.456 & 2.175 & 1.658 & 0.513 & - \\
K. Low IES + Inter. + Multisec. & 2.721 & 2.456 & 1.857 & - & - & - \\
L. Idio. Shocks 1 Type & 2.478 & 2.456 & 2.418 & 2.347 & 2.202 & - \\
M. Idio. Shocks 2 Types & 2.485 & 2.456 & 2.407 & - & - & - \\
\hline
\end{tabular}

"_" represents that a steady state did not exist.

Table 3: Impact of Raising Inflation from $2 \%$ to $4 \%$

\begin{tabular}{lccccccccc}
\hline Change in Variables & $\Delta \frac{\Omega}{\bar{Y}}$ & $\Delta \overline{M C}$ & $\Delta \bar{\nu}$ & $\Delta \log \left(\frac{C_{\text {old }}}{C_{\text {young }}}\right)$ & $\Delta \log \bar{K}$ & $\Delta \log (\bar{L})$ & $\Delta \log (\bar{Y})$ & $\Delta \log (\bar{W})$ & $\Delta \bar{r}$ \\
\hline A. Baseline & -0.089 & -0.515 & 0.621 & -0.435 & -0.411 & 0.000 & -0.757 & -0.667 & -0.032 \\
B. Endog. Labor & -0.089 & -0.515 & 0.621 & -0.330 & -0.315 & 0.189 & -0.600 & -0.698 & -0.024 \\
C. Low IES & -0.086 & -0.518 & 0.621 & -0.212 & 0.144 & 0.000 & -0.569 & -0.481 & -0.077 \\
D. Menu Costs & -0.129 & 0.099 & -0.004 & -0.633 & 0.718 & 0.000 & 0.249 & 0.345 & -0.046 \\
E. Menu Costs (Internal) & -0.095 & 0.099 & -0.004 & -0.464 & 0.567 & 0.000 & 0.197 & 0.294 & -0.034 \\
F. High Firm Discount & -0.310 & -0.296 & 0.621 & -1.554 & 0.932 & 0.000 & -0.301 & 0.014 & -0.113 \\
G. Adjusted Profit Share & -0.277 & -0.303 & 0.621 & -0.525 & -0.021 & 0.000 & -0.625 & -0.330 & -0.038 \\
H. Inter. Goods & -0.211 & -0.524 & 0.621 & -1.045 & -1.045 & 0.000 & -1.749 & -1.661 & -0.076 \\
I. Multiple Sectors & -0.362 & -1.475 & 1.913 & -1.828 & -0.664 & 0.000 & -2.114 & -1.745 & -0.133 \\
J. Low IES + High Discount & -0.302 & -0.304 & 0.621 & -0.755 & 2.933 & 0.000 & 0.379 & 0.687 & -0.275 \\
K. Low IES + Inter. + Multisec. & -0.624 & -1.571 & 1.885 & -1.613 & 1.378 & 0.000 & -3.738 & -3.478 & -0.586 \\
L. Idio. Shocks 1 Type & -0.089 & -0.518 & 0.621 & -0.472 & -0.344 & 0.000 & -0.735 & -0.645 & -0.037 \\
M. Idio. Shocks 2 Types & -0.089 & -0.523 & 0.621 & -0.562 & -0.207 & 0.000 & -0.688 & -0.599 & -0.048 \\
\hline
\end{tabular}

$\frac{\bar{C}_{\text {old }}}{\bar{C}_{\text {young }}}$ represents the fraction of mean consumption of the old half of agents (those agents aged 46.5-78) over the young half of agents (those agents aged 24-46.25). 
Figure 5: Baseline Calibration: Asset Supply and Demand

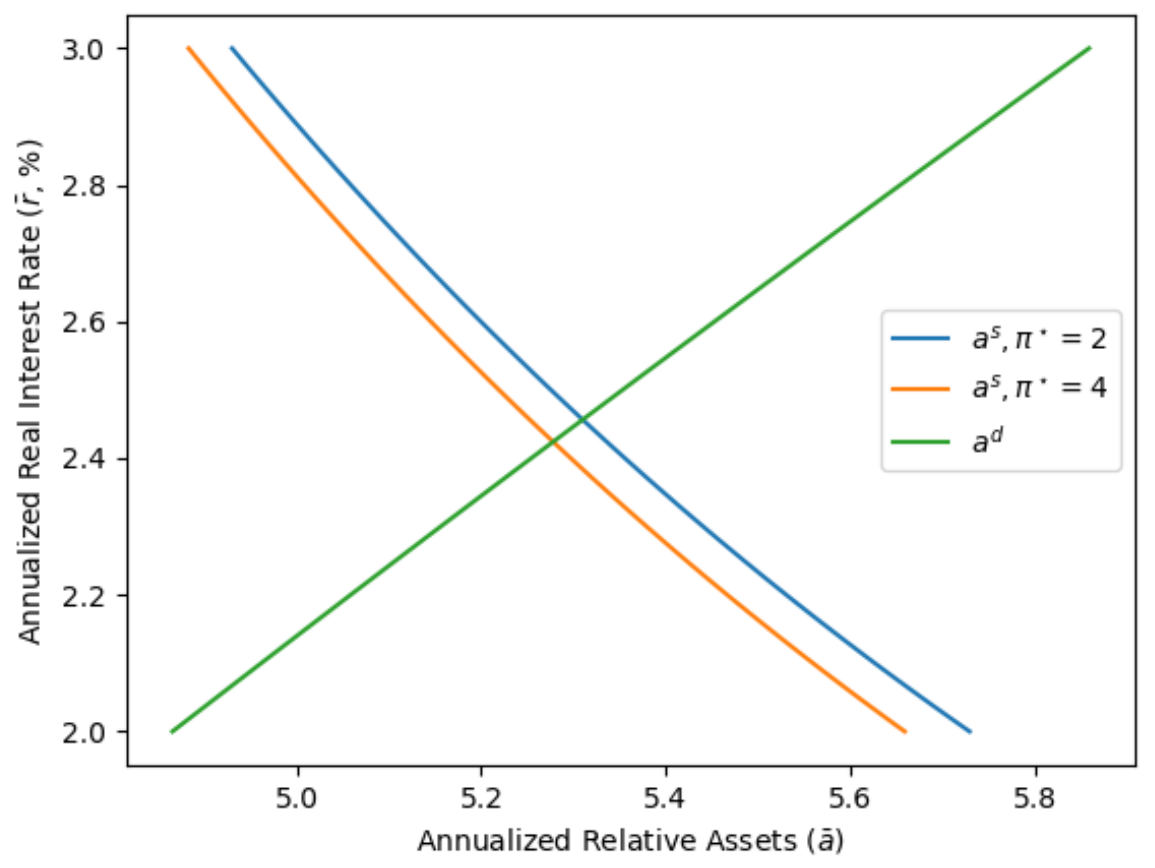

this rise in inflation. It can be seen that the dynamics are exactly the same as in the simple model, that is, figure 3. A rise in inflation lowers the profitability of firms, which reduces the value of shares and thus lowers the supply of assets for a given real interest rate. As a result, the supply of assets shifts left for any given real interest rate. Since there are fewer assets in which the young can save, they accept a lower real return in order to save, implying a fall in the real interest rate. Note that the reason the assets supply is downward sloping is because the vertical axis is the real interest rate, which increases when the price of assets falls.

Table 3 outlines in detail what happens to the economy when trend inflation rises from 2 percent to 4 percent. A rise in inflation lowers the profit share 9 basis points. The rise in inflation has two impacts: It lowers the marginal cost faced by firms 0.52 percentage points (which actually raises profits), but this is dominated by the rise in price dispersion of 0.62 percentage points. Consumption of the old half of agents falls by 0.43 percent relative to the young half's consumption. There are two potential effects on capital. First, the marginal cost at which firms operate encourages lower capital use, but second, the real interest rate also falls, which means capital becomes cheaper for firms. In the baseline case, the first effect dominates, and capital falls 0.41 percent. There are two effects on output: first, the fall in capital lowers output; second, the rise in price dispersion means effective aggregate output falls. Thus, output falls 0.76 percentage points. Wages fall, since the fall in capital and the marginal cost both mean labor is less effective. It can also be observed in table 2 that as inflation increases, the real interest rate falls relatively more. This is because as inflation rises, profits fall relatively more.

Model B introduces endogenous labor. In this case, the real interest rate falls from 2.456 to 2.432 , which is a smaller increase than in the baseline case. The reason for this is that when inflation rises and profitability falls, meaning there are fewer assets in which to save, the old choose to work relatively more. As a result, 
Figure 6: IES = 0.1: Asset Supply and Demand

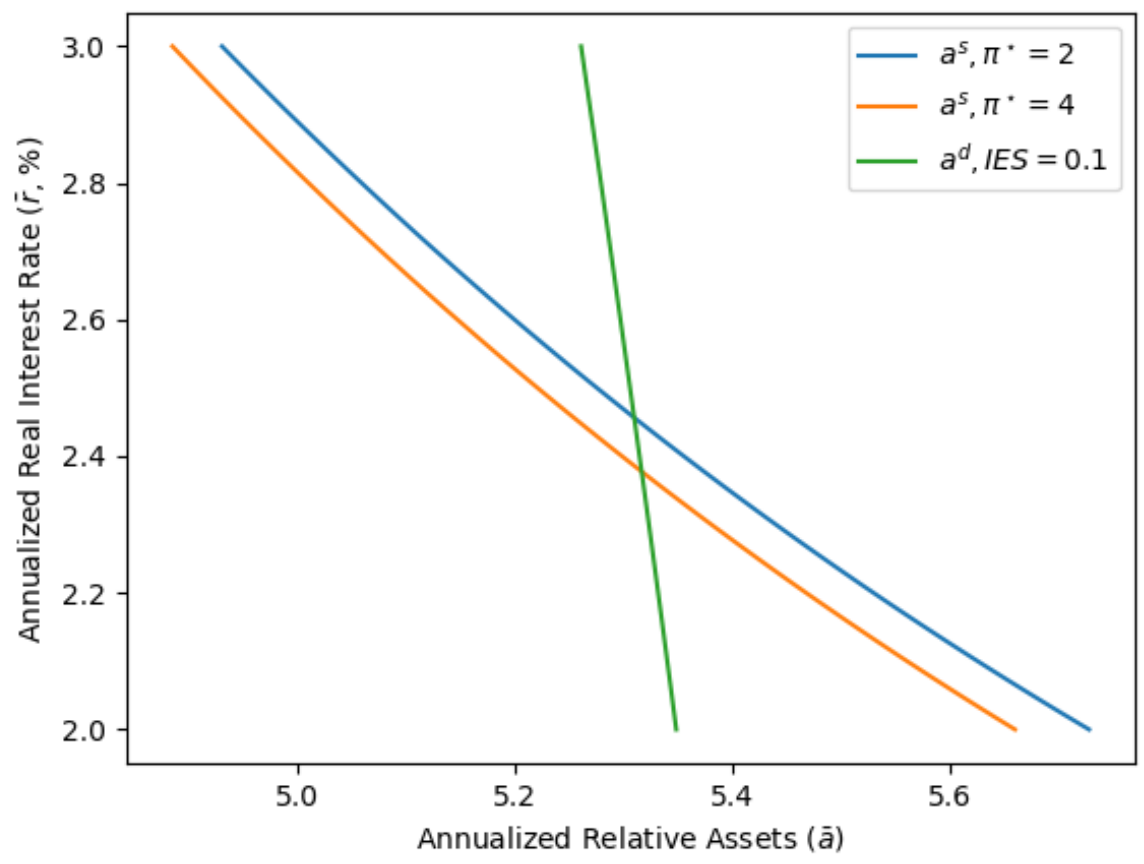

labor increases 0.19 percent. The increase in labor means that capital is more effective, which is why capital falls less than in the baseline case.

Recent estimates from Best et al. (2018) suggest that the intertemporal elasticity of substitution (IES) is 0.1. Model C lowers the IES from 0.5 to 0.1. Table 2 shows that this strengthens the effect of raising inflation on the real interest rate. The intuition is that when the supply of savings falls, agents are much more reluctant to lower their consumption when they are old relative to when they are young. Thus, they accept a much lower return on savings so they can transfer consumption to when they are older. This is why in table 3 the fall in consumption is smaller for the old than it is for the young. Capital also rises, since the young save capital so they can transfer consumption to when they are old.

Figure 6 plots the effect of a rise in inflation from 2 percent to 4 percent on asset supply and demand under an IES of 0.1 rather than 0.5. The plot demonstrates that the fall in the IES causes the demand for assets to tilt backward. The intuition is that when the real interest rate falls, agents are keener to consume when they are older and thus save more, despite the lower return.

Models D and E introduce menu costs. The reason for considering menu costs is that one might be skeptical about firms not changing the frequency with which they set prices when inflation is high. Model $D$ considers the case where firms have to pay a menu cost that lowers their profits. This amplifies the degree to which raising inflation lowers the profit share. Thus, I also introduce model E, which considers the case where menu costs are internalized so firms take them into account when they set prices but they do not affect profits. Appendix E.1 explains how menu costs are introduced into the model.

Table 2 demonstrates that with menu costs, the effects are actually slightly larger at low levels of inflation than they are with Calvo pricing. When inflation increases from 2 percent to 4 percent the real interest rate falls from 2.456 percent to 2.409 percent when menu costs are external and to 2.422 percent when they 
are internal. The effects are also significantly stronger under menu costs when inflation changes from 0 percent to 2 percent. This is because, with low inflation, after adjusting their price, some firms will receive idiosyncratic shocks that lower their costs, implying that their markup increases above the markup to which they reset when they pay the menu cost. Since firms face fixed costs of price adjustment, they may choose to wait rather than adjust, implying a high average markup under low inflation. Thus, when inflation rises under low inflation, it means these high average markups dissipate more quickly, lowering profits by more than they do under Calvo. However, with higher levels of inflation, the effect is weaker than it is under Calvo, since firms increase the frequency with which they change their prices, which implies that inflation has less of an impact on the markup. That being said, there are still decreases in the real interest rate as inflation increases at higher levels under menu costs.

Table 3 shows some differences in how other economic variables respond to a rise in inflation from 2 percent to 4 percent under menu costs. The marginal cost rises while price dispersion remains unchanged, implying a similar overall change in the profit share. Since the marginal cost rises at the same time as the real interest rate falls, capital actually rises in this case. This in turn implies that output and wages rise.

Model $\mathrm{F}$ considers the case where firms discount by the real interest rate that corresponds to their cost of financing rather than the discount factor of the household. This implies that firms care less about the future and thus are more reluctant to raise their price. Consequently, under higher inflation levels, markups fall by more, and the effect on the real interest rate is greater. Appendix E.2 explains how this alternative form of discounting is introduced into the model. From table 2, it can be seen that a rise in inflation from 2 percent to 4 percent implies that the real interest rate falls 12 basis points.

Model G introduces firm death into the model. Without firm death, a high subsidy on marginal production is needed to reduce firm profitability. Otherwise, the supply of assets (and thus the real interest rate) is too high. However, with the high subsidy on marginal production, the profit share is low. In the baseline calibration, firm profitability is 1.84 percent compared with the average profit share in 1987-2006 of 6.06 percent. Introducing firm death reduces the value of shares without lowering their profitability. The probability of firm death is calibrated to match the profit share. Appendix E.3 explains how firm death is introduced into the model. There are two effects of introducing firm death on the strength of the impact of raising inflation on the real interest rate. First, higher firm death means firms discount more, which strengthens the effect as was seen in model F. Second, firm death implies that assets are worth less, so a fall in profitability lowers the supply of assets by less. On balance, the first effect dominates slightly, and table 2 demonstrates that the real interest rate falls from 2.456 percent to 2.417 percent rather than to 2.424 percent when inflation rises from 2 percent to 4 percent .

As Nakamura and Steinsson (2010) demonstrate, introducing intermediate goods and multiple sectors can have a big impact on the degree of monetary non-neutrality. Model H introduces intermediate goods, and model I introduces multiple sectors with different frequencies of price change. These are introduced into the main model in appendices E.4 and E.5, respectively. Both of these features imply that a rise in inflation lowers the real interest rate by more. A rise in inflation from 2 percent to 4 percent lowers the real interest rate 8 basis points with intermediate goods and 13 basis points with multiple sectors.

Introducing multiple features can boost the degree to which raising inflation lowers the real interest rate. Model J reports the case with a low IES and where firms discount by the cost of their financing rather than the discount factor of the household. Model K reports results with a low IES, intermediate goods, and multiple sectors. A rise in inflation from 2 percent to 4 percent lowers the real interest rate 28 basis points in model $\mathrm{J}$ and 60 basis points in model $\mathrm{K}$. 
Models L and M introduce idiosyncratic shocks into the baseline model. There are two reasons for studying this case. First, there has been great focus on this form of heterogeneity in recent years. Second, introducing idiosyncratic shocks allows for a better match of the consumption path of cohorts across their lifetime. Appendix E.6 explains how idiosyncratic shocks are introduced into the main model. The probability that an agent is unemployed at time $t$ is 5 percent if the agent was employed at $t-1$. The probability that agent is unemployed at time $t$ is 50 percent if the agent was unemployed at time $t-1$. Unemployment allows the agent to work for only 10 percent of the hours of employment. Model L considers the case where all agents have identical preferences with a discount factor of 0.97 . Model M considers the case with the same unemployment risk as model L, but where there are two types of agents: a patient type with a discount factor of 0.98 and an impatient type with a discount factor of 0.94 . Table 2 demonstrates that these changes somewhat strengthen the relationship between inflation and the real interest rate.

Figure 7 shows the consumption paths of the cohorts across their lives in the baseline model, model L, and model $\mathrm{M}$. The consumption path in the baseline model is effectively a straight line. This comes from the Euler condition, which dictates that the consumption path is determined by $(\beta \bar{R})^{\frac{1}{\gamma}}$ in the steady state. Thus, if $\bar{R}>\frac{1}{\beta}$, the consumption path is always increasing; if $\bar{R}<\frac{1}{\beta}$, the consumption path is always decreasing; and if $\bar{R}=\frac{1}{\beta}$, the consumption path is flat. In the calibration of the baseline model, $\beta$ is chosen such that $\bar{R}=\frac{1}{\beta}$ under 2 percent inflation, implying a flat consumption path. Introducing idiosyncratic shocks implies that at the start of agents' lives they save in order to insure against possible unemployment, which explains the increase in their consumption as they age when they are young. In model L, agents are assumed to have a lower discount factor, and so the consumption path is decreasing once idiosyncratic shocks are not important, which explains the decrease in their consumption as they age when they are old. Thus, through idiosyncratic shocks and a lower discount factor, it is possible to generate a hump-shaped consumption path. Introducing a second type of impatient agents allows for a greater fall in consumption as agents age, since the impatient agents have saved little for when they are old.

\section{Optimal Inflation Target under the IMR Channel}

Many economists argue that the recent fall in the real interest rate makes it optimal for central banks to raise their inflation targets to help avoid the zero lower bound (ZLB). This section considers how the IMR channel affects how much it is optimal to raise the inflation target.

The reason many economists have argued the inflation target should be increased is because the equilibrium real rate has fallen for reasons exogenous to the IMR channel, such as, demographics or the global savings glut. To aid clarity, the exogenous real interest rate in an economy is defined as the steady state real interest rate on bonds that the economy would experience under a 0 percent inflation target. This exogenous real rate is independent of the IMR channel, since it always considers the real interest rate at the same level of inflation. The reason the real interest rate on bonds is considered is because it determines whether the ZLB binds or not. $\pi^{\star}(r)$ is then defined to represent the optimal inflation target when the exogenous real rate is $r$. The way the exogenous real rate is varied across a given model is by changing the degree to which agents hold safe bonds through the $\xi$ parameter (by equation 25). For example, if a low exogenous real rate is desired, it is assumed that agents obtain additional utility from safe bonds (and thus $\xi$ is positive), which implies that the real interest rate on bonds is lower than it is on capital or shares.

The next difficulty involves computing the counterfactual of what the optimal inflation target would be without the IMR channel. $\pi_{f}^{\star}(r)$ is defined to represent the optimal inflation target when the real interest rate 
Figure 7: Baseline Calibration: Consumption Path



on bonds is fixed as $r$ under any level of inflation. The IMR channel implies that a rise in inflation lowers the real interest rate on bonds. To fix the real interest rate as $r$ under any level of inflation, a counteracting force is needed. Thus, $\xi$ is adjusted (by equation 25) to hold constant the real interest on bonds. For example, if inflation rises, this lowers the real interest rate on capital and shares, so $\xi$ needs to fall, which lowers the relative value of safe bonds and therefore raises the real interest rate on bonds to hold it at $r$.

To compute $\pi^{\star}(r)$ and $\pi_{f}^{\star}(r)$, I employ a grid search method where the grid is refined using estimates of $\hat{\pi}^{\star}(r)$. The method is explained in appendix F.1. Two models are considered. The first is the basic model with endogenous labor, which corresponds to model B in table 2. The second is an extended model that allows for a stronger IMR channel through a lower intertemporal elasticity of demand $(\gamma=0.1)$ and additional firm discounting (which is explained in appendix E.2). This corresponds to model J in table 2 (with endogenous labor supply).

The results under different exogenous real rates are displayed in table 4 . The second and third columns plot the results for the basic model, and the fourth and fifth columns plot the results for the extended model. The second and fourth columns represent the case with the IMR channel, that is, $\pi^{\star}(r)$; while the third and fifth columns represent the case without the IMR channel, that is, $\pi_{f}^{\star}(r)$. In both the basic and the extended models, there is a clear monotonic increase in the optimal inflation rate as the exogenous real interest falls. This corresponds to the analysis by Andrade et al. (2019). Here optimal inflation rises an average of 67 percent and 57 percent of the increase in the exogenous real interest rate in the basic and extended models, respectively.

A fall in the exogenous real interest rate causes optimal inflation to rise more under the IMR channel but only slightly more. With a high exogenous real rate, the optimal inflation target is the same regardless of whether the real interest rate on bonds is fixed or not. However, as the exogenous real rate falls, the optimal 
Table 4: Optimal Inflation at Different Real Interest Rates

\begin{tabular}{c|cc|cc}
\hline & \multicolumn{2}{|c|}{ Basic Model } & \multicolumn{2}{c}{ Extended Model } \\
\hline$r$ & With IMR $\left(\pi^{\star}(r)\right)$ & Without IMR $\left(\pi_{f}^{\star}(r)\right)$ & With IMR $\left(\pi^{\star}(r)\right)$ & Without IMR $\left(\pi_{f}^{\star}(r)\right)$ \\
\hline-3.0 & 4.280 & 4.249 & 3.884 & 3.849 \\
-2.5 & 3.892 & 3.869 & 3.664 & 3.633 \\
-2.0 & 3.503 & 3.486 & 3.402 & 3.372 \\
-1.5 & 3.116 & 3.104 & 3.106 & 3.078 \\
-1.0 & 2.734 & 2.726 & 2.787 & 2.759 \\
-0.5 & 2.361 & 2.356 & 2.453 & 2.425 \\
0.0 & 2.000 & 1.997 & 2.114 & 2.087 \\
0.5 & 1.654 & 1.652 & 1.778 & 1.753 \\
1.0 & 1.327 & 1.325 & 1.455 & 1.433 \\
1.5 & 1.020 & 1.019 & 1.155 & 1.137 \\
2.0 & 0.738 & 0.738 & 0.887 & 0.875 \\
2.5 & 0.484 & 0.484 & 0.659 & 0.655 \\
3.0 & 0.261 & 0.263 & 0.481 & 0.488 \\
\hline
\end{tabular}

inflation target rises more under the IMR channel, but only slightly more. Focusing on the case where the real interest rate on bonds falls from 2 percent to -1 percent: in the basic model, the optimal inflation target rises only 0.8 basis points more with the IMR channel, even though the real interest rate falls an additional 1.8 basis points. ${ }^{6}$ This is an increase of only 44 percent of the additional fall in the real interest rate. In the extended model, the optimal inflation target rises only an additional 0.8 basis points, even though the real interest rate falls an additional 10.6 basis points, which is an increase of 8 percent of the additional fall in the real interest rate. This is much less than the percentage increase in optimal inflation following a general increase in the exogenous real rate, which are approximately 67 percent and 57 percent for the basic and extended models, respectively. Thus, there is a question as to why the optimal inflation target does not rise more due to the IMR channel.

To explore this further, figure 8 graphically decomposes the different effects of a rise in the desire for safe assets, which lowers the real interest rate on bonds. A mathematical decomposition is also provided in appendix F.2. The social planner can pick the inflation target $\pi^{\star}$, which is displayed on the $\mathrm{x}$ axis. This determines the frequency with which the economy hits the ZLB, which is displayed on the y axis. In a given model, there is a constraint (similar to a budget constraint) that dictates the feasible values of inflation and ZLB probabilities. This is downward sloping, since higher inflation implies a lower ZLB probability. Lines (a) and (c) represent the feasible values of inflation and the ZLB probability under a high and low exogenous real rate, respectively. It can be observed that line (a) has a strictly lower probability of hitting the ZLB than does line (c) for a given inflation level since the real interest on bonds is higher and thus the nominal interest rate is higher for any given inflation level. The dashed lines represent indifference curves of the social planner. The shape of the indifference curve reflects the fact that the social planner does not like hitting the ZLB but also does not like high inflation. The optimal inflation level is then the point where the feasible values of inflation and probability of ZLB are tangential to an indifference curve. Thus, when the exogenous real rate falls, taking into account the IMR channel, the optimum for the economy moves from point $A$ to point $C$.

Now the case without the IMR channel is considered. Line (b) represents the feasible values of inflation and ZLB probabilities without the IMR channel when the real interest rate on bonds is fixed (by adjusting

\footnotetext{
${ }^{6}$ The computation here is $\left(\pi^{\star}(-0.01)-\pi^{\star}(0.02)\right)-\left(\pi_{f}^{\star}(-0.01)-\pi_{f}^{\star}(0.02)\right)$.
} 
Figure 8: Graphical Decomposition of Impact of IMR Channel on Response of Optimal Inflation to a Fall in the Exogenous Real Rate

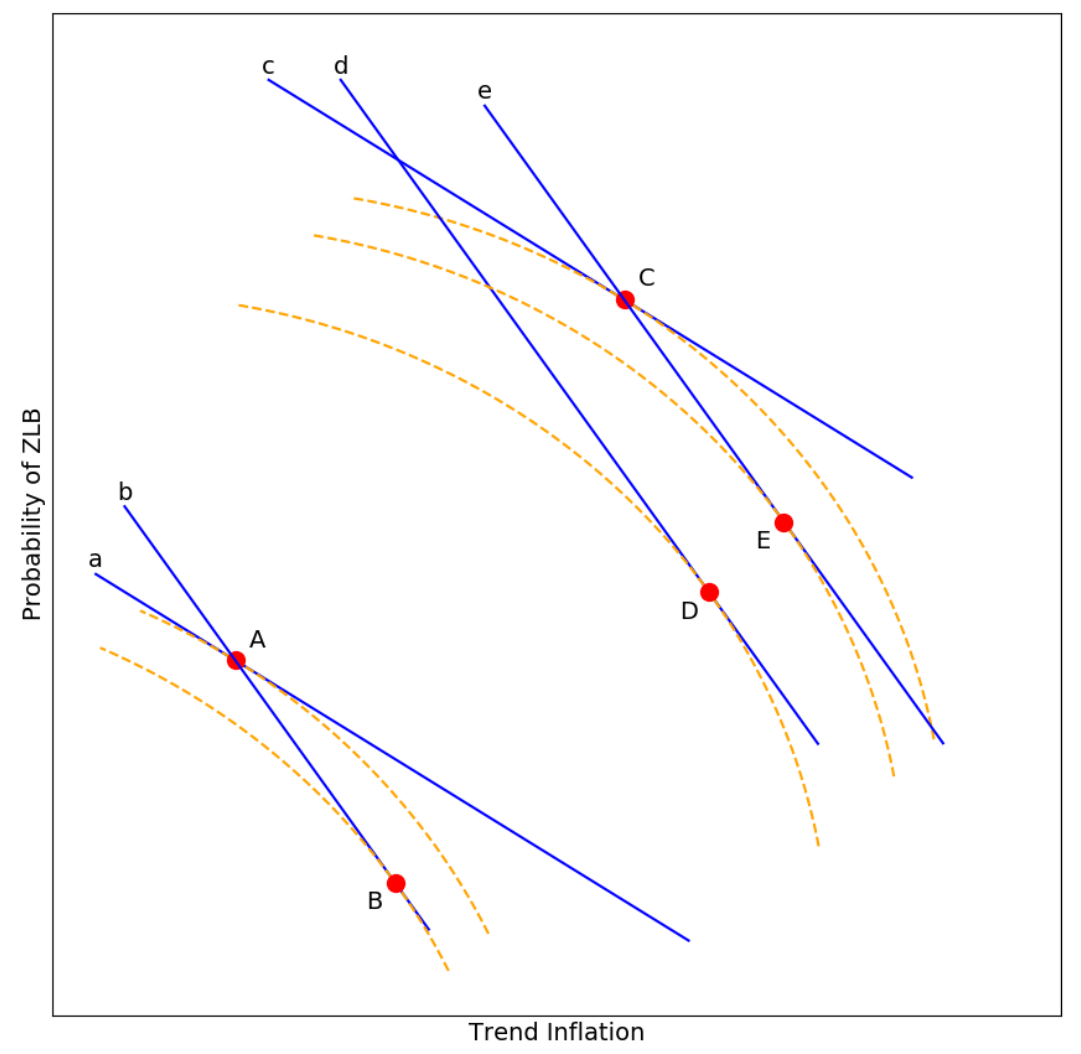


the utility from safe bonds) at the same value it takes in point $A$. Thus, line (b) passes through point $A$ because if inflation is at $\pi_{A}^{\star}$ and the real interest rate on safe bonds is the same as at $A$ (so the utility from safe bonds is the same), the economic situation is identical to $A$. It can also be seen that line (b) has a steeper gradient than line (a). This is because under line (b), a rise in inflation does not lower the real interest rate, implying that nominal interest rates rise by more and thus that the probability of hitting the ZLB falls by more than it does under line (a). Line (e) represents the feasible values of inflation and ZLB probabilities when the real interest rate on bonds is fixed at the same value it takes at point $C$. Thus, similarly to line (b), line (e) passes through point $C$ and has a steeper gradient than line (c).

The difference between the high and low real interest rate cases at points $A$ and $C$ is that there has been an increase in the desire of agents to hold safe bonds through an increase in $\xi$. Between points A and C, the real interest rate falls by more than just the impact of the increased desire for safe bonds due to the increase in inflation that lowers the real interest rate. Line (d) captures the feasible values of inflation and ZLB probabilities when the real interest rate is fixed at the level it was at $A$ minus only the impact of the exogenous fall in the real interest rate on bonds due to the increased desire for safe bonds but not due to the additional fall in the real interest rate through the IMR channel. The real interest rate in line (d) is higher than in line (e) since line (c) captures both the fall in the real interest rate on bonds due to the increased desire for safe bonds and from the IMR channel. Thus, the probability of hitting the ZLB is lower for (d) than for (e) for any given inflation level. Without the IMR channel, the impact of the fall in the exogenous real rate moves the optimum of the economy from point $B$ to point $D$.

A fall in the exogenous real rate moves the optimum of the economy $\pi_{A}^{\star}$ to $\pi_{C}^{\star}$ and $\pi_{B}^{\star}$ to $\pi_{D}^{\star}$, respectively, with and without the IMR channel. The difference between these changes is decomposed into three effects in equation 63. The first effect $\left(\pi_{E}^{\star}-\pi_{D}^{\star}\right)$ isolates the impact of the IMR channel on the real interest rate and considers how this fall in the real interest rate raises optimal inflation. The second effect $\left(\pi_{B}^{\star}-\pi_{A}^{\star}\right)$ captures a substitution effect. This comes from the fact that if the real interest rate on bonds is fixed at the level it takes at $A$ (rather than falling as inflation rises), it will be more beneficial to raise inflation, since nominal interest rates will then rise more. Thus, when the real interest rate is fixed at the level it takes at $A$ as in line (b), it implies that optimal inflation is higher. Therefore, $\pi_{B}^{\star}>\pi_{A}^{\star}$. The third effect $\left(-\left(\pi_{E}^{\star}-\pi_{C}^{\star}\right)\right)$ captures a second substitution effect for the same reasons as with $A$ and $B$, so $\pi_{E}^{\star}>\pi_{C}^{\star}$. Consequently, it can be observed that the impact of including the IMR channel depends on the direct effect of how the fall in the real interest rate raises optimal inflation and on how the relative benefit of raising inflation is affected by the IMR channel.

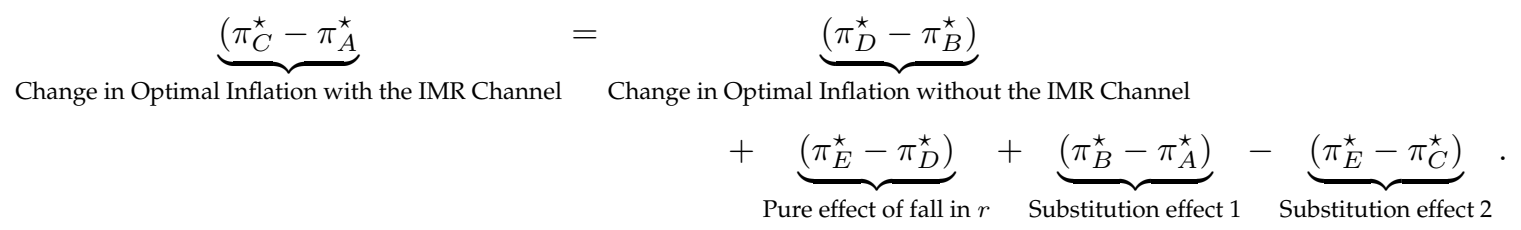

Table 5 decomposes the effect of introducing the IMR channel for both the basic and the extended models. The pure effect of the fall in the real interest rate $\left(\pi_{E}^{\star}-\pi_{D}^{\star}\right)$ through the rise in optimal inflation raises optimal inflation 1.2 and 6.8 basis points in the basic and extended models, respectively. This is 67 percent and 64 percent of the fall in the real interest rate, which corresponds much more closely to the degree by which a fall in the exogenous real rate raises optimal inflation. 
Table 5: Decomposition of IMR Channel Results

\begin{tabular}{ccc}
\hline Impact of Fall in $r_{B}$ from $2 \%$ to $-1 \%$ & Basic & Extended \\
\hline$\Delta \pi^{\star}$ with IMR $\left(\pi_{C}^{\star}-\pi_{C}^{\star}\right)$ & 1.996 & 1.900 \\
$=\Delta \pi^{\star}$ without IMR $\left(\pi_{D}^{\star}-\pi_{B}^{\star}\right)$ & 1.989 & 1.889 \\
+ Effect of Fall in $r$ only $\left(\pi_{E}^{\star}-\pi_{D}^{\star}\right)$ & 0.012 & 0.068 \\
+ Substitution Effect $1\left(\pi_{B}^{\star}-\pi_{A}^{\star}\right)$ & 0.002 & 0.004 \\
- Substitution Effect $2\left(-\left(\pi_{E}^{\star}-\pi_{C}^{\star}\right)\right)$ & -0.008 & -0.061 \\
\hline
\end{tabular}

There is also the indirect effect of the IMR channel through the two substitution effects. The first substitution effect $\left(\pi_{B}^{\star}-\pi_{A}^{\star}\right)$ represents the degree to which shutting down the IMR channel implies a higher optimal inflation target when the exogenous real rate is high. Therefore, this substitution effect is small because under a high exogenous real rate, the optimal inflation target is low and section 5 demonstrates that this implies that raising a low inflation target lowers the real interest rate and the nominal interest rate only a little. Table 5 demonstrates that the first substitution effect raises the degree to which it is optimal to raise inflation 2 and 4 basis points in the basic and extended models, respectively. The second substitution effect $\left(\pi_{E}^{\star}-\pi_{C}^{\star}\right)$ represents the degree to which shutting down the IMR channel implies a higher optimal inflation target when the exogenous real rate is low. Therefore, this substitution effect is large because under a low exogenous real rate, the optimal inflation target is high and section 5 demonstrates that this implies that raising a high inflation target lowers the real interest rate and the nominal interest rate a lot. Table 5 demonstrates that the second substitution effect raises the degree to which it is optimal to raise inflation 2 and 4 basis points in the basic and extended models, respectively.

Overall, the IMR channel has two primary effects on how much a central bank should raise the inflation target in response to a fall in the exogenous real rate. First, the higher inflation under a lower exogenous real rate implies that the real interest rate on bonds falls and thus optimal inflation is higher. Second, the marginal benefit of lowering the inflation target is lower, because it implies that the real interest rate falls and thus the nominal interest rate does not rise as much. The first effect seems to dominate the second effect, but the existence of the second effect suggests that even if the IMR channel implies raising the inflation target substantially lowers the exogenous real rate, the optimal inflation target is unlikely to rise significantly.

\section{Conclusion}

In recent years, many economists have proposed raising the inflation target. They argue that this will raise the average nominal interest rate and thus reduce the probability of hitting the zero lower bound (ZLB). It is a general assumption and a feature of standard models that raising the inflation target has no impact on the equilibrium real rate.

I show that once heterogeneity is introduced into a standard New Keynesian model through either generational features or idiosyncratic shocks, raising the inflation target will lower the equilibrium real rate. In my baseline calibration of a New Keynesian model with life-cycle features, a rise in the inflation target from 2 percent to 4 percent lowers the equilibrium real rate 3 basis points in a baseline calibration and as much as 70 basis points with extended features. Even though the IMR channel implies that raising the inflation target will reduce the problem of the ZLB by less, it also implies that raising the inflation target is less marginally beneficial. In a simulation, I find these two effects roughly cancel out each other and that 
it is optimal to raise the inflation target by about the same amount in response to an exogenous fall in the equilibrium real rate.

The channel I propose is empirically realistic. It relies on the existence of price stickiness (or other forms of price rigidity) and the existence of a consumer life cycle. Both of these features are observable in the real world. Moreover, although it is difficult to study this question, there is structural empirical evidence that supports the IMR channel.

The results of this paper provide valuable insights for policymakers. A rise in the inflation target will lower the equilibrium real rate and therefore lead to an increase in average nominal interest rates that is smaller than generally believed. This implies that raising the inflation target is likely to be less effective than expected in reducing the probability of hitting the ZLB. Through a calibrated model, I demonstrate that the introduction of the IMR channel does not substantially affect how much it is optimal to raise the inflation target because, while the IMR channel implies lower real interest rates and a higher probability of hitting the ZLB, it also implies that the effectiveness of raising the inflation target is lower. 


\section{Appendices}

\section{A Intuition in a Simplified Model Details}

This section provides additional details relating to section 2 .

\section{A.1 Calvo Pricing: Inflation and the Markup}

Here, the standard Calvo pricing setup is assumed, and the relationship between inflation and the markup is derived. This is an example of the inflation-markup relationship discussed in section 2.1.

There is a continuum of intermediate firms indexed by $i$ that produce differentiated intermediate goods. There is a competitive final goods firm with constant elasticity of substitution (CES) production with CES parameter $\sigma$. The final goods firm's demand for good $i$ is represented by:

$$
Y_{i, t}=\left(\frac{P_{i, t}}{P_{t}}\right)^{-\sigma} Y_{t}
$$

where

$$
\begin{gathered}
\int_{0}^{1} P_{i, t} Y_{i, t} d i=P_{t} Y_{t}, \\
P_{t}=\left(\int_{0}^{1} P_{i, t}^{1-\sigma} d i\right)^{\frac{1}{1-\sigma}}, \\
Y_{t}=\left(\int_{0}^{1} Y_{i, t}^{\frac{\sigma-1}{\sigma}} d i\right)^{\frac{\sigma}{\sigma-1}} .
\end{gathered}
$$

Intermediate firms have some probability $\lambda$ of updating their price each period. Firms have the following maximization problem:

$$
\max _{P_{t}^{\star},\left\{Y_{t+k}^{\star}\right\}_{k=0}^{\infty}} \mathbb{E}_{t}\left[\sum_{k=0}^{\infty}(1-\lambda)^{k} \beta^{k}\left[\frac{P_{t}^{\star} Y_{t+k}^{\star}}{P_{t+k}}-M C_{t+k} P_{t+k} Y_{t+k}^{\star}\right]\right]
$$

s.t. $\forall k$

$$
Y_{t+k}^{\star}=Y_{t+k}\left(\frac{P_{t}^{\star}}{P_{t+k}}\right)^{-\sigma} .
$$

Inputting equation 68 into equation 67 and taking FOCs yields:

$$
\mathbb{E}_{t}\left[\sum_{k=0}^{\infty}(1-\lambda)^{k} \beta^{k}\left((1-\sigma) P_{t}^{\star-\sigma} Y_{t+k} P_{t+k}^{\sigma-1}+\sigma M C_{t+k} Y_{t+k} P_{t}^{\star-\sigma-1} P_{t+k}{ }^{\sigma}\right]\right] .
$$

In the steady state, this can be rewritten as:

$$
\sum_{k=0}^{\infty}(1-\lambda)^{k} \beta^{k} \bar{\Pi}^{k \sigma}\left[\overline{\left(\frac{P^{\star}}{P}\right)} \frac{1}{\bar{\Pi}^{k}}-\frac{\sigma}{\sigma-1} \overline{M C}\right] .
$$


This can be further simplified to get:

$$
\overline{M C}=\frac{\sigma-1}{\sigma} \frac{1-(1-\lambda) \beta \bar{\Pi}^{\sigma}}{1-(1-\lambda) \beta \bar{\Pi}^{\sigma-1}} \overline{\left(\frac{P^{\star}}{P}\right)} .
$$

A price dispersion term is defined:

$$
\nu_{t}=\int_{0}^{1}\left(\frac{P_{i, t}}{P_{t}}\right)^{-\sigma} d i
$$

This can be rewritten as:

$$
\nu_{t}=\lambda\left(\frac{P_{t}^{\star}}{P_{t}}\right)^{-\sigma}+(1-\lambda) \nu_{t-1} \Pi_{t}^{\sigma}
$$

In the steady state:

$$
\bar{\nu}=\frac{\lambda}{1-(1-\lambda) \bar{\Pi}^{\sigma}}{\overline{\left(\frac{P^{\star}}{P}\right)}}^{-\sigma} .
$$

Multiplying both sides of equation 69 by $\bar{\nu}$ yields:

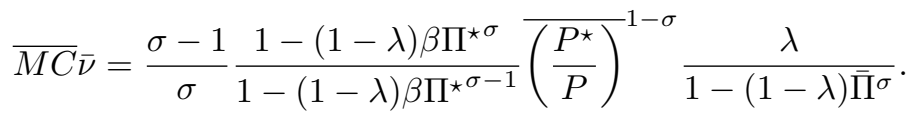

Equation 66 can be rewritten as:

$$
1=\lambda\left(\frac{P_{t}^{\star}}{P_{t}}\right)^{1-\sigma}+(1-\lambda) \Pi_{t}^{\sigma-1}
$$

where $\Pi_{t}=\frac{P_{t}}{P_{t-1}}$ and also $\pi_{t}=\Pi_{t}-1$. In the steady state:

$$
\left(\frac{P^{\star}}{P}\right)^{1-\sigma}=\frac{1}{\lambda}\left[1-(1-\lambda) \bar{\Pi}^{\sigma-1}\right] .
$$

Inputting equation 72 into equation 71 and simplifying yields:

$$
\overline{M C} \bar{\nu}=\frac{\sigma-1}{\sigma}\left[\frac{1-(1-\lambda) \bar{\Pi}^{\sigma-1}}{1-(1-\lambda) \beta \bar{\Pi}^{\sigma-1}}\right]\left[\frac{1-(1-\lambda) \beta \bar{\Pi}^{\sigma}}{1-(1-\lambda) \bar{\Pi}^{\sigma}}\right] .
$$

$\bar{m}$ is defined to be $\bar{m}=(\overline{M C} \bar{\nu})^{-1}$, which is a measure of the effective markup (this is further discussed in appendix A.2). Therefore, equation 73 can be rewritten as:

$$
\bar{m}=\frac{\sigma}{\sigma-1}\left[\frac{\bar{\Pi}^{1-\sigma}-(1-\lambda) \beta}{\bar{\Pi}^{1-\sigma}-(1-\lambda)}\right]\left[\frac{\bar{\Pi}^{-\sigma}-(1-\lambda)}{\bar{\Pi}^{-\sigma}-(1-\lambda) \beta}\right] .
$$

Informal: Raising Inflation Lowers the Markup Raising $\bar{\Pi}$ increases the first square bracket but lowers the second. When $\beta<1$, the second square bracket dominates since $\bar{\Pi}^{-\sigma}$ changes by more than $\bar{\Pi}^{1-\sigma}$, so raising average inflation lowers the markup.

Note that here the markup is effectively the average markup weighted by sales. This is why the results are qualitatively different from those of Ascari and Sbordone (2014), who consider the non-weighted average markup and show that it can rise when inflation rises. 
Formal: Raising Inflation Lowers the Markup The result that raising inflation lowers the markup when $\beta<1$ is now shown formally. First derivatives are applied:

$$
\begin{array}{r}
\frac{d \bar{m}}{d \bar{\Pi}}=\left[\frac{(1-\sigma) \bar{\Pi}^{-\sigma}}{\bar{\Pi}^{1-\sigma}-(1-\lambda) \beta}-\frac{(1-\sigma) \bar{\Pi}^{-\sigma}}{\bar{\Pi}^{1-\sigma}-(1-\lambda)}-\frac{\sigma \bar{\Pi}^{-\sigma-1}}{\bar{\Pi}^{-\sigma}-(1-\lambda)}+\frac{\sigma \bar{\Pi}^{-\sigma-1}}{\bar{\Pi}^{-\sigma}-(1-\lambda) \beta}\right] \\
\frac{\sigma}{\sigma-1}\left[\frac{\bar{\Pi}^{1-\sigma}-(1-\lambda) \beta}{\bar{\Pi}^{1-\sigma}-(1-\lambda)}\right]\left[\frac{\bar{\Pi}^{-\sigma}-(1-\lambda)}{\bar{\Pi}^{-\sigma}-(1-\lambda) \beta}\right] .
\end{array}
$$

Concentrating on the first square bracket:

$$
\frac{d \bar{m}}{d \bar{\Pi}} \propto-\frac{(1-\sigma) \bar{\Pi}^{-\sigma}(1-\lambda)(1-\beta)}{\left(\bar{\Pi}^{1-\sigma}-(1-\lambda) \beta\right)\left(\bar{\Pi}^{1-\sigma}-(1-\lambda)\right)}-\frac{\sigma \bar{\Pi}^{-\sigma-1}(1-\lambda)(1-\beta)}{\left(\bar{\Pi}^{-\sigma}-(1-\lambda)\right)\left(\bar{\Pi}^{-\sigma}-(1-\lambda) \beta\right)} .
$$

Rearranging and removing $(1-\lambda)(1-\beta)$ (which would not be possible if $\beta=1$ ):

$$
\frac{d \bar{m}}{d \bar{\Pi}^{-}} \propto \frac{\bar{\Pi}^{-\sigma}}{\left(\bar{\Pi}^{1-\sigma}-(1-\lambda) \beta\right)\left(\bar{\Pi}^{1-\sigma}-(1-\lambda)\right)}-\frac{\sigma}{\sigma-1} \frac{\bar{\Pi}^{-\sigma-1}}{\left(\bar{\Pi}^{-\sigma}-(1-\lambda)\right)\left(\bar{\Pi}^{-\sigma}-(1-\lambda) \beta\right)} .
$$

Substituting out $\frac{\sigma}{\sigma-1}$ using equation 74 and rearranging to get:

$$
\frac{d \bar{m}}{d \bar{\Pi}} \propto \bar{\Pi}^{-\sigma}\left(\bar{\Pi}^{-\sigma}-(1-\lambda)\right)^{2}-\bar{m} \bar{\Pi}^{-\sigma-1}\left(\bar{\Pi}^{1-\sigma}-(1-\lambda)\right)^{2} .
$$

Simplifying:

$$
\frac{d \bar{m}}{d \bar{\Pi}} \propto \bar{\Pi}^{-\sigma}\left(\bar{\Pi}^{-\sigma}-(1-\lambda)\right)^{2}-\bar{m} \bar{\Pi}^{-\sigma-1}\left(\bar{\Pi}^{1-\sigma}-(1-\lambda)\right)^{2} .
$$

$\bar{m} \geq 1$, otherwise firms exit the market and $\frac{d \bar{m}}{d \bar{\Pi}}$ is decreasing in $\bar{m}$. Therefore, $\frac{d \bar{m}}{d \bar{\Pi}}$ takes its highest possible value when $\bar{m}=1$. It is shown that even in this case $\frac{d \bar{m}}{d \bar{\Pi}}<0$, and thus the markup always decreases in inflation. Under $\bar{m}=1 \frac{d \bar{m}}{d \bar{\Pi}}$ (equation 75 ) simplifies to yield:

$$
\begin{gathered}
\frac{d \bar{m}}{d \bar{\Pi}_{\bar{m}=1} \propto} \bar{\Pi}^{-3 \sigma}+(1-\lambda)^{2} \bar{\Pi}^{-\sigma}-\left[\bar{\Pi}^{1-3 \sigma}+\bar{\Pi}^{-\sigma-1}(1-\lambda)^{2}\right], \\
\frac{d \bar{m}}{d \bar{\Pi}_{\bar{m}=1}} \propto(\bar{\Pi}-1)\left((1-\lambda)^{2}-\bar{\Pi}^{-2 \sigma}\right) .
\end{gathered}
$$

Then note that by equation $74 \bar{\Pi}^{-\sigma} \geq 1-\lambda$ since this is required for $\bar{m}>1$. Thus, $\frac{d \bar{m}}{d \bar{\Pi}}<0$, so it has been demonstrated that under Calvo pricing, when average inflation rises, the average markup always falls when $\beta<1$.

\section{A.2 Asset Demand with Price Dispersion}

This section provides the derivation for the profit of the firm in section 2.2 in the simple model when firms do not set identical prices.

Intermediate firms produce output $Y_{i, t}$ by a linear production function over labor $L_{i, t}$ :

$$
Y_{i, t}=L_{i, t}
$$


Inputting equation 64 into equation 76 and aggregating yields:

$$
Y_{t} \nu_{t}=L_{t}
$$

where $\nu_{t}$ is defined by equation 70 and:

$$
L_{t}=\int_{0}^{1} L_{i, t}
$$

The real marginal cost $M C_{t}$ of intermediate firms is just their wage bill $\left(W_{t}\right)$ :

$$
M C_{t}=W_{t}
$$

Each intermediate firm has the following real profits $\Omega_{i, t}$ :

$$
\Omega_{i, t}=\frac{P_{i, t} Y_{i, t}}{P_{t}}-M C_{t} Y_{i, t} .
$$

Inputting equation 64 into equation 79 and aggregating (and applying equation 65) yields:

$$
\Omega_{t}=\left(1-M C_{t} \nu_{t}\right) Y_{t}
$$

where

$$
\Omega_{t}=\int_{0}^{1} \Omega_{i, t} d i
$$

Next, $m_{t}$ is defined to be $\frac{1}{M C_{t} \nu_{t}}$. We input this into equation 80 :

$$
\Omega_{t}=\left(1-\frac{1}{m_{t}}\right) Y_{t}
$$

$m_{t}$ represents the inverse of real costs of firms, which is a measure of the average markup across firms. When $m_{t}=1$ (the competitive case), firms make no profits. However, as the markup rises, $m_{t} \uparrow$, firms make higher profits.

Next, RHS of equation 81 is multiplied by $\frac{W_{t}}{M C_{t}}$ (which equals 1 by equation 78), and then equation 77 is applied to get:

$$
\begin{aligned}
\Omega_{t} & =\left(1-\frac{1}{m_{t}} \frac{W_{t} L_{t}}{M C_{t} \nu_{t}},\right. \\
\Omega_{t} & =\left(m_{t}-1\right) W_{t} L_{t} .
\end{aligned}
$$

Thus, profits are the same as in the case without price dispersion.

\section{A.3 OLG in a Non-annualized Model}

Figure 9 shows the case where the OLG model is non-annualized, unlike figure 3 where it is annualized. The real interest rate is very high since it represents the return from one generation to the next.

\section{B Model Details}

This section provides additional details on the derivations of section 3 . 
Figure 9: Equilibrium under a Fall in the Markup: 2. OLG (Not Annualized)

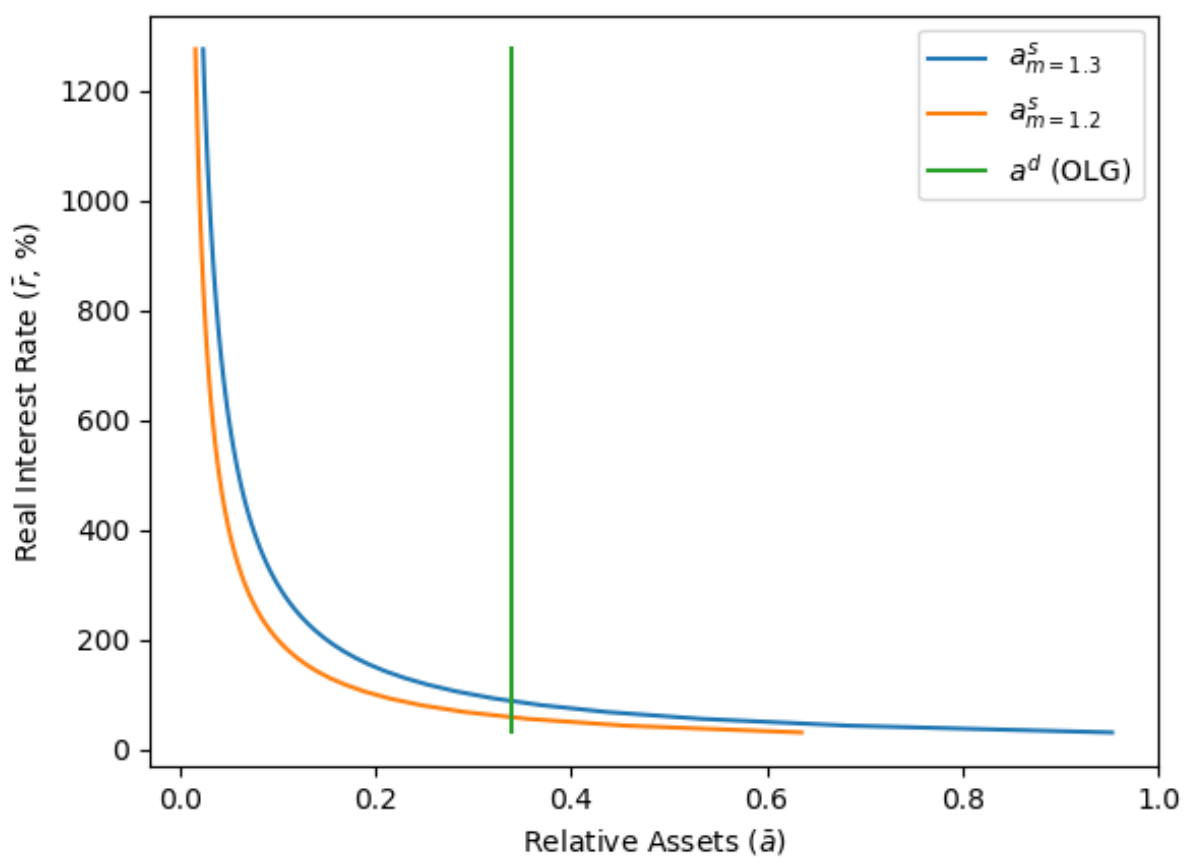

\section{B.1 Aggregating Household Conditions}

Define per capita capital $K_{t}$ as the per capita capital (equation 83). This can be computed by summing the population-weighted capital held by each cohort $\left(\sum_{i=0}^{M-1} N_{t-i} T_{i, t}\right)$ divided by the total population $\left(\mathbb{N}_{t}\right)$. This equation can be written more simply in terms of $n$. These steps are shown in equation 83 .

$$
K_{t}=\frac{\sum_{i=0}^{M-1} N_{t-i} K_{i, t}}{\mathbb{N}_{t}}=\frac{\sum_{i=0}^{M-1} N_{t-i} K_{i, t}}{\sum_{i=0}^{M-1} N_{t-i}}=\frac{\sum_{i=0}^{M-1} N_{t} \frac{1}{(1+n)^{i}} K_{i, t}}{\sum_{i=0}^{M-1} N_{t} \frac{1}{(1+n)^{i}}}=\frac{\sum_{i=0}^{M-1} \frac{1}{(1+n)^{i}} K_{i, t}}{\sum_{i=0}^{M-1} \frac{1}{(1+n)^{i}}} .
$$

Other per-capita variables are defined similarly: per capita total labor $\left(L_{t}\right)$, per capita savings held at $t$ ( $T_{t}$, equation 83), per capita savings made at $t\left(S_{t+1}\right.$, equation 35), aggregate bonds ( $B_{t}$, equation 84$)$, aggregate shares $\left(\omega_{t}\right.$, equation 85$)$.

$$
\begin{aligned}
& T_{t}=\frac{\sum_{i=0}^{M-1} \frac{1}{(1+n)^{i}} T_{i, t}}{\sum_{i=0}^{M-1} \frac{1}{(1+n)^{i}}} . \\
& B_{t}=\frac{\sum_{i=0}^{M-1} \frac{1}{(1+n)^{i}} B_{i, t}}{\sum_{i=0}^{M-1} \frac{1}{(1+n)^{i}}}, \\
& \omega_{t}=\frac{\sum_{i=0}^{M-1} \frac{1}{(1+n)^{i}} \omega_{i, t}}{\sum_{i=0}^{M-1} \frac{1}{(1+n)^{i}}} .
\end{aligned}
$$

Next, recall that the total holdings of shares $\left(\tilde{\omega}_{i, t}\right)$ in a firm must sum to 1 ; that is, $\sum_{i=0}^{M-1} N_{t-i} \tilde{\omega}_{i, t}=1$. Applying the definition of $\omega_{i, t}=\tilde{\omega}_{i, t} \mathbb{N}_{t}$ implies that the aggregate per capita holdings of shares in a firm $\omega_{t}$ 
must also always equal 1 . This is shown formulaically in equation 86 .

$$
\omega_{t}=\frac{\sum_{i=0}^{M-1} N_{t-i} \omega_{i, t}}{\mathbb{N}_{t}}=\frac{\sum_{i=0}^{M-1} N_{t-i} \tilde{\omega}_{i, t} \mathbb{N}_{t}}{\mathbb{N}_{t}}=\sum_{i=0}^{M-1} N_{t-i} \tilde{\omega}_{i, t}=1 .
$$

Inputting equation 32 into equation 83 and then applying equations 82 and 84 to 86 yields equation 36 . Equation 36 states that the total assets held at $t$ equal the total return on bonds, capital, and shares. Similarly, inputting equation 31 into equation 35 and then applying equations 82 and 84 to 86 yields equation 37.7

\section{Steady State Details}

This section provides fuller derivations of the steady state. The conditions are summarized in section 4.2.

\section{C.1 Markup and Inflation Target}

First, note that the steady state inflation level equals the target inflation level: $\bar{\Pi}=\Pi^{\star}$. Next, equation 58 can be rewritten to express the optimal relative price as a function of steady state inflation:

$$
\overline{\frac{P^{\star}}{P}}=\left(\frac{1-(1-\lambda) \bar{\Pi}^{\sigma-1}}{\lambda}\right)^{\frac{1}{1-\sigma}} .
$$

Next, $\bar{U}, \bar{V}$ can be expressed as functions of $\bar{Y}, \overline{M C}, \bar{\Pi}, \bar{R}$ :

$$
\begin{gathered}
\bar{U}=\bar{Y}\left(1-\frac{1-\lambda}{\bar{R}} \bar{\Pi}^{\sigma-1}\right), \\
\bar{V}=\bar{Y} \frac{\sigma}{\sigma-1}(1+\tau) \overline{M C}\left(1-\frac{1-\lambda}{\bar{R}} \bar{\Pi}^{\sigma}\right) .
\end{gathered}
$$

Combining equations 87 to 89 allows the marginal cost to be rewritten as a function of $\bar{\Pi}, \bar{R}$ :

$$
\overline{M C}=\left(1-\frac{1-\lambda}{\bar{R}} \bar{\Pi}^{\sigma-1}\right)\left(\frac{1-(1-\lambda) \bar{\Pi}^{\sigma-1}}{\lambda}\right)^{\frac{1}{1-\sigma}}\left(\frac{\sigma}{\sigma-1}(1+\tau)\left(1-\frac{1-\lambda}{\bar{R}} \bar{\Pi}^{\sigma}\right)\right)^{-1}
$$

The steady state price dispersion is given by equation 90 :

$$
\nu_{t}=\frac{1}{1-(1-\lambda) \bar{\Pi}^{\sigma}} \lambda\left(\frac{\overline{P^{\star}}}{P}\right)^{-\sigma} .
$$

\footnotetext{
${ }^{7}$ To derive equation 37 , the following steps can be made for bonds, capital, and shares:

$$
\frac{\sum_{i=0}^{M-1} N_{t-i} K_{i+1, t+1}}{\mathbb{N}_{t}}=\frac{\sum_{i=1}^{M} N_{t-i} K_{i, t+1}}{\mathbb{N}_{t}}=\frac{\sum_{i=0}^{M-1} N_{t-i} K_{i, t+1}}{\mathbb{N}_{t}}=(1+n) \frac{\sum_{i=0}^{M-1} N_{t-i} K_{i, t+1}}{\mathbb{N}_{t+1}}=(1+n) K_{t+1} .
$$

The first equality is just an adjustment of the summation index. The second equality uses $K_{0, t+1}=K_{M, t+1}=0$ to adjust the summation beginning and starting points. The third equality adjusts $\mathbb{N}_{t}$. The fourth equality is just a definition.
} 


\section{C.2 Relative Asset Supply}

Equation 91 follows from equation 37 and the definition of $s$ :

$$
\bar{a}^{s}=\frac{(1+n) \bar{K}+\bar{Z}}{\bar{W} \bar{L}} .
$$

Inputting equation 27 into equation 91 yields equation 92:

$$
\bar{a}^{s}=\frac{(1+n) \bar{K}+\frac{\bar{\Omega}}{\frac{R}{1+n}-1}}{\bar{W} \bar{L}} .
$$

Inputting equation 52 into equation 92 yields equation 93, where $m$ is defined such that $m=\frac{1}{M C \bar{\nu}}$ (it is akin to the markup):

$$
\bar{a}^{s}=\frac{(1+n) \bar{K}+\frac{\bar{Y}\left(1-\frac{1}{m}\right)}{\frac{R}{1+n}-1}}{\bar{W} \bar{L}} .
$$

Equations 49 and 50 can be combined to yield equation 94 . Inputting equations 50 and 94 into equation 93 yields equation 95:

$$
\begin{gathered}
\frac{\bar{K}}{\bar{W} \bar{L}}=\frac{\alpha}{1-\alpha} \frac{1}{\bar{R}-1+\delta}, \\
\bar{a}^{s}=(1+n) \frac{\alpha}{1-\alpha} \frac{1}{\bar{R}-1+\delta}+\frac{m-1}{\frac{\bar{R}}{1+n}-1} \frac{1}{1-\alpha} .
\end{gathered}
$$

We observe that $\bar{a}^{s}$ is an increasing function of $m$. This makes sense, because when the markup rises, profits are higher and thus the value of firms is higher and the quantity of assets supplied rises.

\section{C.3 Relative Asset Demand}

Relative Consumption The total savings that agents hold at the start of a period must equal the amount they saved in the previous period plus the return. This yields equation 96 . This is shown formally by applying arbitrage conditions on bonds and shares (equations 25 and 29) to equations 36 and 37:

$$
\bar{T}=\bar{R} \bar{S} .
$$

Applying equation 96 to the individual period budget constraint (equation 39) and then iterating yields the intertemporal steady state budget constraint equation 97 :

$$
\sum_{i=0}^{M-1} \frac{\bar{C}_{i}}{\bar{R}^{i}}=\bar{W} \sum_{i=0}^{M-1} \frac{\bar{L}_{i}}{\bar{R}^{i}} .
$$

The Euler condition (equation 26) can be rewritten as equation 98:

$$
\bar{C}_{i+1}=(\beta \bar{R})^{\frac{1}{\gamma}} \bar{C}_{i}
$$

Iterating over equation 98 yields equation 99:

$$
\bar{C}_{i}=(\beta \bar{R})^{\frac{i}{\gamma}} \bar{C}_{0}
$$


Inputting this back into equation 97 and simplifying yields equation 100:

$$
\bar{C}_{0}=\left(\sum_{i=0}^{M-1} \beta^{\frac{i}{\gamma}} \bar{R}^{\frac{i(1-\gamma)}{\gamma}}\right)^{-1} \bar{W} \sum_{i=0}^{M-1} \frac{\bar{L}_{i}}{\bar{R}^{i}} .
$$

Therefore, applying equation 98 to equation 100 yields an expression for consumption in any period in terms of $\bar{R}$ :

$$
\bar{C}_{j}=(\beta \bar{R})^{\frac{j}{\gamma}}\left(\sum_{i=0}^{M-1} \beta^{\frac{i}{\gamma}} \bar{R}^{\frac{i(1-\gamma)}{\gamma}}\right)^{-1} \bar{W} \sum_{i=0}^{M-1} \frac{\bar{L}_{i}}{\bar{R}^{i}} .
$$

Relative consumption for each cohort $i$ is defined as consumption by that cohort divided by labor income:

$$
\bar{c}_{i}=\frac{\bar{C}_{i}}{\bar{W} \bar{L}}
$$

Thus, equation 101 can be rewritten as equation 102:

$$
\bar{c}_{j}=(\beta \bar{R})^{\frac{j}{\gamma}}\left(\sum_{i=0}^{M-1} \beta^{\frac{i}{\gamma}} \bar{R}^{\frac{i(1-\gamma)}{\gamma}}\right)^{-1} \sum_{i=0}^{M-1} \frac{\bar{L}_{i}}{\overline{\bar{R}}^{i}} .
$$

Endogenous Labor Relative Labor Supply In the case with exogenous labor, relative consumption for each cohort has been rewritten purely in terms of $\bar{R}$. However, in the case with endogenous labor, $\frac{\bar{L}_{i}}{L}$ are endogenous, so the labor part of equation 102, that is $\sum_{i=0}^{M-1} \frac{\bar{L}_{i}}{L} \frac{1}{\bar{R}^{i}}$, needs to be rewritten in terms of $\bar{R}$ only.

Substituting the labor-leisure condition (equation 28) into the Euler condition (equation 26) yields the intertemporal labor supply condition:

$$
\frac{v^{\prime}\left(L_{i, t}\right)}{W_{t}}=\beta R_{t+1} \frac{v^{\prime}\left(L_{i, t+1}\right.}{W_{t+1}}
$$

Applying the steady state and the disutility of working function to equation 103 yields:

$$
x_{i} \bar{L}_{i}^{\eta}=\beta \bar{R} x_{i+1} \bar{L}_{i+1}^{\eta} \text {. }
$$

Rewriting equation 104:

$$
\bar{L}_{i+1}=\left(\frac{1}{\beta \bar{R}}\right)^{\frac{1}{\eta}}\left(\frac{x_{i}}{x_{i+1}}\right)^{\frac{1}{\eta}} \bar{L}_{i}
$$

Iterating over equation 105:

$$
\bar{L}_{i}=\left(\frac{1}{\beta \bar{R}}\right)^{\frac{i}{\eta}}\left(\frac{x_{0}}{x_{i}}\right)^{\frac{i}{\eta}} \bar{L}_{0} .
$$

Next, note that the (population-weighted) total labor supply is given by:

$$
\bar{L}=\left(\sum_{i=0}^{M-1} \frac{1}{(1+n)^{i}}\right)^{-1} \sum_{i=0}^{M-1} \frac{1}{(1+n)^{i}} \bar{L}_{i} .
$$


Inputting equation 106 into equation 107 yields:

$$
\bar{L}=\left(\sum_{i=0}^{M-1} \frac{1}{(1+n)^{i}}\right)^{-1} \sum_{i=0}^{M-1} \frac{1}{(1+n)^{i}}\left(\frac{1}{\beta \bar{R}}\right)^{\frac{i}{\eta}}\left(\frac{x_{0}}{x_{i}}\right)^{\frac{i}{\eta}} \bar{L}_{0} .
$$

Substituting out $\bar{L}_{0}$ from equation 106 using equation 108 yields the relative labor supplied by each cohort given by equation 109 .

$$
\frac{\bar{L}_{j}}{\bar{L}}=\left(\sum_{i=0}^{M-1} \frac{1}{(1+n)^{i}}\left(\frac{1}{\beta \bar{R}}\right)^{\frac{i}{\eta}}\left(\frac{x_{0}}{x_{i}}\right)^{\frac{i}{\eta}}\right)^{-1}\left(\frac{1}{\beta \bar{R}}\right)^{\frac{j}{\eta}}\left(\frac{x_{0}}{x_{i}}\right)^{\frac{j}{\eta}} \sum_{i=0}^{M-1} \frac{1}{(1+n)^{i}} .
$$

The economic intuition is that when $\bar{R}$ is higher, old agents supply relatively less labor because they are already getting a high return on their savings and therefore don't need to work as much.

Relative Asset Demand Cohort relative assets are defined in equation 110:

$$
\bar{a}_{i}=\frac{\bar{S}_{i}}{\bar{W} \bar{L}}
$$

Equation 111 can be rewritten in terms of each cohort's relative assets and relative consumption:

$$
\bar{c}_{i}+\bar{a}_{i+1}=\frac{\bar{L}_{i}}{\bar{L}}+\bar{R} \bar{a}_{i}
$$

Note that $\bar{a}_{0}=\bar{a}_{M}=0$ (since agents start with zero assets and have no need for assets when they are dead) and we have already computed $\bar{c}_{i}$ in terms of $\bar{R}$. Therefore, this yields $M-1$ equations from equation 111 and $M-1$ unknowns $\bar{a}_{1}, \ldots, \bar{a}_{M-1}$. Thus, if we know $\bar{R}, \bar{a}_{i}$ can be solved for by iterating over equation 111 starting from the beginning or end.

Finally, note that by equation 35, the demand for relative assets is given by equation 112:

$$
\bar{a}^{d}=\left(\sum_{i=0}^{M-1} \frac{1}{(1+n)^{i}}\right)^{-1} \sum_{i=0}^{M-1} \frac{1}{(1+n)^{i}} \bar{a}_{i} .
$$

\section{Calibration Details}

This section provides more details on the calibration explained in section 4.5.

\section{D.1 Endogenous Labor Supply}

Substituting the labor-leisure condition (equation 28) into the Euler condition (equation 26) yields the intertemporal labor supply condition:

$$
\frac{v^{\prime}\left(L_{i, t}\right)}{W_{t}}=\beta R_{t+1} \frac{v^{\prime}\left(L_{i, t+1}\right.}{W_{t+1}}
$$

In the steady state this becomes:

$$
x_{i} \bar{L}_{i}^{\eta}=\beta \bar{R} x_{i+1} \bar{L}_{i+1}^{\eta} .
$$


Equation 114 can be rewritten as:

$$
x_{i+1}=\frac{1}{\beta \bar{R}} x_{i}\left(\frac{\bar{L}_{i}}{\bar{L}_{i+1}}\right)^{\eta}
$$

Iterating over this yields:

$$
x_{i}=\frac{1}{(\beta \bar{R})^{i}} x_{0}\left(\frac{\bar{L}_{0}}{\bar{L}_{i}}\right)^{\eta} .
$$

$x_{0}$ is a free variable, since the $x$ terms are relative, so $x_{0}$ is set to be 1 . To keep things simple, I set $x_{i} \forall i>0$ so that the labor supply is the same as the exogenous case parameterization when $\beta \bar{R}=1$, so:

$$
x_{i}=\left(\frac{\bar{L}_{0}}{\bar{L}_{i}}\right)^{\eta}
$$

where the $\bar{L}$ ratios are the same as in the exogenous labor case.

\section{E Model Extensions}

This section describes how extensions to the main model (section 3) are introduced.

\section{E.1 Menu Costs}

It is interesting to consider how changing the price rigidity affects the relationship between inflation and the real interest rate. In the main model, Calvo pricing was considered. Here, menu costs are considered instead.

Intermediate Firm Problem The same basic structure as under Calvo pricing is assumed. There is a competitive final goods firm with CES production that aggregates intermediate goods into a final good. There are monopolistic intermediate firms.

Idiosyncratic shocks are introduced to generate continuous distributions of price changes. To introduce shocks, it is assumed that intermediate firms have idiosyncratic productivity $A_{i, t}$. Therefore, their output $Y_{i, t}$ is given by equation 116:

$$
Y_{i, t}=A_{i, t} K_{i, t}^{\alpha} L_{i, t}^{1-\alpha}
$$

where

$$
\log \left(A_{i, t}\right)=\rho_{a i} \log \left(A_{i, t-1}\right)+\left(1-\rho_{a i}\right) \log (\bar{A})+\epsilon_{i, t}
$$

and $\epsilon_{i, t} \sim N\left(0, \sigma_{a i}\right)$.

Under $A_{i, t}=1$, firms have the same cost minimization problem as in section 3.2 (when $A_{t}=1$ ). There are no aggregate shocks, so real aggregate variables are constant and do not vary with time. The marginal cost of a firm with $A_{i, t}=1$ is defined as $M C$. Thus, the idiosyncratic marginal cost can be rewritten as equation 117.

$$
M C_{i, t}=\frac{M C}{A_{i, t}} .
$$

An intermediate goods firm pays a fixed cost $f$ that is a function of aggregate output $Y$ if it changes its 
price. The firm's profit function is then given by equation 118:

$$
\Omega_{i, t}=\frac{P_{i, t}}{P} Y_{i, t}-M C_{i, t} Y_{i, t}-f Y \mathbb{1}_{\text {pricechange }, i} .
$$

Inputting the demand from the final goods firm (equation 41) and the idiosyncratic marginal cost (equation 117) into equation 118 yields equation 119:

$$
=Y\left[\left(\frac{P_{i, t}}{P}\right)^{1-\sigma}-\frac{M C}{A_{i, t}}\left(\frac{P_{i, t}}{P_{t}}\right)^{-\sigma}\right] .
$$

The problem can then be aggregated. The relative price of a firm $p_{i, t}=\frac{P_{i, t}}{P_{t}}$ is defined to get equation 120:

$$
\Omega_{i, t}=Y\left[p_{i, t}^{1-\sigma}-\frac{M C}{A_{i, t}} p_{i, t}^{-\sigma}-f \mathbb{1}_{\text {pricechange }, i}\right]
$$

Relative profits, that is a firm's profits relative to output, are defined as $\omega_{i, t}=\frac{\Omega_{i, t}}{Y}$. A firm's profits are then a function of idiosyncratic productivity and a firm's price, which are defined as a function $\omega$ in equation 121:

$$
\omega_{i, t}=\frac{\Omega_{i, t}}{Y}=\omega\left(p_{i, t}, A_{i, t}\right)=p_{i, t}^{1-\sigma}-\frac{M C}{A_{i, t}} p_{i, t}^{-\sigma} .
$$

Each period, firms have two choices:

1. Pay a menu cost $\mu Y$, in which case a firm will get to reset its price at time $t$, and firms receive profits of $\left.Y \omega\left(p_{i, t}, A_{i, t}\right)-\mu\right)$ in the current period.

2. Do not pay a menu cost, in which case a firm will not reset its price and will use the same price as in the previous period. Thus, $p_{i, t}=\frac{P_{i, t-1}}{P_{t}}=\frac{p_{i, t-1}}{\Pi}$, where $\Pi$ is gross inflation $\frac{P_{t+1}}{P_{t}}$ that is constant in the steady state and so does not require a time subscript. In this case, firms receive profits of $Y \omega\left(\frac{p_{i, t-1}}{\Pi}, A_{i, t}\right)$ in the current period.

Therefore, the problem is rewritten as follows (where profits have been divided by $Y$ to simplify the problem and where 0 represents the current period and -1 represents the previous period):

$V\left(p_{i,-1}, A_{i, 0}\right)=\max \left\{\max _{p_{i, 0}} \omega\left(p_{i, 0}, A_{i, 0}\right)+\beta \mathbb{E}\left[V\left(\frac{p_{i, 0}}{\Pi^{\star}}, A_{i, 1}\right)\right]-\mu, \omega\left(\frac{p_{i,-1}}{\Pi}, A_{i, 0}\right)+\beta \mathbb{E}\left[V\left(\frac{p_{i,-1}}{\Pi^{\star}}, A_{i, 1}\right)\right]\right\}$.

This value function iteration problem can then be solved to give firm price distributions given a marginal cost $M C$ and menu cost $f$.

Aggregate Conditions Equation 42 can be rewritten as equation 122:

$$
1=\int_{0}^{1} p_{i, t}^{1-\sigma}
$$

Equation 122 holds only when $M C$ is at the correct level. If $M C$ is too high, firms will set their prices too high. If $M C$ is too low, firms will set their prices too low.

The aggregate profit share can be computed by aggregating equation 120 . To do this, aggregate profits are defined as $\Omega=\int_{0}^{1} \Omega_{i, t} d i$. Then integrating over $i$ and applying equation 122 yields equation 123, where 
$\nu$ is defined in equation 124:

$$
\begin{gathered}
\frac{\Omega}{Y}=1-M C \nu-f Y \text { prob }_{\text {pricechange }}, \\
\nu=\int_{0}^{1} \frac{p_{i}^{-\sigma}}{A_{i}} .
\end{gathered}
$$

In equation 123, it can be observed that if a rise in inflation raises the probability of a price change, the profit share falls. In practice, menu costs may represent internal costs of changing prices, so it may be preferable to exclude this impact on the profit share, in which case the profit share is given simply by equation 125:

$$
\frac{\Omega}{Y}=1-M C \nu-f Y \text { prob }_{\text {pricechange }}
$$

Calibration As in the main model, $\sigma=8$. The standard deviation of productivity shocks $\left(\sigma_{a i}\right)$ and the persistence of productivity shocks $\left(\rho_{a i}\right)$ are set to be respectively 0.0428 and 0.66 as in Nakamura and Steinsson (2008). The model is calibrated to set the monthly frequency of price changes to be 8.7 percent (which also is based on Nakamura and Steinsson 2008). The model calibration proceeds with two iterative steps. The first step is that the $M C$ are computed that satisfy equation 122 under a low and a high value of $f$. The second step is that the $f$ is computed that yields 8.7 percent frequency of price change under the low and high $M C$ that have been computed. The steps are alternated until convergence is achieved.

\section{E.2 Firm Additional Discounting}

Firms may discount at a greater rate than households do, since they face funding constraints that mean their cost of borrowing may be higher than $\bar{r}$. To incorporate this feature into the model, a wedge is added to the degree to which firms borrow. Thus, rather than discount by $\frac{1}{\bar{R}}$, firms instead discount by $\frac{\beta_{f}}{\bar{R}}$.

The choice of $\beta_{f}$ is based on the weighted average cost of capital (WACC), which is the average a company is expected to pay to finance its assets. ${ }^{8}$ Jagannathan et al. (2016) estimate that it was 8 percent in 2003, when the expected 10-year rate on real bonds $\left(r^{e}\right)$ was 2.8 percentage points. Graham and Harvey (2011) estimate it was 10.0 percent in 2011Q1, when $r^{e}$ was 2.2 percent. Graham and Harvey (2012) estimate it was 9.3 percent in $2012 \mathrm{Q} 2$, when $r^{e}$ was 1.3 percent. From these three surveys, the average wedge between WACC and the expected real rate is 7 percentage points. Therefore, a firm discount of $\beta_{f}=\left(\frac{1}{1.07}\right)^{\frac{1}{4}}$ is applied.

\section{E.3 Firm Death}

In the baseline model, the value of shares in firms is very high, which implies a high real interest rate, unless we apply a significant subsidy on marginal production. One way to get a more reasonable level for firm value is to assume that with some probability firms die each period.

To model firm death, it is assumed that each period after paying out profits, only a fraction $\zeta$ of firms survive. The firms that do not survive are restructured and sold by entrepreneurs who are not modeled. Therefore, agents receive a payout of $\zeta \tilde{Z}_{t}$ only on the shares they bought in the previous period and sell in the current period. Then equation 27 becomes equation 126, which, using the same steps as in the main

\footnotetext{
${ }^{8}$ This is used since it is the cost to the firm of not obtaining funds earlier by setting a lower markup.
} 
model, simplifies to equation 127 :

$$
\begin{gathered}
\tilde{Z}_{t} u^{\prime}\left(C_{i, t}\right)=\beta \mathbb{E}_{t}\left[u^{\prime}\left(C_{i+1, t+1}\right)\left(\tilde{\Omega}_{t+1}+\zeta \tilde{Z}_{t+1}\right)\right], \\
Z_{t} u^{\prime}\left(C_{i, t}\right)=\beta \mathbb{E}_{t}\left[u^{\prime}\left(C_{i+1, t+1}\right)(1+n)\left(\Omega_{t+1}+\zeta Z_{t+1}\right)\right] .
\end{gathered}
$$

Firm survival $(\zeta=0.985)$ is calibrated so that the profit share equals 6.06 percent, which was its average value in the 1987-2006 period.

\section{E.4 Intermediate Goods}

An approach similar to that of Basu (1995) is followed to introduce intermediate goods into the model. This impacts only the firm cost minimization part of the model. A "roundabout" production structure is assumed where final goods are used as intermediate inputs in the production of other goods. Thus, $M_{i, j, t}$ represents the amount of the final good used in production by firm $i$ in sector $j$ at time $t$, while other elements are defined similarly to how they are defined in the main model:

$$
Y_{i, t}=M_{i, t}^{\chi}\left(A_{t} K_{i, t}^{\alpha} L_{i, t}^{1-\alpha}\right)^{1-\chi}
$$

Intermediate firms minimize their costs. They face the following problem:

$$
\min _{K_{i, t}, L_{i, t}}\left(R_{t}-1+\delta\right) K_{i, j, t}+W_{t} L_{i, j, t}+M_{i, j, t}
$$

s.t. equation 128.

We define $M_{t}=\int_{0}^{1} M_{i, t}$. Taking FOCs and noting that the ratios $\frac{K_{i, t}}{L_{i, t}}, \frac{K_{i, t}}{M_{i, t}}$ are the same across firms yields equations 129 to 131 .

$$
\begin{gathered}
M C_{t}=\frac{r_{t}}{(1-\chi) \alpha A_{t}^{1-\chi} K_{t}^{(1-\chi) \alpha-1} L_{t}^{(1-\chi)(1-\alpha)} M_{t}^{\chi}}, \\
M C_{t}=\frac{W_{t}}{(1-\chi)(1-\alpha) A_{t}^{1-\chi} K_{t}^{(1-\chi) \alpha} L_{t}^{(1-\chi)(1-\alpha)-1} M_{t}^{\chi}}, \\
M C_{t}=\frac{1}{\chi A_{t}^{1-\chi} K_{t}^{(1-\chi) \alpha} L_{t}^{(1-\chi)(1-\alpha)} M_{t}^{\chi-1}} .
\end{gathered}
$$

Inputting equation 41 into equation 128 and noting that the ratios $\frac{K_{i, t}}{L_{i, t}}, \frac{K_{i, t}}{M_{i, t}}$ are constant across firms allows equation 128 to be rewritten as equation 132, where $\nu_{t}$ is defined in the same way as it is in equation 48:

$$
\nu_{t} Y_{t}=M_{t}^{\chi}\left(A_{t} K_{t}^{\alpha} L_{t}^{1-\alpha}\right)^{1-\chi} .
$$

Next, equation 132 can be inputted into equations 129 to 131 to replace $M_{t}$ with $Y_{t}$, which yields equations 133 and 134:

$$
\begin{gathered}
(1-\chi) \alpha \nu_{t} M C_{t}=\frac{r_{t} K_{t}}{Y_{t}}, \\
(1-\chi)(1-\alpha) \nu_{t} M C_{t}=\frac{W_{t} L_{t}}{Y_{t}},
\end{gathered}
$$




$$
\chi \nu_{t} M C_{t}=\frac{M_{t}}{Y_{t}}
$$

Output can also be rewritten without intermediate goods by first rewriting equation 131 as equation 136 and then inputting equation 136 into equation 132 to get equation 137:

$$
\begin{gathered}
M_{t}^{1-\chi}=M C_{t} \chi A_{t}^{1-\chi} K_{t}^{(1-\chi) \alpha} L_{t}^{(1-\chi)(1-\alpha)} \\
Y_{t} \nu_{t}=A_{t} K_{t}^{\alpha} L_{t}^{1-\alpha}\left(M C_{t} \chi\right)^{\frac{\chi}{1-\chi}}
\end{gathered}
$$

It is also useful to note that inputting equations 129 to 131 into equation 137 yields equation 138:

$$
M C_{t}=\frac{1}{A_{t}^{1-\chi}}\left(\frac{R_{t}-1+\delta}{\alpha(1-\chi)}\right)^{(1-\chi) \alpha}\left(\frac{W_{t}}{(1-\chi)(1-\alpha)}\right)^{(1-\chi)(1-\alpha)}\left(\frac{1}{\chi}\right)^{\chi} .
$$

Profits simplify in a manner similar to the way they do in the main model to yield equation 52.

Calibration Without price rigidity or price dispersion, equation 135 becomes equation 139. Nakamura and Steinsson (2010) point out that the average revenue share of intermediate inputs in the US private sector using CPI expenditure weights was 52 percent. Thus, $\frac{M_{t}}{Y_{t}}$ can be estimated to be 0.52 , while $\sigma=8$. Thus, $\chi$ is estimated to be 0.594 .

$$
\chi=\frac{\sigma}{\sigma-1} \frac{M_{t}}{Y_{t}} .
$$

\section{E.5 Multiple Sectors}

Multiple sectors are introduced in this section. The key difference between sectors is in their price rigidity. Sectors are also allowed to differ in size. This follows models by Carvalho, Ferrero, and Nechio (2016) and Nakamura and Steinsson (2010).

Final Goods Firm There is a single competitive final goods firm that aggregates goods in different industries to produce a final good. There are $J$ industries in total, denoted by $1, \ldots, J$. The final goods firm has CES production, and each industry has a weight $a_{j}$ (equation 140):

$$
Y_{t}=\left(\sum_{j=1}^{J} a_{j}^{\frac{1}{\sigma_{2}}} Y_{j, t}^{\frac{\sigma_{2}-1}{\sigma_{2}}} d j\right)^{\frac{\sigma_{2}}{\sigma_{2}-1}}
$$

Therefore, the final goods firm has the usual CES demand (taking into account industry weights) for each industry good given by equation 141 . The price aggregator also takes the usual form given by equation 142 . Note that weights $a_{j}$ need to be added for each industry:

$$
\begin{gathered}
Y_{j, t}=a_{j}\left(\frac{P_{j, t}}{P_{t}}\right)^{-\sigma_{2}} Y_{t}, \\
P_{t}=\left(\sum_{j=1}^{J} a_{j} P_{j, t}^{1-\sigma_{2}} d j\right)^{\frac{1}{1-\sigma_{2}}} .
\end{gathered}
$$


Industry Aggregator A perfectly competitive firm aggregates all the intermediate goods in that industry to produce the good for sector $j$. The sector firm has the following production function:

$$
Y_{j, t}=\left(\int_{0}^{1} Y_{i, j, t}^{\frac{\sigma-1}{\sigma}} d i\right)^{\frac{\sigma}{\sigma-1}}
$$

Therefore, the industry aggregator has the usual CES demand for each intermediate good given by equation 143 . The price aggregator also takes the usual form given by equation 144 :

$$
\begin{gathered}
Y_{i, j, t}=Y_{j, t}\left(\frac{P_{i, j, t}}{P_{j, t}}\right)^{-\sigma}, \\
P_{j, t}=\left(\int_{0}^{1} P_{i, j, t}^{1-\sigma} d i\right)^{\frac{1}{1-\sigma}} .
\end{gathered}
$$

Intermediate Firm Profit Maximization Firms in each industry $j$ have an exogenous $\lambda_{j}$ probability of updating their price each period (Calvo pricing). When they do get to change their price, firms maximize equation 145 subject to the demand for their good from the industry aggregator firm (equation 143). Therefore, firms maximize equation 145 subject to the demand from industry aggregator firms (equation 143):

$$
\max _{P_{j, t}^{\star}, Y_{i, j, t}} \sum_{k=0}^{\infty}\left(\frac{1}{\bar{R}}\right)^{k}\left(1-\lambda_{j}\right)^{k}\left[\frac{P_{j, t}^{\star} Y_{i, j, t+k}}{P_{t+k}}-M C_{t+k} Y_{i, j, t+k}\right]
$$

The solution to equation 145 can be rewritten as the first-order condition (equation 146) plus two auxiliary equations (equations 147 and 148). The derivation is discussed in appendix G:

$$
\begin{gathered}
U_{j, t} \frac{P_{j, t}^{\star}}{P_{j, t}} \frac{P_{j, t}}{P_{t}}-V_{j, t}=0, \\
U_{j, t}=\left(\frac{P_{j, t}}{P_{t}}\right)^{-\sigma_{2}} Y_{t}+\mathbb{E}_{t}\left[\frac{1}{\bar{R}}\left(1-\lambda_{j}\right) \Pi_{j, t+1}^{\sigma} \Pi_{t+1}^{-1} U_{j, t+1}\right], \\
V_{j, t}=\left(\frac{P_{j, t}}{P_{t}}\right)^{-\sigma_{2}} Y_{t} \frac{\sigma}{\sigma-1} M C_{t}+\mathbb{E}_{t}\left[\frac{1}{\bar{R}}\left(1-\lambda_{j}\right) \Pi_{j, t+1}^{\sigma} V_{j, t+1}\right] .
\end{gathered}
$$

Aggregate price dispersion is defined by equation 149. The price dispersion in industry $j$ is defined by equation 150:

$$
\begin{gathered}
\nu_{t}=\sum_{j=1}^{J} a_{j}\left(\frac{P_{j, t}}{P_{t}}\right)^{-\sigma_{2}} \nu_{j, t} d j, \\
\nu_{j, t}=\int_{0}^{1}\left(\frac{P_{i, j, t}}{P_{j, t}}\right)^{-\sigma} d i .
\end{gathered}
$$

Under Calvo pricing, Equation 150 can be rewritten as equation 151. Equation 144 can be rewritten as equation 152. There is a relationship between inflation in an industry and the relative price in that industry that holds by definition and is shown in equation 153. And equation 142 can be rewritten as equation 154. 
These steps are discussed in appendix G:

$$
\begin{gathered}
\nu_{j, t}=\lambda_{j}\left(\frac{P_{j, t}^{\star}}{P_{j, t}}\right)^{-\sigma}+\left(1-\lambda_{j}\right) \nu_{j, t-1} \Pi_{j, t}^{\sigma}, \\
1=\lambda_{j}\left(\frac{P_{j, t}^{\star}}{P_{j, t}}\right)^{1-\sigma}+\left(1-\lambda_{j}\right) \Pi_{j, t}^{\sigma-1}, \\
\Pi_{j, t}=\frac{P_{j, t}}{P_{t}} \frac{P_{t}}{P_{t-1}} \frac{P_{t-1}}{P_{j, t-1}}, \\
1=\sum_{j=1}^{J} a_{j}\left(\frac{P_{j, t}}{P_{t}}\right)^{1-\sigma_{2}} .
\end{gathered}
$$

Steady State Introducing multiple sectors impacts the steady state marginal cost only in the steady state, that is, appendix C.1. It has no impact on the demand of relative assets or the supply of relative assets given the markup. To derive the revised steady state, first note that:

$$
\bar{\Pi}=\bar{\Pi}_{j}=\Pi^{\star} .
$$

Equation 152 can be rewritten to get a steady state equation for $\frac{\overline{P_{j}^{\star}}}{P_{j}}$, which is shown in equation 155 . Equation 151 can be rewritten to get a steady state equation for $\bar{\nu}_{j}$, which is shown in equation 156:

$$
\begin{gathered}
\overline{\left(\frac{P_{j}^{\star}}{P_{j}}\right)}=\left(\frac{1-\frac{1-\lambda_{j}}{\Pi^{\star 1-\sigma}}}{\lambda_{j}}\right)^{\frac{1}{1-\sigma}}, \\
\bar{\nu}_{j}=\frac{1}{1-\left(1-\lambda_{j}\right) \Pi^{\star \sigma}} \lambda_{j}{\overline{\left(\frac{P_{j}^{\star}}{P_{j}}\right)}}^{-\sigma} .
\end{gathered}
$$

In the steady state equations 146 to 148 become, respectively:

$$
\begin{gathered}
\frac{\overline{P_{j}}}{P}=\frac{\bar{V}_{j}}{\bar{U}_{j}}\left(\overline{\frac{P_{j}^{\star}}{P_{j}}}\right)^{-1}, \\
\bar{U}_{j}=\frac{1}{1-\frac{1}{\bar{R}}\left(1-\lambda_{j}\right) \bar{\Pi}^{\sigma-1}}\left(\frac{\overline{P_{j}}}{P}\right)^{-\sigma_{2}} \bar{Y}, \\
\bar{V}_{j}=\frac{1}{1-\frac{1}{\bar{R}}\left(1-\lambda_{j}\right) \bar{\Pi}^{\sigma}}\left(\frac{\overline{P_{j}}}{P}\right)^{-\sigma_{2}} \bar{Y} \frac{\sigma}{\sigma-1} \overline{M C} .
\end{gathered}
$$

Equations 158 and 159 can be inserted into equation 157 to derive equation 160:

$$
\overline{\left(\frac{P_{j}}{P}\right)}=\frac{\sigma}{\sigma-1} \frac{1-\left(1-\lambda_{j}\right) \frac{1}{R} \Pi^{\star \sigma-1}}{1-\left(1-\lambda_{j}\right) \frac{1}{R} \Pi^{\star \sigma}}{\overline{\left(\frac{P_{j}^{\star}}{P_{j}}\right.}}^{-1} \overline{M C} .
$$

Equation 142 can be rewritten as equation 161. $\overline{\left(\frac{P_{j}}{P}\right)}$ can then be input from equation 160 into equa- 
tion 161 to get equation 162:

$$
\begin{aligned}
& \int_{0}^{1} a_{j}{\overline{\left(\frac{P_{j}}{P}\right)}}^{1-\sigma_{2}} d j=1 \\
& (\overline{M C})^{1-\sigma_{2}} \int_{0}^{1} a_{j}\left[\frac{\sigma}{\sigma-1} \frac{1-\left(1-\lambda_{j}\right) \frac{1}{\bar{R} \Pi^{\star \sigma-1}}}{1-\left(1-\lambda_{j}\right) \frac{1}{\bar{R}} \Pi^{\star \sigma}}\left(\frac{P_{j}^{\star}}{P_{j}}\right)^{-1}\right]^{1-\sigma_{2}} d j=1 .
\end{aligned}
$$

$\overline{M C}$ can be backed out from equation 162. $\overline{\left(\frac{P_{j}}{P}\right)}$ can then be found from equation 160. $\bar{\nu}$ can be backed out by its definition (equation 149).

Calibration The industry weights and frequencies of price adjustment are set to match the analysis with nine sectors in Nakamura and Steinsson (2010). The elasticity of substitution between industries $\left(\sigma_{2}\right)$ is set to be the same as $\sigma$, as in Nakamura and Steinsson (2010).

\section{E.6 Idiosyncratic Shocks}

This section explains how idiosyncratic shocks are introduced into the model.

Idiosyncratic shocks are considered only in the steady state case. As section 5 shows, in the steady state it is possible to break down the model into the demand for assets from households and the supply of relative assets from firms. Idiosyncratic shocks affect only the household side, and thus it is necessary to consider only the derivation of the demand for assets.

Asset Demand with Idiosyncratic Shocks Notation is similar to that in section 3.1. The cohort is represented by $i$, and time is represented by $t$. Cohorts have the same life cycle as in section 3.1. Since there are idiosyncratic shocks within cohorts, it is necessary to consider how individuals within a cohort will respond. For each cohort, it is therefore assumed that there is a continuum of individuals denoted by $h$ between 0 and 1 for each cohort $i$.

Agents can invest in the same assets with the same returns as in section 3.1, and to keep things simple, it is assumed there is no additional utility on holding bonds $(\xi=0)$. From section 3.1, it can also be observed that agents are indifferent to a first-order approximation (and also in the steady state) between holding different types of assets and (assuming $\xi=0$ ) all assets yield the same return to a first-order approximation. Consequently, it does not matter in the steady state which type of asset agents hold, since agents are indifferent and the assets yield the same returns. Consequently, it is necessary to consider only the total savings held by a given individual $h$ of cohort $i$ at time $t$, which is represented by $S_{h, i, t}$. As in the main model, it is assumed that agents start with zero assets, so $S_{h, i, t}=0$. Their consumption and labor supply are represented by $C_{h, i, t}$ and $L_{h, i, t}$, respectively. Agents work for a real wage $W$ and receive a real return $R$ on their assets. Consequently, an agent's budget constraint is given by equation 163:

$$
C_{h, i, t}+S_{h, i+1, t+1} \leq W L_{h, i, t}+R S_{h, i, t}
$$

Agents have an exogenous supply of labor. The amount that agents work depends on whether they are employed or unemployed. If they are employed, they work for $e L_{i}$, and if they are unemployed, they work for $u L_{i}$. $L_{i}$ differs by cohort. Whether agents are employed or unemployed is determined by a Markov process. $e, u$, and the Markov process are such that the average labor supplied across a cohort is $L_{i}$. Consequently, the total labor supplied by households is also represented by equation 34 . 
Agents have Epstein-Zin utility. The advantage of using this utility framework is that it allows the effects of risk aversion and income elasticity of substitution to be separated. An agent's utility is thus defined recursively. Their relative risk aversion is denoted by $\gamma$, and their intertemporal elasticity of substitution is denoted by $\rho$ :

$$
V_{i, t}=\left((1-\beta) C_{h, i, t}^{1-\rho}+\beta\left(\mathbb{E}_{t}\left[V_{i, t+1}^{1-\gamma}\right]^{\frac{1-\rho}{1-\gamma}}\right)\right)^{\frac{1}{1-\rho}} .
$$

Therefore, an agent of age $k$ faces the following problem:

$$
\max _{\left\{C_{h, i, t+i}, S_{h, i+1, t+i+1}\right\}_{i=k}^{M-1}} \mathbb{E}_{t}\left[V_{i, t}\right]
$$

s.t. $\forall i \in k, \ldots, M-1$

$$
\begin{gathered}
V_{i, t}=\left((1-\beta) C_{h, i, t}^{1-\rho}+\beta\left(\mathbb{E}_{t}\left[V_{i, t+1}^{1-\gamma}\right]^{\frac{1-\rho}{1-\gamma}}\right)\right)^{\frac{1}{1-\rho}}, \\
C_{h, i, t}+S_{h, i+1, t+1} \leq W L_{h, i, t}+R S_{h, i, t}, \\
S_{M, t+M} \geq 0 .
\end{gathered}
$$

As in the main model, the problem is rewritten in relative terms, that is, divided by labor income. Relative assets, consumption and savings are defined in equations 62,167, and 168, respectively:

$$
\begin{aligned}
& c_{h, i, t}=\frac{C_{h, i, t}}{W L}, \\
& s_{h, i, t}=\frac{S_{h, i, t}}{W L} .
\end{aligned}
$$

The problem can then be rewritten as ${ }^{9}$ :

$$
\max _{\left\{C_{h, i, t+i}, S_{h, i+1, t+i+1}\right\}_{i=,}^{M-1}} \mathbb{E}_{t}\left[V_{i, t}\right],
$$

s.t. $\forall i \in k, \ldots, M-1$

$$
\begin{gathered}
V_{i, t}=\left((1-\beta) c_{h, i, t}^{1-\rho}+\beta\left(\mathbb{E}_{t}\left[V_{i, t+1}^{1-\gamma}\right]^{\frac{1-\rho}{1-\gamma}}\right)\right)^{\frac{1}{1-\rho}}, \\
c_{h, i, t}+s_{h, i+1, t+1} \leq \frac{L_{h, i, t}}{L}+R s_{h, i, t}, \\
s_{M, t+M} \geq 0 .
\end{gathered}
$$

The problem can then be solved by iterating over value functions. The value of savings and labor income in the final period of the agent's life is given by the utility of consuming all the remaining assets of the agent:

$$
V_{i, M-1}=\left((1-\beta)\left(\frac{L_{M-1}}{L}+R s_{M-1}\right)^{1-\rho}\right)^{\frac{1}{1-\rho}} .
$$

Then, working backwards the value of an agent of cohort $i$ 's savings and labor income can be computed using the value of an agent of cohort $i+1$ 's savings and labor income.

Observe that the distribution of $s_{h, i}$ can be computed for every cohort $i$ given the value of $R$. Therefore, the relative savings is effectively a function of $R$. And therefore the demand for relative assets is simply the

\footnotetext{
${ }^{9}$ This has been simplified by cancelling a constant in the utility function.
} 
population-weighted sum of relative savings by each cohort (equation 171):

$$
a^{d}(R)=\left(\sum_{i=0}^{M-1} \frac{1}{(1+n)^{i}}\right)^{-1} \sum_{i=0}^{M-1} \frac{1}{(1+n)^{i}} \int_{0}^{1} s_{h, i+1}(R) d h .
$$

Multiple Types The case where there are two different types of households, patient and impatient, is also considered. The asset supply for the patient type (denoted by $a_{p}^{d}(R)$ ) and for the impatient type (denoted by $\left.a_{i}^{d}(R)\right)$ can each be computed separately using the same steps as when there is only one type of household facing idiosyncratic shocks. The aggregate demand for assets is then simply $a^{d}(R)=0.5 a_{p}^{d}(R)+0.5 a_{i}^{d}(R)$.

Parameterization $L_{i}$ is set the same as it is in the exogenous labor case in section 4.5. The probability that an agent is employed in the current period if they were employed in the previous period is set as 0.95 . The probability that an agent is unemployed in the current period if they were unemployed in the previous period is set as 0.5 . The probability that the youngest cohort begins as unemployed is set as 9.09 percent, which is the steady state of the Markov system. Thus, an individual in any cohort has an unconditional 9.09 percent chance of being unemployed. $u$ is set as $0.1 e$, which implies that $u=0.109$ and $e=1.09$.

Two cases are considered. First, a case with a single type of agent with $\beta=0.97$ is considered. The reason $\beta$ is lower than in the case without idiosyncratic shocks is because this implies that agents consume less as they get older, which fits with the latter part of agents' hump-shaped consumption path. Second, a case with two types of agents is considered. Half the agents are patient, with $\beta=0.98$, and half the agents are impatient, with $\beta=0.94$.

\section{F Simulation Details}

\section{F.1 Simulation Methods Details}

The method is explained using $\pi^{\star}(r)$ (the case where the real interest rate on bonds falls when inflation rises), but exactly the same steps are followed for $\pi_{f}^{\star}(r)$. Each simulation is for 10,000 periods using the same seeded shocks as in the method outlined in section 4.4. The case with endogenous labor is considered (Model B in sec:inflation-real-results). Welfare is then computed by applying the utility of consumption (equation 22) and the disutility of working (equation 23).

1. For each $r \in\{-0.01,-0.009,-0.008, \ldots, 1.018,1.019,1.02\}$, compute the welfare for each inflation level that would yield a positive nominal interest rate for $\pi^{\star} \in:\{0,0.005,0.01, \ldots, 0.07,0.075,0.08\}$.

2. Set $\pi^{\star}(r)$ for each estimated $r$ as the inflation level that yielded that highest welfare for that $r$. Estimate $\hat{\pi}^{\star}(r)$ by doing a linear regression of $\pi^{\star}$ on $r$.

3. For each $r \in\{-0.01,-0.009,-0.008, \ldots, 1.018,1.019,1.02\}$, compute the welfare for each inflation level that would yield a positive nominal interest rate in $\left\{-0.02+\hat{\pi}^{\star}(r),-0.019+\hat{\pi}^{\star}(r), \ldots, 0.019+\right.$ $\left.\hat{\pi}^{\star}(r), 0.02+\hat{\pi}^{\star}(r)\right\}$.

4. Using the same method as in step 2 , recompute $\hat{\pi}^{\star}(r)$.

5. For each $r \in\{-0.01,-0.0095,-0.009, \ldots, 1.019,1.0195,1.02\}$, compute the welfare for each inflation level that would yield a positive nominal interest rate in $\left\{-0.005+\hat{\pi}^{\star}(r),-0.0048+\hat{\pi}^{\star}(r), \ldots, 0.0048+\right.$ $\left.\hat{\pi}^{\star}(r), 0.005+\hat{\pi}^{\star}(r)\right\}$. 
6. Using the same method as in step 2, except with a cubic rather than a linear regression, recompute $\hat{\pi}^{\star}(r)$.

7. For each $r \in\{-0.01,-0.0098,-0.0096, \ldots, 1.0196,1.0198,1.02\}$, compute the welfare for each inflation level that would yield a positive nominal interest rate in $\left\{-0.001+\hat{\pi}^{\star}(r),-0.0009+\hat{\pi}^{\star}(r), \ldots, 0.0009+\right.$ $\left.\hat{\pi}^{\star}(r), 0.001+\hat{\pi}^{\star}(r)\right\}$.

8. Using the same method as in step 2, except with a cubic rather than a linear regression, recompute $\hat{\pi}^{\star}(r)$. The estimated $\pi^{\star}(r)$ is then $\hat{\pi}^{\star}(r)$.

Figure 10 shows a plot of the points $\left(r, \pi^{\star}(r)\right)$ where $\pi^{\star}(r)$ is the $\pi$ that yielded the highest welfare for a given $r$ together with $\hat{\pi}^{\star}(r)$ from step 8 .

\section{F.2 Mathematical Decomposition of Impact of IMR Channel on Response of Optimal Inflation to a Fall in the Exogenous Real Rate}

Here a fall in the exogenous real rate from $r_{h}$ to $r_{l}$ is investigated. It can immediately be observed that $\pi_{A}^{\star}=\pi^{\star}\left(r_{h}\right)$ and $\pi_{C}^{\star}=\pi^{\star}\left(r_{l}\right)$.

To aid the mathematical decomposition, additional definitions are required. $r^{b}(\pi)$ is defined to represent the steady state real interest rate on bonds when trend inflation is at the level $\pi$. In general, it can be observed that $r^{b}\left(\pi^{\star}(r)\right)<r$. The reason for this is that $r$ represents the real interest rate that the economy would take when trend inflation is zero. However, taking into account the zero lower bound, the optimal inflation target will be positive and thus the real interest rate on bonds will actually be lower than in the zero trend inflation case. Note that it also follows that $\pi_{f}^{\star}\left(r^{b}\left(\pi^{\star}(r)\right)\right)$ represents the optimal inflation target when the real interest rate on bonds is fixed as $r^{b}\left(\pi^{\star}(r)\right)$ where $r^{b}\left(\pi^{\star}(r)\right)$ represents the real interest rate when inflation is at its optimal level and the real interest rate on bonds is not fixed. Therefore, $\pi_{b}^{\star}=\pi_{f}^{\star}\left(r^{b}\left(\pi^{\star}\left(r_{h}\right)\right)\right)$, $\pi_{e}^{\star}=\pi_{f}^{\star}\left(r^{b}\left(\pi^{\star}\left(r_{l}\right)\right)\right)$, and $\pi_{d}^{\star}=\pi_{f}^{\star}\left(r^{b}\left(\pi^{\star}\left(r_{h}\right)\right)-\left(r_{h}-r_{l}\right)\right)$.

One additional minor note for clarity: table 4 and table 5 yield slightly different results for how a fall in the exogenous real rate affects optimal inflation. Consider, for example, the case in which the exogenous real rate falls from 2 percent to -1 percent. Columns 3 and 5 of table 4 consider how the optimal inflation responds to specific levels of the exogenous real rate at 2 percent and -1 percent, that is, $\pi_{f}^{\star}(2), \pi_{f}^{\star}(-1)$; whereas table 5 considers the optimal inflation level when the real interest rate is fixed as the same as what it would be in the IMR case under 2 percent and a corresponding fall in the exogenous real rate, that is, $\pi_{f}^{\star}\left(r^{b}\left(\pi^{\star}\left(r_{h}\right)\right)\right)$ and $\pi_{f}^{\star}\left(r^{b}\left(\pi^{\star}(2)\right)-3\right)$. Given this difference, a fall in the exogenous real rate is found to be 0.8 basis points in table 4 and 0.7 basis points in table 5 for the basic model.

\section{G Multiple Sectors Extension Details}

The firm's problem is:

$$
\max _{P_{j, t}^{\star}, Y_{i, j, t}} \mathbb{E}_{t}\left[\sum_{k=0}^{\infty}\left(\frac{1}{\bar{R}}\right)^{k}\left(1-\lambda_{j}\right)^{k}\left[\frac{P_{j, t}^{\star} Y_{i, j, t+k}}{P_{t+k}}-M C_{j, t+k} Y_{i, j, t+k}\right]\right],
$$

s.t.

$$
Y_{i, j, t+k}=\left(\frac{P_{j, t}^{\star}}{P_{j, t+k}}\right)^{-\sigma} Y_{j, t+k}
$$


Figure 10: Graph of Optimal Inflation and Real Interest Rate with Line of Best Fit

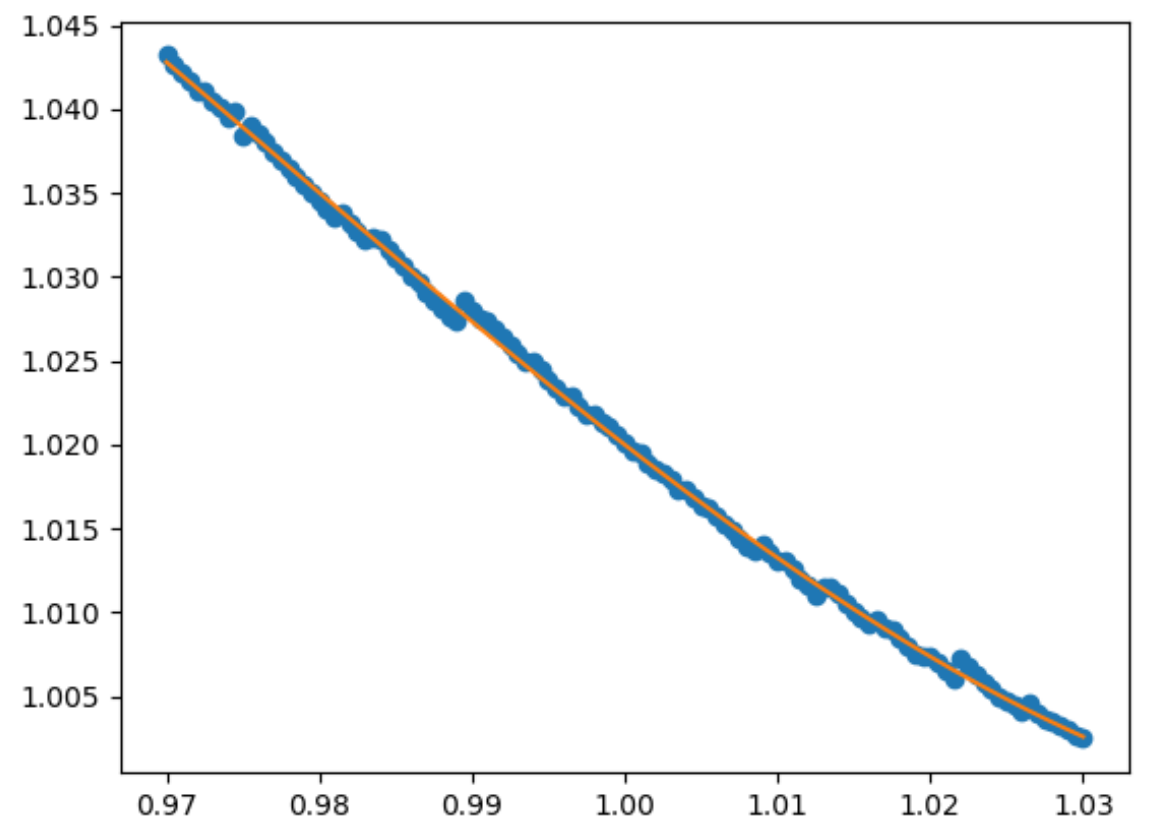

Equation 173 can be input into equation 172 to get:

$$
\max _{P_{j, t}^{\star}} \mathbb{E}_{t}\left[\sum_{k=0}^{\infty}\left(\frac{1}{\bar{R}}\right)^{k}\left(1-\lambda_{j}\right)^{k}\left[P_{j, t}^{\star 1-\sigma} P_{j, t+k}^{\sigma} Y_{j, t+k}-M C_{j, t+k} P_{j, t}^{\star}{ }^{-\sigma} P_{j, t+k}^{\sigma} \frac{1}{P_{t+k}} Y_{j, t+k}\right]\right] .
$$

Taking FOCs:

$$
\mathbb{E}_{t}\left[\sum_{k=0}^{\infty}\left(\frac{1}{\bar{R}}\right)^{k}\left(1-\lambda_{j}\right)^{k}\left[(1-\sigma) P_{j, t}^{\star}{ }^{-\sigma} P_{j, t+k}^{\sigma} \frac{1}{P_{t+k}} Y_{j, t+k}+\sigma M C_{j, t+k} P_{j, t}^{\star-\sigma-1} P_{j, t+k}^{\sigma} Y_{j, t+k}\right]\right]
$$

Rearranging:

$$
\mathbb{E}_{t}\left[\sum_{k=0}^{\infty}\left(\frac{1}{\bar{R}}\right)^{k}\left(1-\lambda_{j}\right)^{k} P_{j, t+k}^{\sigma} Y_{j, t+k}\left[\frac{P_{j, t}^{\star}}{P_{t+k}}-\frac{\sigma}{\sigma-1} M C_{j, t+k}\right]\right] .
$$

Inputting $Y_{j, t+k}$ and dividing by $P_{j, t}^{\sigma}$ :

$$
\mathbb{E}_{t}\left[\sum_{k=0}^{\infty}\left(\frac{1}{\bar{R}}\right)^{k}\left(1-\lambda_{j}\right)^{k}\left(\frac{P_{j, t+k}}{P_{j, t}}\right)^{\sigma}\left(\frac{P_{j, t+k}}{P_{t+k}}\right)^{-\sigma_{2}} Y_{t+k}\left[\frac{P_{j, t}^{\star}}{P_{j, t}} \frac{P_{j, t}}{P_{t}} \frac{P_{t}}{P_{t+k}}-\frac{\sigma}{\sigma-1} M C_{j, t+k}\right]\right] .
$$

Next, define:

$$
U_{j, t}=\mathbb{E}_{t}\left[\sum_{k=0}^{\infty}\left(\frac{1}{\bar{R}}\right)^{k}\left(1-\lambda_{j}\right)^{k}\left(\frac{P_{j, t+k}}{P_{j, t}}\right)^{\sigma}\left(\frac{P_{j, t+k}}{P_{t+k}}\right)^{-\sigma_{2}} Y_{t+k} \frac{P_{t}}{P_{t+k}}\right],
$$




$$
V_{j, t}=\mathbb{E}_{t}\left[\sum_{k=0}^{\infty}\left(\frac{1}{\bar{R}}\right)^{k}\left(1-\lambda_{j}\right)^{k}\left(\frac{P_{j, t+k}}{P_{j, t}}\right)^{\sigma}\left(\frac{P_{j, t+k}}{P_{t+k}}\right)^{-\sigma_{2}} Y_{t+k} \frac{\sigma}{\sigma-1} M C_{j, t+k}\right]
$$

Then:

$$
U_{j, t} \frac{P_{j, t}^{\star}}{P_{j, t}} \frac{P_{j, t}}{P_{t}}-V_{j, t}=0
$$

$U_{j, t}, V_{j, t}$ can then be rewritten as:

$$
\begin{gathered}
U_{j, t}=\left(\frac{P_{j, t}}{P_{t}}\right)^{-\sigma_{2}} Y_{t}+\mathbb{E}_{t}\left[\frac{1}{\bar{R}}\left(1-\lambda_{j}\right) \Pi_{j, t+1}^{\sigma} \Pi_{t+1}^{-1} U_{j, t+1}\right], \\
V_{j, t}=\left(\frac{P_{j, t}}{P_{t}}\right)^{-\sigma_{2}} Y_{t} \frac{\sigma}{\sigma-1} M C_{t}+\mathbb{E}_{t}\left[\frac{1}{\bar{R}}\left(1-\lambda_{j}\right)\left(\frac{P_{j, t+1}}{P_{j, t}}\right)^{\sigma} V_{j, t+1}\right] .
\end{gathered}
$$

The evolution of the price dispersion equation for industry $j$ (equation 151) can be rewritten as:

$$
\begin{gathered}
\nu_{j, t}=\int_{0}^{1}\left(\frac{P_{i, j, t}}{P_{j, t}}\right)^{-\sigma} d i, \\
=\lambda_{j}\left(\frac{P_{j, t}^{\star}}{P_{j, t}}\right)^{-\sigma}+\left(1-\lambda_{j}\right) \int_{0}^{1}\left(\frac{P_{i, j, t-1}}{P_{j, t}}\right)^{-\sigma} d i, \\
=\lambda_{j}\left(\frac{P_{j, t}^{\star}}{P_{j, t}}\right)^{-\sigma}+\left(1-\lambda_{j}\right) \nu_{j, t-1} \Pi_{j, t}^{\sigma} .
\end{gathered}
$$

The price aggregator for individual industries (equation 144) can be rewritten as:

$$
\begin{gathered}
P_{j, t}^{1-\sigma}=\int_{0}^{1} P_{i, j, t}^{1-\sigma} d i, \\
=\lambda_{j} P_{j, t}^{\star 1-\sigma}+\left(1-\lambda_{j}\right) P_{j, t-1}^{1-\sigma}, \\
1=\lambda_{j}\left(\frac{P_{j, t}^{\star}}{P_{j, t}}\right)^{1-\sigma}+\left(1-\lambda_{j}\right) \Pi_{j, t}^{\sigma-1} .
\end{gathered}
$$

Also observe that by definition:

$$
\Pi_{j, t}=\frac{P_{j, t}}{P_{j, t-1}}=\frac{P_{j, t}}{P_{t}} \frac{P_{t}}{P_{t-1}} \frac{P_{t-1}}{P_{j, t-1}} .
$$

And the final price evolution equation (equation 142) can be rewritten as:

$$
\begin{gathered}
P_{t}^{1-\sigma_{2}}=\sum_{j=1}^{J} a_{j} P_{j, t}^{1-\sigma_{2}}, \\
1=\sum_{j=1}^{J} a_{j}\left(\frac{P_{j, t}}{P_{t}}\right)^{1-\sigma_{2}} .
\end{gathered}
$$




\section{H Bibliography}

Andrade, Philippe, Jordi Galí, Hervé Le Bihan, and Julien Matheron. 2019. "The Optimal Inflation Target and the Natural Rate of Interest." Brookings Papers on Economic Activity. Fall 2019.

Ascari, Guido, and Argia M. Sbordone. 2014. "The Macroeconomics of Trend Inflation." Journal of Economic Literature 52(3): 679-739.

Ball, Laurence. 2014. "The Case for a Long-Run Inflation Target of Four Percent." Technical Report. IMF Working Paper No. 14/92.

Basu, Susanto. 1995. "Intermediate Gods and Business Cycles: Implications for Productivity and Welfare." The American Economic Review 85(3): 512-531.

Best, Michael Carlos, James Cloyne, Ethan Ilzetzki, and Henrik Kleven. 2018. "Estimating the Elasticity of Intertemporal Substitution Using Mortgage Notches." Technical Report.

Blanchard, Olivier, Giovanni Dell'Ariccia, and Paolo Mauro. 2010. "Rethinking Macroeconomic Policy." Journal of Money, Credit and Banking 42(s1): 199-215.

Caballero, Ricardo J., and Emmanuel Farhi. 2017. "The Safety Trap." Review of Economic Studies 85(1): 223-274.

Carvalho, Carlos, Andrea Ferrero, and Fernanda Nechio. 2016. “Demographics and Real Interest Rates: Inspecting the Mechanism." European Economic Review 88(C): 208-226.

Coibion, Olivier, Yuriy Gorodnichenko, and Johannes Wieland. 2012. "The Optimal Inflation Rate in New Keynesian Models: Should Central Banks Raise Their Inflation Targets in Light of the ZLB?" Review of Economic Studies 79(4): 1371-1406.

De Michelis, Andrea, and Matteo Iacoviello. 2016. "Raising an Inflation Target: The Japanese Experience with Abenomics." European Economic Review 88: 67-87.

Del Negro, Marco, Domenico Giannone, Marc P. Giannoni, and Andrea Tambalotti. 2017. "Safety, Liquidity, and the Natural Rate of Interest." Brookings Papers on Economic Activity. Spring 2017.

Diamond, Peter A. 1965. "National Debt in a Neoclassical Growth Model." American Economic Review 55(5): $1126-1150$.

Doepke, Matthias, Martin Schneider, and Veronika Selezneva. 2015. "Distributional Effects of Monetary Policy." Technical Report. Hutchins Center on Fiscal \& Monetary Policy at Brookings Working Paper No. 14.

Eggertsson, Gauti B., Neil R. Mehrotra, and Jacob A. Robbins. 2019. “A Model of Secular Stagnation: Theory and Quantitative Evaluation." American Economic Journal: Macroeconomics 11(1): 1-48.

Fisher, Irving. 1907. The Rate Of Interest. The Macmillan Company.

Gagnon, Etienne. 2009. "Price Setting during Low and High Inflation: Evidence from Mexico." The Quarterly Journal of Economics 124(3): 1221-1263. 
Gagnon, Etienne, Benjamin K. Johannsen, and David Lopez-Salido. 2016. “Understanding the New Normal: The Role of Demographics." Technical Report. Board of Governors Federal Reserve System Finance and Economics Discussion Series 2016-080.

Galí, Jordi. 2008. Monetary Policy, Inflation, and the Business Cycle: An Introduction to the New Keynesian Framework. Princeton, NJ: Princeton University Press.

Graham, John, and Cam Harvey. 2011. Technical Report. Duke/CFO Magazine Global Business Outlook survey US topline tables, released March 9, 2011.

Graham, John, and Cam Harvey. 2012. Technical Report. Duke/CFO Magazine Global Business Outlook survey US topline tables, released June 6, 2012.

Guerrieri, Luca, and Matteo Iacoviello. 2015. “OccBin: A Toolkit for Solving Dynamic Models with Occasionally Binding Constraints Easily." Journal of Monetary Economics 70(C): 22-38.

Holston, Kathryn, Thomas Laubach, and John C. Williams. 2017. "Measuring the Natural Rate of Interest: International Trends and Determinants." Journal of International Economics 108(S1): S59-S75.

Jagannathan, Ravi, David A. Matsa, Iwan Meier, and Vefa Tarhan. 2016. “Why Do Firms Use High Discount Rates?" Journal of Financial Economics 120(3): 445-463.

Johannsen, Benjamin K., and Elmar Mertens. 2016. “A Time Series Model of Interest Rates with the Effective Lower Bound." Technical Report. Board of Governors Federal Reserve System Finance and Economics Discussion Series 2016-033.

Kaplan, Greg, Benjamin Moll, and Giovanni L. Violante. 2018. "Monetary Policy According to HANK." American Economic Review 108(3): 697-743.

Kiley, Michael T. 2015. “What Can the Data Tell Us about the Equilibrium Real Interest Rate?" Technical Report. Board of Governors of the Federal Reserve System Finance and Economics Discussion Series 2015-077.

Kiley, Michael T., and John M. Roberts. 2017. “Monetary Policy in a Low Interest Rate World." Technical Report. Brookings Papers on Economic Activity BPEA Conference Drafts, March 23-24, 2017.

King, Robert, and Mark W. Watson. 1997. “Testing Long Run Neutrality.” Economic Quarterly 83(3): 69-101.

Krugman, Paul. 2014. “Inflation Targets Reconsidered.” Technical Report. Draft paper for ECD Sintra Conference.

Lancastre, Manuel. 2018. “Inequality and Real Interest Rates.” Technical Report. MPRA Paper No. 85047.

Laubach, Thomas, and John C. Williams. 2016. "Measuring the Natural Rate of Interest Redux." Business Economics 51(2): 57-67.

Lepetit, Antoine. 2018. "The Optimal Inflation Rate with Discount Factor Heterogeneity." Technical Report. Board of Governors of the Federal Reserve System Finance and Economics Discussion Series 2018-086.

L'Huillier, Jean-Paul, and Raphael Schoenle. 2019. "Raising the Inflation Target: How Much Extra Room Does It Really Give?" Technical Report. 
Lubik, Thomas A., and Christian Matthes. 2015. "Calculating the Natural Rate of Interest: A Comparison of Two Alternative Approaches." Technical Report. Federal Reserve Bank of Richmond Economic Brief EB15-10.

McKay, Alisdair, Emi Nakamura, and Jón Steinsson. 2016. "The Power of Forward Guidance Revisited." American Economic Review 106(10): 3133-3158.

Mundell, Robert. 1963. “Inflation and Real Interest.” Journal of Political Economy 71(3): 280-283.

Nakamura, Emi, and Jón Steinsson. 2008. "Five Facts about Prices: A Reevaulation of Menu Cost Models." The Quarterly Journal of Economics 123(4): 1415-1464.

Nakamura, Emi, and Jón Steinsson. 2010. “Monetary Non-Neutrality in a Multi-Sector Menu Cost Model." Quarterly Journal of Economics 125(3): 961-1013.

Rapach, David E. 2003. "International Evidence on the Long-Run Impact of Inflation." Journal of Money, Credit and Banking 35(1): 23-48.

Stockman, Alan. 1981. "Anticipated Inflation and the Capital Stock in a Cash in Advance Economy." Journal of Monetary Economics 8(3): 387-393.

Tobin, James. 1965. “Money and Economic Growth.” Econometrica 33(4): 671-684.

Werning, Iván. 2015. "Incomplete Markets and Aggregate Demand." Technical Report. NBER Working Paper No. 21448.

Woodford, Michael. 2003. Interest and Prices: Foundations of a Theory of Monetary Policy. Princeton, NJ: Princeton Unversity Press.

Yi, Kei-Mu, and Jing Zhang. 2017. "Understanding Global Trends in Long-Run Real Interest Rates." Technical Report. Federal Reserve Bank of Chicago Economic Perspectives 2/2017. 